\title{
Decadal Seismicity Prior to Great Earthquakes at Subduction Zones: Roles of Major Asperities and Low-Coupling Zones
}

\author{
Lynn R. Sykes \\ Lamont-Doherty Earth Observatory of Columbia University, Palisades New York, USA \\ Email: sykes@ldeo.columbia.edu
}

How to cite this paper: Sykes, L.R. (2021) Decadal Seismicity Prior to Great Earthquakes at Subduction Zones: Roles of Major Asperities and Low-Coupling Zones. International Journal of Geosciences, 12, 845-926.

https://doi.org/10.4236/ijg.2021.129046

Received: July 23, 2021

Accepted: September 27, 2021

Published: September 30, 202

Copyright $\odot 2021$ by author(s) and Scientific Research Publishing Inc. This work is licensed under the Creative Commons Attribution International License (CC BY 4.0).

http://creativecommons.org/licenses/by/4.0/

(c) (i) Open Access

\begin{abstract}
Decadal forerunning seismic activity of magnitude $\mathrm{Mw} \geq 5.0$ is mapped for all 45 mainshocks of Mw 7.7 to 9.1 at subduction zones of the world from 1993 to mid 2020. The zones of high slip in nearly all great earthquakes were nearly quiescent beforehand and are identified as the sites of great asperities and zones of strong seismic coupling. Much forerunning activity occurred at smaller asperities along the peripheries of the rupture zones of many great and giant mainshocks. Those sizes of great asperities as ascertained from forerunning activity generally agree with the areas of high seismic slip as determined by others from geodetic and tide-gauge data and finite-source seismic modeling. Asperities are strong, well-coupled portions of plate interfaces. Different patterns of forerunning activity on time scales of about 5 to 45 years are attributed to either the sizes and spacing of asperities (or lack of). This permits many great asperities to be mapped decades before they rupture in great and giant shocks. Several poorly coupled subduction zones such as Java, Lesser Sunda, Marianas, Tonga and Kermadec are characterized by few great thrust earthquakes and little, in any forerunning activity. Rupture zones of many great and giant earthquakes are bordered either along strike, updip, or downdip by zones of lower plate coupling. Several bordering regions were sites of forerunning activity, aftershocks, and slow-slip events. The detection of forerunning and precursory activities of various kinds should be sought on the peripheries of great asperities as well as within zones of high co-seismic slip.
\end{abstract}

\section{Keywords}

Earthquakes, Subduction, Prediction, Plate Coupling, Asperities 


\section{Introduction}

Most of the world's great and giant earthquakes have occurred at shallow depths along plate boundaries at active subduction zones. They are particularly important to understand since many have caused extensive destruction and loss of life. Some have generated large seismic sea waves (tsunamis). Much new seismic, geodetic and tide-gauge information has become available for shocks of magnitude 7.7 to 9.1 that occurred during the last several decades. I examine the spatial distribution of nearby moderate to large shocks in the 5 to 45 years preceding 45 mainshocks of magnitude 7.7 and greater from 1993 to mid 2020 for the subduction zones of the world. It is surprising how little has been written about such preceding events, which I call forerunning earthquakes to distinguish them from foreshocks of shorter duration. The first aim of this paper is simply to describe the spatial distribution of forerunning events. Additional earthquakes are shown in the Supplement.

The second aim is to use forerunning shocks to map great asperities that were clearly definable and those that were not in the years to decades before they subsequently ruptured in great and giant shocks. Understanding forerunning seismic activity and where it occurs with respect to both the centroids of slip in mainshocks and their high displacements are emphasized. Very large mainshocks and their forerunning events are described in terms of the rupture of asperities of various sizes, i.e., strong, well-coupled portions of plate interfaces at subduction zones. Some parts of plate boundaries consist of great asperities that are well coupled, i.e., largely locked, during the slow process of stress buildup to very large earthquakes. Others, so called low-coupling zones (LCZ), are identified as the sites of smaller asperities and moderate-size forerunning and aftershock activity. Much forerunning activity as well as several slow-slip events described in the literature occurred in low-coupling zones adjacent to or on the peripheries of great asperities. I also describe forerunning cumulative seismic moment before a few great and giant earthquakes and how it changes (or not) with time. A third aim of the paper is to discuss its implications for earthquake prediction and hazards assessment for various time scales.

In the past, most shorter-term precursory seismic activity was identified only after the occurrence of large earthquakes. Typically, it has been difficult to distinguish it from other events that happen during the long periods of stress buildup to large earthquakes. One such example is the series of moderate to large events that occurred several days before the giant Tokoku-oki Japanese earthquake of 2011. Most seismologists now regard that series as a short-term precursor but did not identify it as such ahead of time. This is not a review of precursory activities but only an attempt to put them in the context of longer-term forerunning phenomena. One reason for distinguishing forerunning from precursory activity is that the latter changes with time. The rate of forerunning shocks may or may not change over decades.

Mogi [1] described rupture in the lab of two quite different substances: ho- 
mogeneous pine resin and inhomogeneous granite, andesite and pumice. The rupture of pine resin at high stress was not preceded by forerunning small seismic events whereas failures of those inhomogeneous rocks were. The presence of inhomogeneities seems to be essential, at least in principle, to the occurrences of forerunning, precursory and aftershock activities not only in the lab but also at larger scales at plate boundaries. The literature contains abundant descriptions of inhomogeneities and asperities of various sizes along plate boundaries.

More study of the distribution of strong and weak regions along and near major faults is needed not only to understand the physics of earthquakes but also whether long-term earthquake prediction is either possible or unlikely for specific segments of plate boundaries. Strong regions that are more difficult to break are called asperities in the rock mechanics and seismological literatures. I use the terms asperities and plate coupling extensively. Some parts of plate boundaries remain locked and well-coupled during stress accumulation; others are sites of poorer coupling, moderate-size shocks, and slow earthquakes. Some information about the physical and geological factors that govern strong and weak asperities such as plate roughness, differences in lithology and fluid pressure are described but not in much detail.

This study examines all shocks of magnitude 7.7 to 9.1 from 1993 to mid 2020 that ruptured segments of the active subduction zones of the world. The distributions of events of magnitude 6 and larger are examined as well for the 40 years before the giant Chilean earthquake of 1960. For most of those great and giant events, others have analyzed the detailed distribution of large displacement (slip) over their main rupture zones using seismic observations and data from the Geodetic Positioning System (GPS) and tide gauges. They found that areas of major displacements were typically smaller than the sizes of aftershock zones.

The main contribution of this paper is to map the distribution of forerunning earthquakes to 47 thrust shocks at subduction zones and to compare them with areas of major slip computed by others from geodetic and seismological data. Most previous work has focused on individual large earthquakes and not on what can be ascertained by examining many of them worldwide. Relatively little attention has been paid to the locations of forerunning activity.

Most very large earthquakes have occurred where plate coupling is high as reported in the literature. I find that rupture zones of many great and giant earthquakes are quiet for decades ahead of time. Those quiet zones are often bordered by zones of poorer plate coupling either along strike, downdip, updip or all of those dimensions. Some of the clearest examples of forerunning activity to large earthquakes are sought with the hope that better knowledge gained from them will permit less well-defined cases to be better interpreted.

How can great asperities be identified beforehand if they do not rupture until the time of a great or giant shock? I find that earthquakes of moderate to major size in the decades before very large events mostly occurred near the peripheries of great asperities that later broke in great earthquakes. Moderate to major size shocks can be used to map great asperities that are mostly quiet seismically be- 
fore they rupture in either great or giant events. This has an analogy to describing the sizes of black holes in cosmology. Activity has been observed on the peripheries of black holes, but their interiors inside event horizons are opaque to astronomers. By analogy, precursory seismic and geodetic changes prior to great events should be sought on the peripheries of great asperities and not just within them. Some claims that large earthquakes do not have precursors resulted from sampling only the faults that ruptured in mainshocks. Those authors often were looking in the wrong places.

This study builds upon previous work on great and giant earthquakes, seismic gaps and forerunning and aftershock activities [2]-[7]. Seismic gaps are segments of active plate boundaries that have not been the sites of large earthquakes for decades to hundreds of years. Pérez and Scholz [6] studied shocks of magnitude 7 and larger before and after six giant earthquakes between 1952 and 1965. They found that forerunning activity tended to be concentrated near the ends of the rupture zones of coming giant earthquakes. These works typically used the extent of aftershock zones in mapping rupture zones of great earthquakes. They did not have access to either GPS data, tide-gauge measurements seaward of subduction zones, centroid locations of earthquakes, information on slow-slip events or finite-fault slip computations of high slip. Forerunning earthquakes of magnitudes as small as 5.0 are used in this paper. This permits many forerunning events to be used for the decades prior to individual great and giant earthquakes. A similar analysis includes great strike-slip and intraplate mainshocks [8].

The distributions of forerunning activity, great and moderate-size asperities, differences in plate coupling, and velocity strengthening and weakening materials can be considered as the building blocks or the architecture of seismic activity at subduction zones. Some may be useful for more detailed predictions or forecasts of earthquakes.

\section{Methods}

Giant earthquakes are defined as those of seismic magnitude 8.5 or larger on the moment magnitude scale, $\mathrm{Mw}$, and great shocks as those of $7.7 \leq \mathrm{Mw}<8.5 \mathrm{Mw}$ and its corollary seismic moment, Mo, are needed to quantify the very large dimensions and magnitudes of great and giant earthquakes. Seismic moment, Mo in $\mathrm{N}-\mathrm{m}$, is related to $\mathrm{Mw}$ by

$$
\log \mathrm{Mo}=1.5 \mathrm{Mw}+9.1
$$

I define major shocks as those of $7.0 \leq \mathrm{Mw}<7.7$ and moderate-size earthquakes as with $5.0 \leq \mathrm{Mw}<7.0$. In this paper I examine earthquakes of Mw 5.0 and greater and focus on shallow events on or near plate boundaries of the subduction type.

From 1993 through mid 2020, 69 shallow earthquakes occurred worldwide of $\mathrm{Mw}$ 2 7.7. Of those, 45 were located at subduction zones, 9 were strike-slip events in the oceans, 8 were strike-slip shocks within continents and subduction 
zones, 5 involved normal faulting, and 2 were thrust events within continents. All 45 great and giant events along subduction plus one earthquake of Mw 7.6 and another in 1992 are examined here. A brief summary follows the analysis of each mainshock.

Earthquake locations, mechanisms and magnitudes are from the Global Centroid Moment Tensor catalog (GCMT) catalog since it started in 1976 [9] [10]. Older locations and magnitudes are from the Bulletin of the International Seismological Centre and the 1992 catalog of Pacheco and Sykes [11]. GeoMapApp [12] was used for bathymetry and topography. Calculations of slip distributions in individual large earthquakes are taken from the literature as identified in the captions.

Centroids of slip are plotted here whenever possible rather than merely the points where slip initiated. Those points or hypocentral locations determined using short-period data are often biased too far landward by the velocity structure of the downgoing plate. GCMT locations and their magnitude, Mw, utilize some of the largest and longest-period seismic waves recorded. In contrast, shorter-period magnitudes, such as $\mathrm{mb}$, do not give an accurate estimate of size for great and giant earthquakes. The types of GCMT focal mechanisms in the figures are distinguished in terms of thrust, normal, strike-slip and reverse faulting. GCMT solutions have improved over time and been extended to events as small as Mw 5.0 [13].

Uncertainties exist in the relative and absolute locations of the centroids of the shocks analyzed here as well as in computations by others of areas of large slip in mainshocks. For the computations of zones of high slip, I used published results where analyses included whenever possible local and distant seismic data, geodetic observations of various types and sea level observations from buoys seaward of subduction zones.

Howe [14] used cross correlation of Love and Rayleigh waves from nearby earthquakes along the eastern Aleutian subduction zone to calculate doubledifference relative locations of events of $\mathrm{Mw}>5.5$. He found, "The resulting epicenters are relocated an average distance of 16:3 \pm 9:5 km." Those uncertainties become too large for some forerunning events of $\mathrm{Mw}<7.8$ and a few as large as 8.0. Relative locations likely can be improved by applying double-difference methods.

Zones of high computed slip for major, great and giant earthquakes, often called finite-fault rupture models, involve variations in slip over the area of individual fault ruptures during large earthquakes. In the figures I typically plot two contours of high slip from sources in the literature along with forerunning activity and the centroids of mainshocks. The high slip contours of 4 and $24 \mathrm{~m}$ are shown for the giant 2011 Japanese earthquake of $\mathrm{Mw} 9.1,0.5$ and $3 \mathrm{~m}$ for the great Iquique shock of $\mathrm{Mw} 8.1$ and $1 \mathrm{~m}$ for two slow-slip events south of Java. Maximum slip typically increased considerably between Mw 7.7 and 9.1.

After the start of the GCMT database in 1976, I needed to have many years of forerunning activity for an adequate analysis of a subsequent shock. Hence, the 
moderate, great, and giant shocks studied here were limited to the period 1993 to August 2020 (Table 1).

Table 1. Mainshocks examined in this paper.

\begin{tabular}{|c|c|c|c|c|c|c|}
\hline \multirow{2}{*}{ Earthquake } & \multirow{2}{*}{ Date } & Latitude & Longitude & Depth & Magnitude & \multirow{2}{*}{ Figure } \\
\hline & & GCMT & GCMT & GCMT & Mw & \\
\hline Hokkaido, west coast & 1993 July 12 & $42.71 \mathrm{~N}$ & $139.28 \mathrm{E}$ & 16 & 7.71 & S12 \\
\hline Guam, Marianas & 1993 Aug 8 & $13.06 \mathrm{~N}$ & $145.31 \mathrm{E}$ & 59 & 7.74 & S2 \\
\hline Java, Indonesia & 1994 June 2 & $11.03 \mathrm{~S}$ & $113.04 \mathrm{E}$ & 15 & 7.8 & 13 \\
\hline Kuril Islands & 1994 Oct 4 & $43.60 \mathrm{~N}$ & $147.63 \mathrm{E}$ & 68 & 8.3 & 38 to 39 \\
\hline Honshu Japan & $1994 \operatorname{Dec} 28$ & $40.56 \mathrm{~N}$ & $142.99 \mathrm{E}$ & 28 & 7.73 & S11 \\
\hline Antofagasta, Chile & 1995 July 30 & $24.17 \mathrm{~S}$ & $70.74 \mathrm{~W}$ & 29 & 8.0 & 19 \\
\hline Solomon Islands & 1995 Aug 16 & $5.51 \mathrm{~S}$ & $153.64 \mathrm{E}$ & 46 & 7.71 & 34 \\
\hline Jalisco Mexico & 1995 Oct 9 & $19.34 \mathrm{~N}$ & $104.80 \mathrm{~W}$ & 15 & 8.0 & S4 \\
\hline Kuril Islands & $1995 \operatorname{Dec} 3$ & $44.82 \mathrm{~N}$ & $150.17 \mathrm{E}$ & 26 & 7.9 & 40 \\
\hline Minahassa Pen Indon & 1996 Jan 1 & $0.74 \mathrm{~N}$ & $119.93 \mathrm{E}$ & 15 & 7.9 & S5 \\
\hline West Irian, Indonesia & 1996 Feb 17 & $0.67 \mathrm{~S}$ & $136.62 \mathrm{E}$ & 15 & 8.2 & 32 \\
\hline Western Aleutians & 1996 June 10 & $51.10 \mathrm{~N}$ & $177.41 \mathrm{~W}$ & 29 & 7.9 & 43 to 44 \\
\hline Peru & 1996 Nov 12 & $15.04 \mathrm{~S}$ & $75.37 \mathrm{~W}$ & 37 & 7.71 & 17 \\
\hline Santa Cruz Islands & 1997 Apr 21 & $13.21 \mathrm{~S}$ & $166.20 \mathrm{E}$ & 51 & 7.69 & S10 \\
\hline Kamchatka & 1997 Dec 5 & $54.31 \mathrm{~N}$ & $161.91 \mathrm{E}$ & 34 & 7.8 & $45-46$ \\
\hline New Ireland & 2000 Nov 16 & $4.56 \mathrm{~S}$ & $152.79 \mathrm{E}$ & 24 & 8.0 & S7 \\
\hline New Ireland & 2000 Nov 16 & $5.03 \mathrm{~S}$ & $153.17 \mathrm{E}$ & 31 & 7.8 & S7 \\
\hline New Brtain-N Ireland & 2000 Nov 17 & $5.26 \mathrm{~S}$ & $152.34 \mathrm{E}$ & 17 & 7.8 & S7 \\
\hline Peru, Arequipa & 2001 Jun 23 & $17.28 \mathrm{~S}$ & $72.71 \mathrm{~W}$ & 30 & 8.4 & 18 \\
\hline Tokachi-oki, Japan & 2003 Sept 25 & $42.21 \mathrm{~N}$ & $143.84 \mathrm{E}$ & 28 & 8.3 & $2 \& 3$ \\
\hline Rat Is, Aleutians & 2003 Nov 17 & $51.14 \mathrm{~N}$ & $177.86 \mathrm{E}$ & 22 & 7.75 & 41 to 42 \\
\hline Sumatra, Indonesia & $2004 \operatorname{Dec} 26$ & $3.09 \mathrm{~N}$ & $94.26 \mathrm{E}$ & 29 & 9.0 & 24 to 25 \\
\hline Nias Sumatra & 2005 Mar 28 & $1.67 \mathrm{~N}$ & $97.07 \mathrm{E}$ & 26 & 8.6 & 27 to 28 \\
\hline Tonga Islands & 2006 May 3 & $20.16 \mathrm{~S}$ & $174.14 \mathrm{~W}$ & 68 & 8.0 & S3 \\
\hline Java, Indonesia & 2006 July 17 & $10.28 \mathrm{~S}$ & $107.78 \mathrm{E}$ & 20 & 7.71 & 13 \\
\hline Kuril Islands & 2006 Nov 15 & $46.71 \mathrm{~N}$ & $154.33 \mathrm{E}$ & 14 & 8.3 & 12 \\
\hline Solomon Islands & 2007 Apr 1 & $7.79 \mathrm{~S}$ & $156.34 \mathrm{E}$ & 14 & 8.1 & 33 \\
\hline Peru & 2007 Aug 15 & 0.00 & $77.04 \mathrm{~W}$ & 34 & 8.0 & 16 \\
\hline Sumatra, Indonesia & 2007 Sept 12 & $3.78 \mathrm{~S}$ & $100.99 \mathrm{E}$ & 24 & 8.5 & 30 \\
\hline Sumatra, Indonesia & 2007 Sept 12 & $2.46 \mathrm{~S}$ & $100.13 \mathrm{E}$ & 24 & 7.9 & 30 \\
\hline Chile, northern & 2007 Nov 14 & $22.64 \mathrm{~S}$ & $70.62 \mathrm{~W}$ & 20 & 7.72 & 20 \\
\hline Irian Jaya, Indonesia & $2009 \operatorname{Jan} 3$ & $0.38 \mathrm{~S}$ & $132.83 \mathrm{E}$ & 15 & 7.66 & S6 \\
\hline
\end{tabular}




\begin{tabular}{|c|c|c|c|c|c|c|}
\hline & & & & & & \\
\hline New Zealand, S Island & 2009 July 15 & $45.85 \mathrm{~S}$ & $166.26 \mathrm{E}$ & 24 & 7.8 & 37 \\
\hline Santa Cruz Islands & 2009 Oct 7 & $11.86 \mathrm{~S}$ & $166.01 \mathrm{E}$ & 42 & 7.8 & S9 \\
\hline Maule, Chile & 2010 Feb 27 & $35.98 \mathrm{~S}$ & $73.15 \mathrm{~W}$ & 23 & 8.8 & 6 to 8 \\
\hline Sumatra, Indonesia & 2010 Apr 6 & $2.07 \mathrm{~N}$ & $96.74 \mathrm{E}$ & 18 & 7.8 & 29 \\
\hline Sumatra, Indonesia & 2010 Oct 25 & $3.71 \mathrm{~S}$ & $99.32 \mathrm{E}$ & 12 & 7.8 & 31 \\
\hline Tohoku-oki, Japan & 2011 Mar 11 & $37.52 \mathrm{~N}$ & $143.05 \mathrm{E}$ & 20 & 9.1 & 9 to 11 \\
\hline Off E Coast Japan & 2011 Mar 11 & 35.92 & 141.38 & 29 & 7.9 & 9 \\
\hline Nicoya, Costa Rica & 2012 Sept 5 & $10.00 \mathrm{~N}$ & $85.64 \mathrm{~W}$ & 30 & 7.62 & 14 \\
\hline Queen Charlotte, BC & 2012 Oct 28 & $52.61 \mathrm{~N}$ & $132.06 \mathrm{~W}$ & 12 & 7.8 & S17 \\
\hline Santa Cruz Islands & 2013 Feb 6 & $11.18 \mathrm{~S}$ & $165.21 \mathrm{E}$ & 20 & 7.9 & 35 to 36 \\
\hline Iquique, Chile & 2014 Apr 1 & $19.70 \mathrm{~S}$ & $70.81 \mathrm{~W}$ & 22 & 8.1 & $4 \& 5$ \\
\hline Tocopilla, Chile & 2014 Apr 3 & $20.43 \mathrm{~S}$ & $70.60 \mathrm{~W}$ & 29 & 7.73 & $4 \& 5$ \\
\hline Illapel, Chile & 2015 Sept 16 & $31.22 \mathrm{~S}$ & $72.27 \mathrm{~W}$ & 18 & 8.2 & 21 \\
\hline Pedenales, Ecuador & 2016 Apr 17 & $0.16 \mathrm{~S}$ & $80.35 \mathrm{~W}$ & 24 & 7.8 & 15 \\
\hline Solomon Islands & $2016 \operatorname{Dec} 8$ & $10.46 \mathrm{~S}$ & $161.12 \mathrm{E}$ & 46 & 7.8 & 34 \\
\hline New Ireland & 2017 Dec 17 & $5.55 \mathrm{~S}$ & $153.76 \mathrm{E}$ & 53 & 7.9 & S8 \\
\hline Shumagin Is, Alaska & 2020 July 22 & $54.84 \mathrm{~N}$ & $159.27 \mathrm{~W}$ & 37 & 7.8 & S13\&14 \\
\hline \multicolumn{7}{|l|}{ Other } \\
\hline Southern Chile & 1960 May 22 & $38.20 \mathrm{~S}$ & 73.50 & & 9.6 & 22 to 24 \\
\hline Flores Indonesia & $1992 \operatorname{Dec} 1$ & $8.34 \mathrm{~S}$ & $122.49 \mathrm{E}$ & 20 & 7.7 & S15 \\
\hline Nepal & 2015 Apr 25 & $27.91 \mathrm{~N}$ & $85.33 \mathrm{E}$ & 12 & 7.9 & S16 \\
\hline
\end{tabular}

\section{Results}

\subsection{Asperities, Earthquakes and Low-Coupling Segments}

Figure 1 illustrates schematically two interacting plates at a subduction zone and the various sizes of asperities that break in earthquakes at different locations and depths. The greatest earthquakes, which are taken here to break the largest asperities, typically occur at depths of about 15 to $40 \mathrm{~km}$ but sometimes as great as $70 \mathrm{~km}$. Great asperities are largely or totally locked during periods of slow stress buildup to mainshocks whereas smaller asperities on their peripheries rupture in forerunning earthquakes of moderate to large size as well as in aftershocks. Many slow-slip seismic events described in the literature occur in low-coupling zones between great asperities as well as down and up dip of them.

Few forerunning shocks of $\mathrm{Mw} \geq 5$ occur along the shallowest part of plate boundaries that extends from the surface of the crust at the trench to depths of about $15 \mathrm{~km}$. Few earthquakes nucleate there. It occasionally ruptures alone in large earthquakes and sometimes along with great shocks at deeper depths, as in the 2011 Tohoku-oki, Japanese event. Analyses of their frequency contents indicate that earthquakes in that very shallow zone rupture more slowly and more 


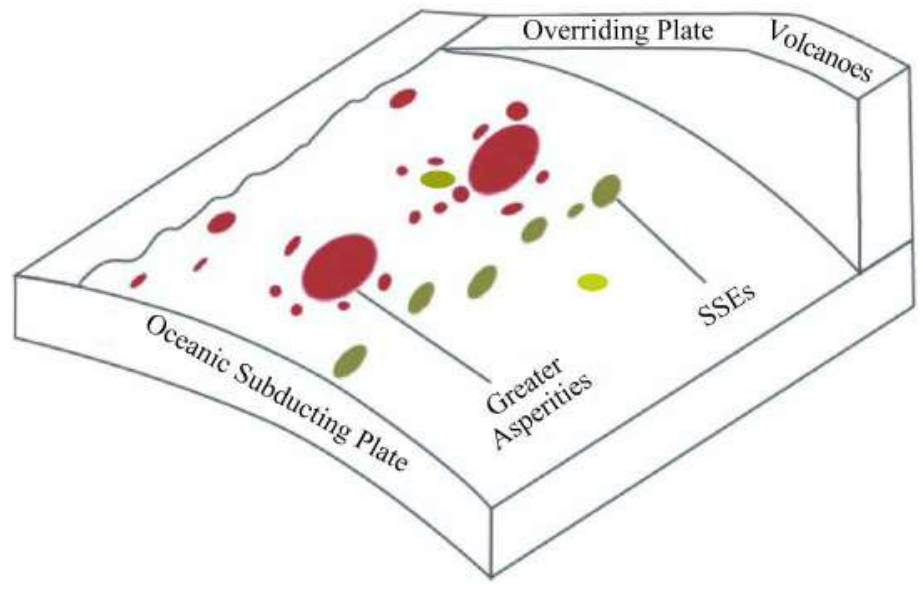

Figure 1. Sketch of distributions and sizes of asperities along downgoing plate boundaries at subduction zones. SSE's denote slow slip earthquakes. The sizes of asperities and their distances with respect to one another differ among segments of subduction zones. The region between the two largest asperities is a low-coupling zone (LCZ).

uniformly than great shocks at deeper depths [15]. Rupture of that very shallow zone often generates large sea waves (tsunami). The shallowest part of the plate boundary, which is farther from observation stations on land, is poorly understood compared to that at greater depths.

Earth materials along much of the shallowest part of the plate boundary are interpreted to be in the velocity-strengthening regime of rock mechanics [16]. In well-coupled subduction zones, rocks in the deeper regime where great asperities and great earthquakes are found, are taken to be in the velocity-weakening regime. Earth materials at all depths in poorly coupled subduction zones like the Marianas, Java and Tonga, where few large thrust earthquakes have occurred, are interpreted to be almost all in a velocity-strengthening regime.

Slow slip events of various durations are reported to have occurred in the transition zone deeper than the rupture zone of great asperities (Figure 1). The plate boundary at depths greater than about 40 to $70 \mathrm{~km}$ at various subduction zones moves without earthquakes. Many shocks at those depths occur instead within the downgoing plate.

\subsection{Differing Patterns of Forerunning Activity}

I first show several different examples of forerunning activity to great and giant earthquakes before discussing the rest of the shocks of Mw > 7.7 from 1993 to August 2020 at subduction zones.

\subsubsection{Tokachi-Oki, Japan, 2003}

Figure 2 illustrates forerunning activity from 1976 until the great Tokachi-oki earthquake of 2003, which occurred offshore of the northern Japanese island of Hokkaido. Its mechanism involved thrust faulting along the downgoing plate boundary. Lay and Rhode conclude [19] that little slip occurred along the shallowest part of the plate boundary to the southeast. The GCMT hypocenter of the 
mainshock, a measure of its centroid location, is shown as a large blue circle. It is situated within the areas of large horizontal slip in 2003 (solid black and dashed lines) as determined from tide gauge data and seismic-wave modeling [17] [18].

Forerunning activity of $\mathrm{Mw} \geq 5.0$ occurred almost exclusively outside either of the two areas of computed maximum slip. Those forerunners were distributed along the peripheries of three sides of the areas of high slip in the coming mainshock. Almost all aftershocks of $\mathrm{Mw} \geq 5.0$ (Figure 3) also occurred outside of those area of high slip. More aftershocks than forerunning activity took place closer to the trench.

The area ruptured in 2003 was broken previously in 1952 during a somewhat larger event whose areas of maximum slip extended farther southeast toward the deepest part of the trench [18]. Nearly the same great asperity broke in 1952 as in 2003 [17]. Hence, those two great events cover a complete seismic cycle of stress buildup and release for which the distribution of high slip has been computed for each mainshock. The zone ruptured previously in 1853 [18].

In summary, the 2003 shock, like other subduction-zone events described later, was characterized by a central large region that was nearly devoid of forerunning events in the preceding decades as well as devoid of aftershock activity. Forerunning activity occurred on the sides of what is interpreted as a great asperity that ruptured in 1952 and 2003.

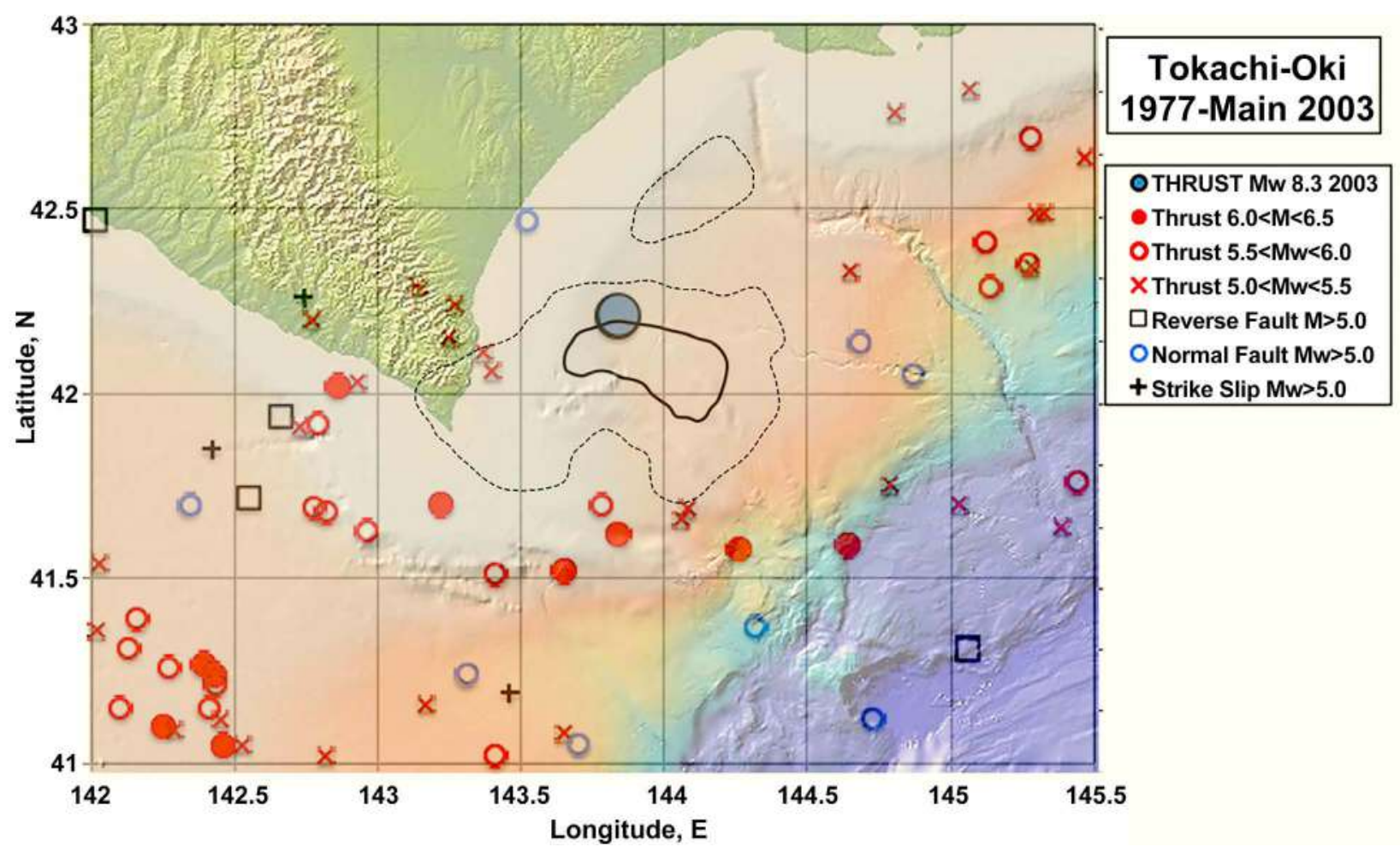

Figure 2. Locations and mechanisms of earthquakes of $\mathrm{Mw} \geq 5.0$ from 1976 through the Tokachi-oki mainshock (large blue circle) off the Japanese island of Hokkaido in 2003 of Mw 8.3. Heavy solid and dashed lines enclose regions of computed slip greater than 2 and $1 \mathrm{~m}$ in the mainshock from [17] [18]. Mechanisms with reverse faulting involve dips of two nodal planes greater than about $40^{\circ}$. 


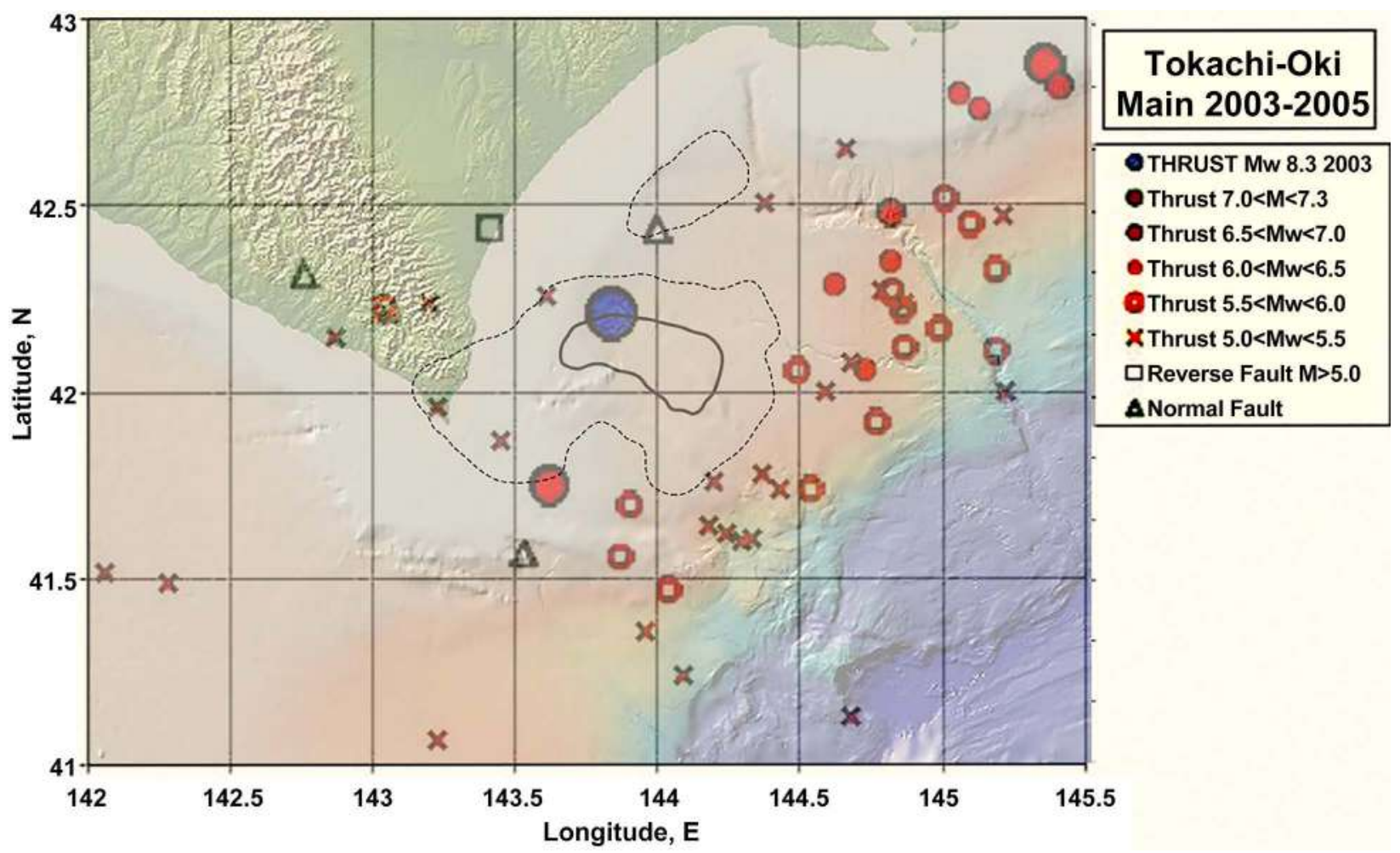

Figure 3. Locations of aftershocks of Mw > 5.0 of the Tokachi-oki mainshock of 2003 (large blue circle) through 2005. Colors denote sizes and mechanisms of earthquakes. Displacements same as in Figure 2.

\subsubsection{Iquique, North Chilean Earthquake of 2014, Mw 8.1}

Figure 4 shows forerunning activity of shocks $\mathrm{Mw}>5.0$ until the mainshock as well as the adjacent Mw 7.7 Tocopilla event two days later. Regions of high slip associated with the 2014 mainshock were determined from local and distant seismic data, GPS networks, other geodetic data and offshore tsunami gauges-one of the best earthquakes with multiple, different sets of forerunning data.

The centroid location (blue square) of the mainshock lies within the computed zone of highest slip, $3 \mathrm{~m}$, (solid black ellipse). Nearly all-forerunning activity of $\mathrm{Mw} \geq 5.0$ was located west and up dip of the two GCMT locations, within the slip contours of 0.5 and $3 \mathrm{~m}$ but not as far as the deepest part of the trench. The mainshock generated only a relatively small tsunami [20], which is consistent with small slip close to the trench. Aftershocks (not shown) were in nearly the same areas as the forerunning events [21].

Smaller earthquakes located using data recorded by a local network occurred to the east and downdip of the centroid shown in Figure 4 [22]. Many small events occurred in the two weeks before the mainshock updip of what [22] call the main asperity. Some of those shocks occurred within the upper plate, something that could not be ascertained solely from the data in Figure 4. The two sets of small earthquakes form what has been called a Mogi donut [23], i.e., seismic activity surrounding the quiet coming rupture zone of the mainshock. Thus, the "donut" consisted of a hole in seismicity surrounded by many forerunning earthquakes. 


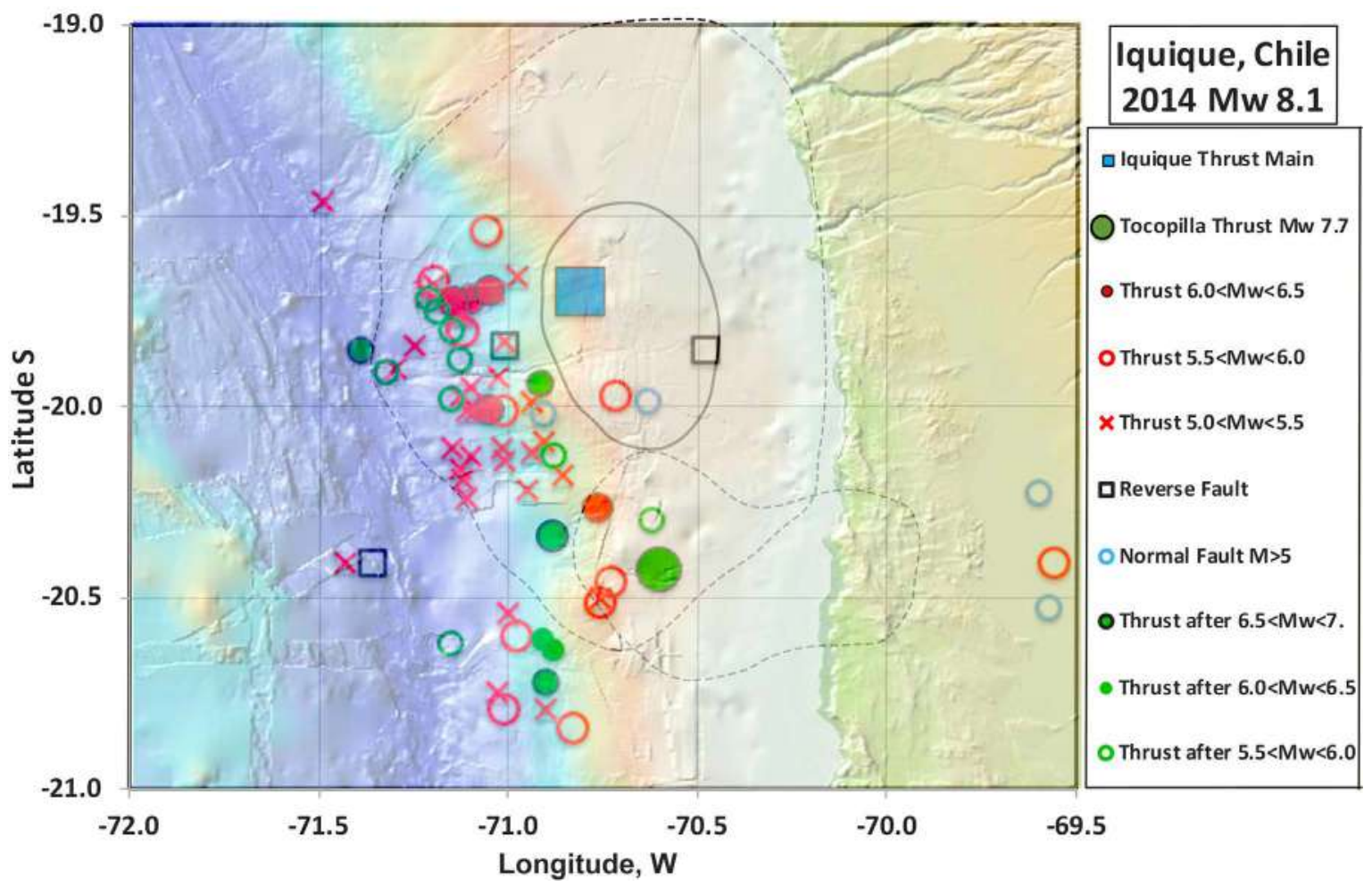

Figure 4. Locations of earthquakes of $\mathrm{Mw}>5.0$ from 1976 through the Iquique, northern Chilean mainshock of 2014 of Mw 8.1 (large blue square). Green circle denotes Tocopilla earthquake of Mw 7.7 two days after the mainshock. Colors indicate sizes and mechanisms of forerunning and aftershock activity. Heavy solid and dashed lines enclose region of slip greater than 3 and $0.5 \mathrm{~m}$ in the 2014 mainshock [22]. Only one forerunning shock (Mw 5.5) occurred to the south of the figure as far as $22.39^{\circ} \mathrm{S}$.

The distribution of data from small events confirms the use in this paper of moderate-to-large forerunning earthquakes in mapping great asperities decades to years ahead of their breaking in great shocks.

A group of coastal GPS stations accelerated toward the trench in the eight months prior to the 2014 earthquake [24]. Small repeating earthquakes likely indicated that aseismic slip took place along the plate boundary during the foreshock sequence [25]. A slow slip event using GPS observations was detected preceded the 2014 earthquake [26]. Significant changes in the rates of microseismicity extending back as far as July 2013 are interpret as large-scale unlocking of the plate interface [27].

The Iquique and Tocopilla earthquakes of 2014 were unusual in that neither rupture zone was the site of a very large shock since the giant earthquake of 1877 [5]. Thus, the 2014 rupture areas had been long-standing seismic gaps. The two largest events of 2014 were situated more than $200 \mathrm{~km}$ along strike from the great southern Peruvian earthquake of 2001 (described later) and well north of a 1977 shock of Mw 7.7 [21]. Hence, forerunning activity in Figure 4 is unlikely to have been affected by nearby great shocks along the plate boundary to either the northwest or the south. The plate boundaries adjacent to the two 2014 events remain seismic gaps that could be sites of future earthquakes of about Mw 7.8 to 8.3. 
Cumulative seismic moment for shocks of $M \geq 5.5$ (Figure 5) for the area of Figure 4 from 1976 until the mainshocks of 2014 indicates a nearly exponential increase starting about 2007, seven years before the mainshock. Following the great 2001 Peruvian shock farther to the northwest, the rate of events of magnitude $\geq 4.5$ increased in the vicinity of the 2014 sequence [28]. The $b$-values, a measure of the number of large to small events, were anomalously low for 5.5 years in the coming rupture zone of the 2014 earthquake [29]. Values of $b$ were normal (larger) outside that zone. Low $b$ values suggest that the coming rupture zone in Chile was the site of high stress ([16], p. 186).

In summary, forerunning activity in Figure 4 was limited to the length along strike of the plate boundary that subsequently broke in 2014 during the two shocks of Mw 8.1 and 7.7. That observation as well as data from the local seismic network might have been used to make a long-term estimate of the length of the plate boundary along strike that would later rupture in those two earthquakes. Little forerunning activity occurred within the central zone where slip exceeded 3 $\mathrm{m}$. Precursory forerunning changes in $b$-value, the formation of a Mogi donut, precursory slow slip events and accelerating seismic moment release occurred prior to the 2014 mainshock. This is one of the best indications of a variety of changes prior to a great earthquake. Together, they might have been the basis for issuing either a hazard watch or a prediction for time scales of about 5 to 10 years.

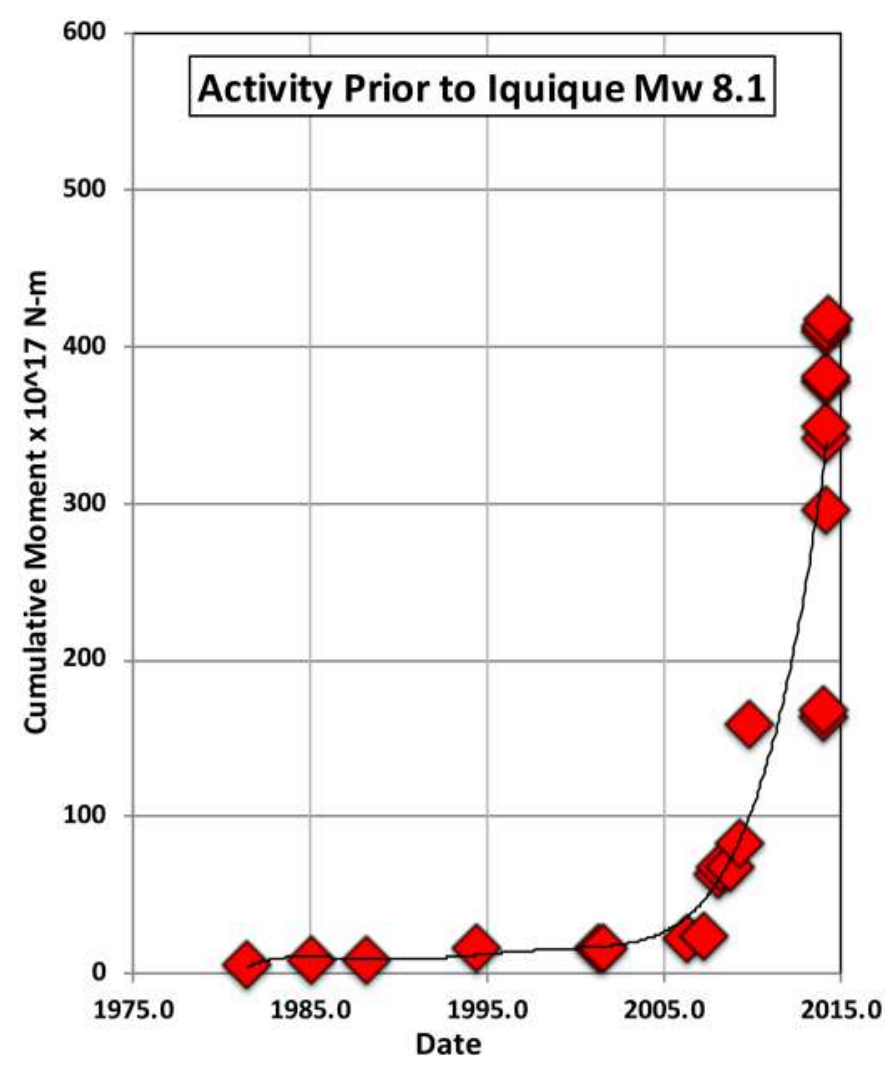

Figure 5. Cumulative seismic moment from 1976 until the Iquique, Chilean earthquake of 2014. Black line is best-fitting exponential increase with time. 


\subsubsection{Maule, Chile Earthquake of 2010, Mw 8.8}

GPS observations were made during the decade that preceded the giant 2010 Maule earthquake, during the mainshock itself and afterwards-the first for any giant shock. The two regions of slip larger than $8 \mathrm{~m}$ (solid curve, Figure 6) in the mainshock as deduced from geodetic and seismic observations are located to the north and south of the seismic moment centroid (red diamond) and the epicenter of initial fault rupture in the same area. None of the forerunning activity of $M \geq 5.0$ in Figure 6 occurred in either of those two zones of slip greater than 8 $\mathrm{m}$. Forerunning activity was located well to the north and south of the centroid and outside of the two areas that slipped more than $8 \mathrm{~m}$.

Two forerunning events also occurred east of the centroid of the mainshock. Nearly all the aftershocks of the 2010 event also occurred outside of the two inferred regions where slip exceeded $8 \mathrm{~m}$ [30]. A similar distribution of earthquakes took place before the 2010 mainshock [31]. Those authors calculated somewhat different amounts of slip in the mainshock than that by [32] that is shown in Figure 6. Nonetheless, the three sets of authors show maxima in slip

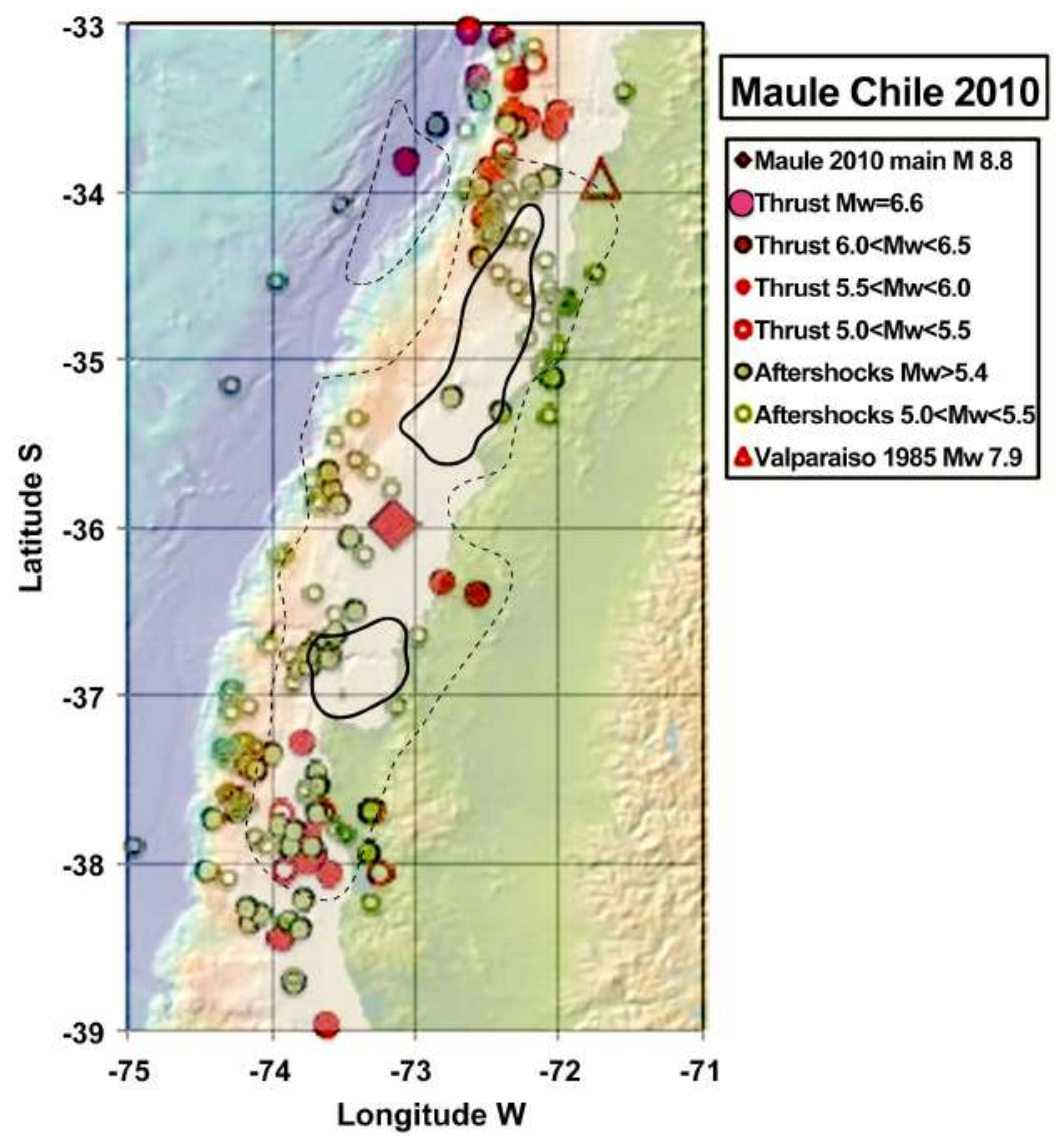

Figure 6. Locations of earthquakes of $\mathrm{Mw} \geq 5.0$ from 1976 through the giant Maule, Chilean mainshock of 2010 of Mw 8.8 (large red diamond). Other red symbols denote thrust activity prior to the mainshock; green circles, aftershocks. Likely aftershocks of the Mw 7.9 Valparaiso earthquake of 1985 (open red triangle), north of $34.6^{\circ} \mathrm{S}$ prior to 1996 are not included. Heavy solid and dashed lines enclose regions of computed slip greater than 8 and $2 \mathrm{~m}$ from [32]. 
both to the north and south of the 2010 centroid. It ruptured bilaterally to the south and then to the north [32]. Substantial slip occurred westward to the trench as determined from tsunami observations [31]. The rupture zone of the 2010 mainshock was locked beforehand, i.e., well coupled [33].

The aftershock zones of the Mw 7.9 1985 Valparaíso and 2010 Maule overlapped about $160 \mathrm{~km}$ at the northern end of the 2010 rupture zone (Figure 7). Computed slip in the 2010 mainshock was relatively small there. Slip at the southern end of the 2010 zone between $37^{\circ}$ and $38^{\circ} \mathrm{S}$ was small, the same area that broke in the foreshock of about Mw 8.1 the day before the giant Chilean shock of May 22, 1960 [34]. The rupture zone of the giant 1960 Chilean shock itself broke from $38^{\circ}$ to $46^{\circ} \mathrm{S}$, mostly to the south of Figure 6 .

Aftershock zones, and by inference the main rupture zones, of several adjacent great and giant earthquakes touched one another without significant over or underlap according to [2] and [4]. Better mapping of the 1985 and 2010 zones shows, however, significant overlap of their aftershocks. That overlap occurred in the region where computed slip in 2010 was relatively small. Many of the great and giant mainshocks reported later in this paper also exhibit relatively small slip at their ends along strike where their aftershock zones overlap. It is understandable that displacements in large shocks do not decease instantaneously to zero at the ends of their rupture zones since doing so would result in a stress singularity.

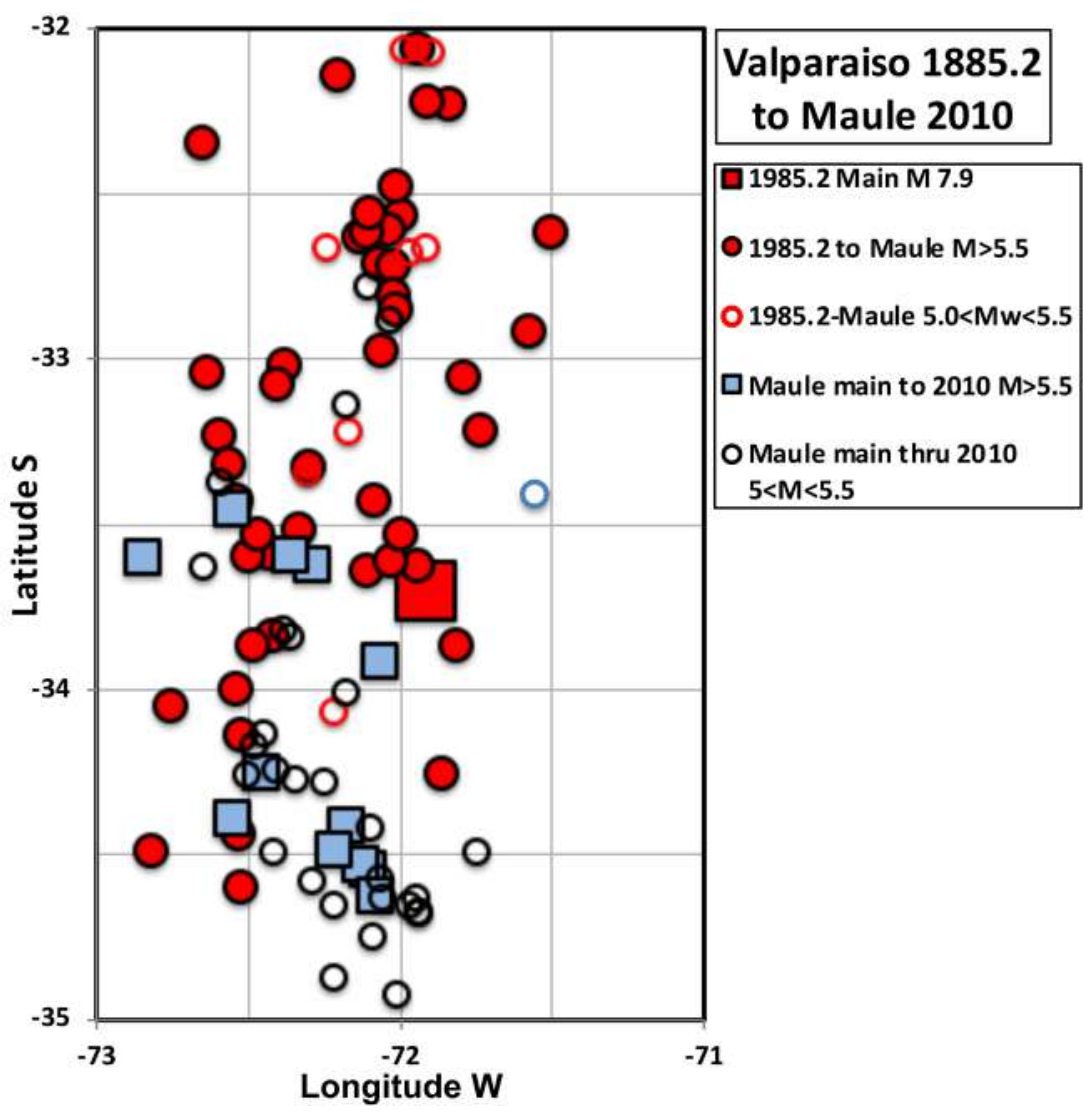

Figure 7. Overlap of aftershocks of the 1985 Valparaiso and 2010 Maule earthquakes. 
The 1985 shock broke part of the seismic gap remaining from the great 1906 Chilean earthquake of about Mw 8.2 to 8.5. The 1906 rupture length from $32^{\circ}$ to $35^{\circ} \mathrm{S}$ was well determined from observations of coastal uplift [7]. Its northern part broke again from north to south in 1971 (Mw 7.8) and 1985 (Mw 7.9). Nishenko [7] stated, "The southern segment of the 1906 zone (from $33.5^{\circ}$ to $35^{\circ} \mathrm{S}$ ) has been quiet for large shocks since 1916, and may be the next segment to rupture." The 2010 Maule shock did rupture that remaining part of the 1906 rupture zone as well as the gap to the south that last broke in the great earthquake of 1835 [7]. It is not surprising that two great asperities, not one, ruptured in 2010 since the whole zone broke in separate great shocks in 1906 and 1835. The northern extent of rupture in 1835 is poorly known, however [7].

An earthquake in 1928 near $35^{\circ} \mathrm{S}$ of revised magnitude Mw 7.7 [11] probably was not nearly as large as the 1835 and 1906 earthquakes. The 1928 felt area was aligned east-west and may not have been a thrust event along the plate boundary [7]. An earthquake of revised magnitude 7.6 in 1939 occurred farther east within the upper plate with a strike-slip mechanism. Since it did not break the plate boundary, it did not rupture the seismic gaps remaining from the 1835 and 1906 earthquakes. A poorly located event in 1914 of revised Mw 7.4 occurred in the same region. In any case, however, the plate boundary between $34.5^{\circ}$ and $38^{\circ} \mathrm{S}$ was a seismic gap for many decades before 2010 .

Many GPS observations were used to compute plate coupling along the Chilean subduction zone between $18^{\circ}$ and $38^{\circ} \mathrm{S}$ [33]. They find that the region is subdivided into seven well-coupled (locked) segments interspersed with at least six low-coupling zones (LCZs). For the three most recent earthquakes of Mw greater than 8-Maule, Iquique and Illapel-Métois et al. [33] report that co-seismic asperities correlate well with highly coupled segments while LCZs to their north and south behaved as barriers that stopped rupture. They argue that the first-order mechanical interpretation of plate coupling in the rate-and-state formalism implies that the LCZs largely creep while the coupled segments remain locked during inter-seismic loading.

Métois et al. [33] call the region to the south between $37^{\circ}$ and $38^{\circ}$ the Araco LCZ. It was the site of earthquakes smaller than the giant shocks of 1960 and 2010 including foreshocks the day before the giant earthquake of 1960 [34]. Many authors unfortunately plot a single rupture zone for the earthquake of May 1960. The region between $37^{\circ}$ and $38.4^{\circ} \mathrm{S}$ has behaved differently from the zones of giant shocks to its north and south. The Araco LCZ is discussed more later in conjunction with slip in the giant 1960 event.

Olsen et al. [35] conclude that much of the south-central Chilean margin from $32^{\circ}$ to $46^{\circ} \mathrm{S}$ contains unusually strong, well-drained sediments. Their study included the rupture zones of the 2010 and 1960 giant earthquakes. They found an exception where the Mocha fracture zone is being subducted between $37^{\circ}$ and $38^{\circ}$ S, i.e., at the Araco LCZ. They infer that it experiences localized overpressure, delaying compaction of incoming sediments and weakening the plate interface. High Poisson's ratios and inferred very high fluid pressures in the region were 
inferred by [30]. These factors are associated with poor coupling along the plate interface and an abundance of forerunning activity to the 2010 mainshock, as well as to the 1960 mainshock (described later).

Figure 8 shows that cumulative seismic moment increased from 1995 until the 2010 Maule mainshock in the region between the 1985 and 2010 rupture zones shown in Figure 7. Accelerating cumulative moment in the southern part of the 2010 zone is dominated by a single large shock. Whether either acceleration of seismic moment was, in fact, casually related to the coming 2010 earthquake is debateable. Deducing a strong connection will require knowledge from future great events.

In summary, most of the plate boundary along the 2010 rupture zone is well coupled and is inferred to consist of two great asperities. Two regions of high slip were mapped, which extend westward as far as the outcrop of the plate boundary at the trench. Little forerunning or aftershock activity occurred in those zones of highest slip. Most forerunning activity occurred near the northern and southern boundaries of slip in 2010 in what has been called low-coupling zones (LCZ). They are inferred to consist of smaller asperities. The northern LCZ was the site of an increase in seismic moment release in the several years before the 2010 shock

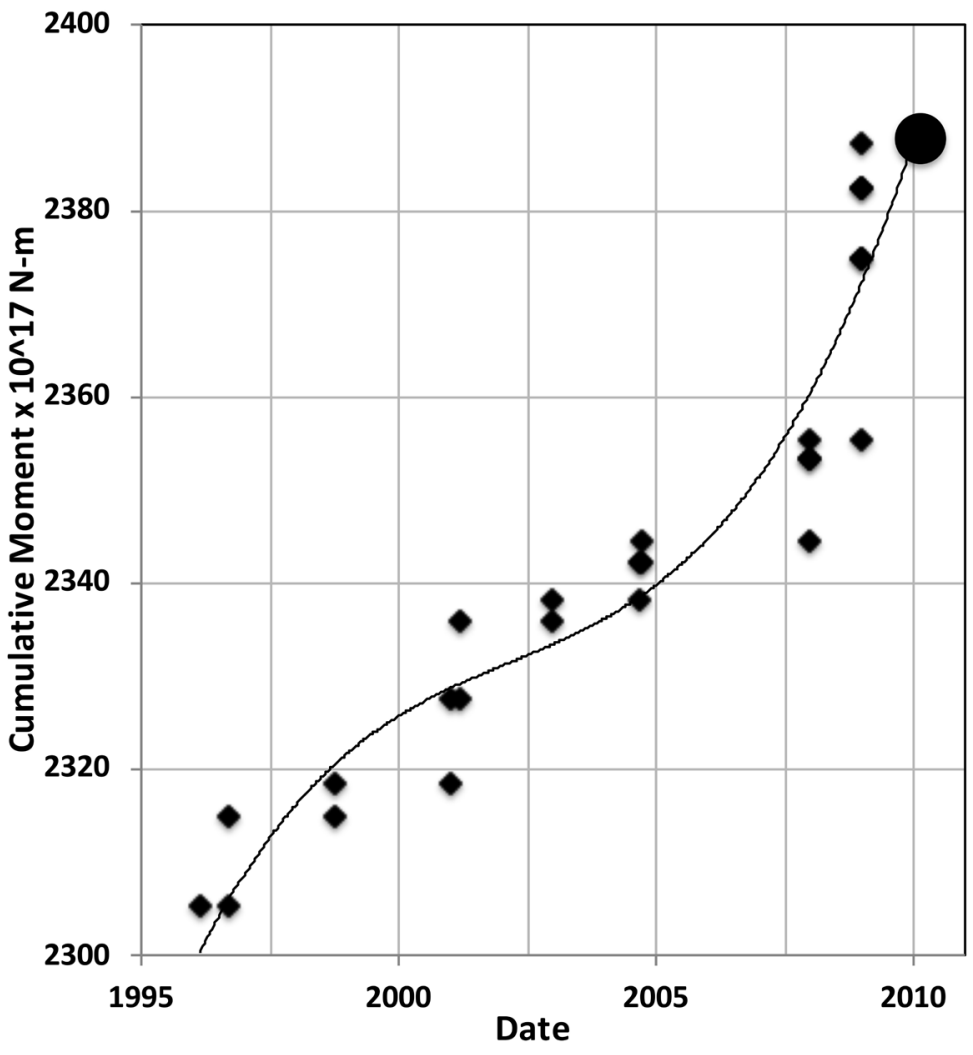

Figure 8. Cumulative seismic moment release from 1995 until the 2010 Maule earthquake in the region between $32^{\circ}$ and $35^{\circ} \mathrm{S}$. Solid line is best-fitting polynomial of low degree. Note increase in moment release starting about 2008. 


\subsubsection{Tohoku-Oki, Japanese Earthquake of 2011, Mw 9.1}

More than 18,000 lives were lost in the giant Japanese earthquake and tsunami of 2011. The World Bank estimated the economic costs as \$ 235 billion, the costliest natural disaster in world history. More than 127,000 buildings totally collapsed and an additional one million were partially damaged. Additional longer-term financial losses have yet to be tallied from radioactive leakage, evacuation of hundreds of thousands of people, and ongoing attempts at cleanup from major explosions and meltdowns at four of the nuclear reactors at nearby Fukushima Daiichi.

Earthquakes of $M \geq 5.5$ in the decade before the giant 2011 shock occurred either between the 4 and $24 \mathrm{~m}$ slip contours in Figure 9, on the periphery of the $24 \mathrm{~m}$ contour or outside them to the southwest near the shock of magnitude 7.9. It occurred about 30 minutes after the mainshock. All but one of the forerunning thrust earthquakes within the $24 \mathrm{~m}$ contour occurred along its periphery. As in several other subduction zones, none extended as far east as the deepest part of the trench.

The 2011 source area was unusual since between 1978 and two days before the mainshock several events of Mw greater than 7.0 took place (Figure 10). One of them, known as a Miyagi-oki earthquake, occurred within the $24 \mathrm{~m}$ contour and

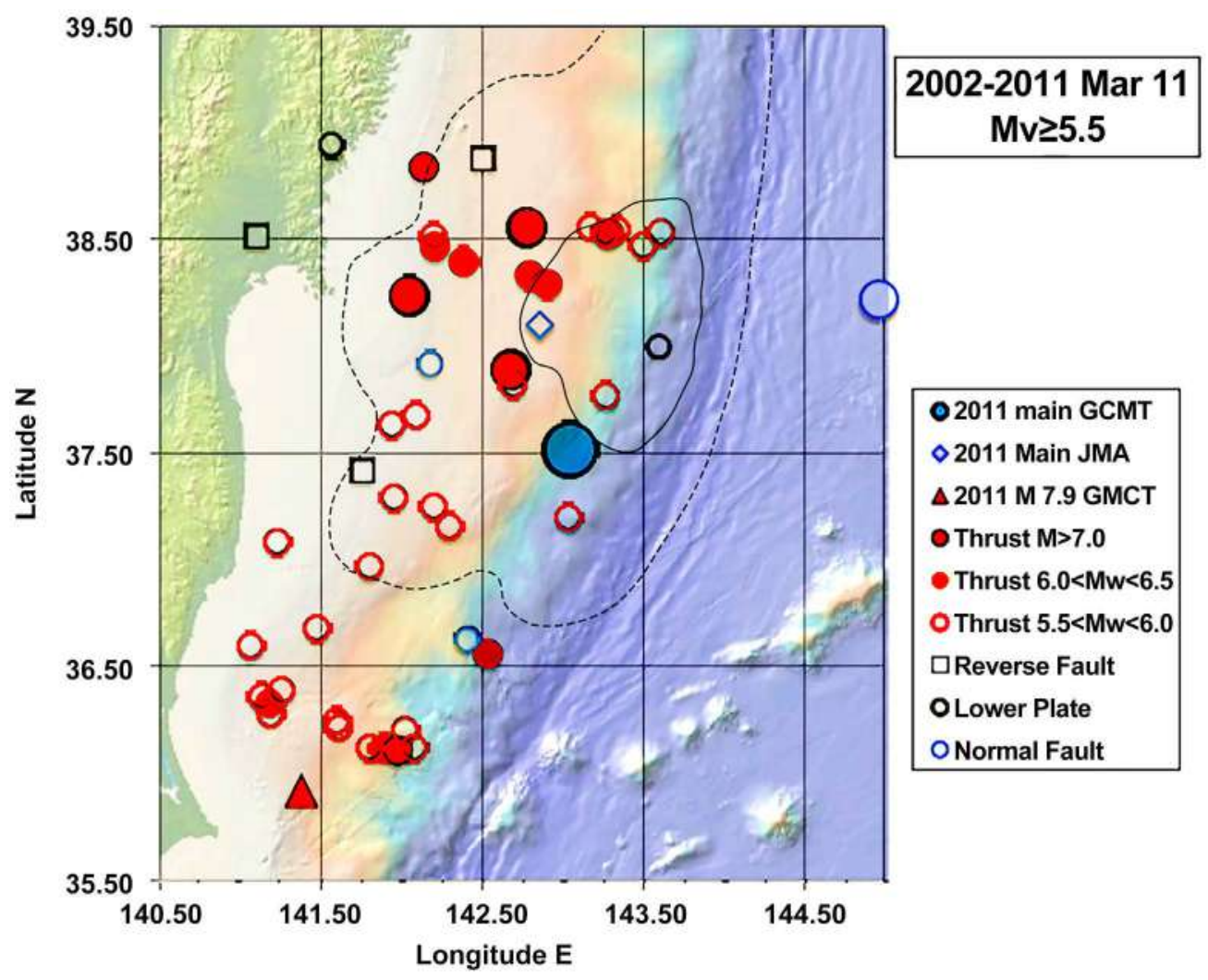

Figure 9. Locations of earthquakes of $\mathrm{Mw} \geq 5.5$ from 2002 through the Tohoku-oki, Japanese mainshock of 2011 of Mw 9.1 (large blue circle) and the immediate aftershock (red triangle) of Mw 7.9. Colors denote sizes and mechanisms of forerunning activity. Heavy solid and dashed lines enclose regions of slip greater than 24 and $4 \mathrm{~m}$ from [36]. 


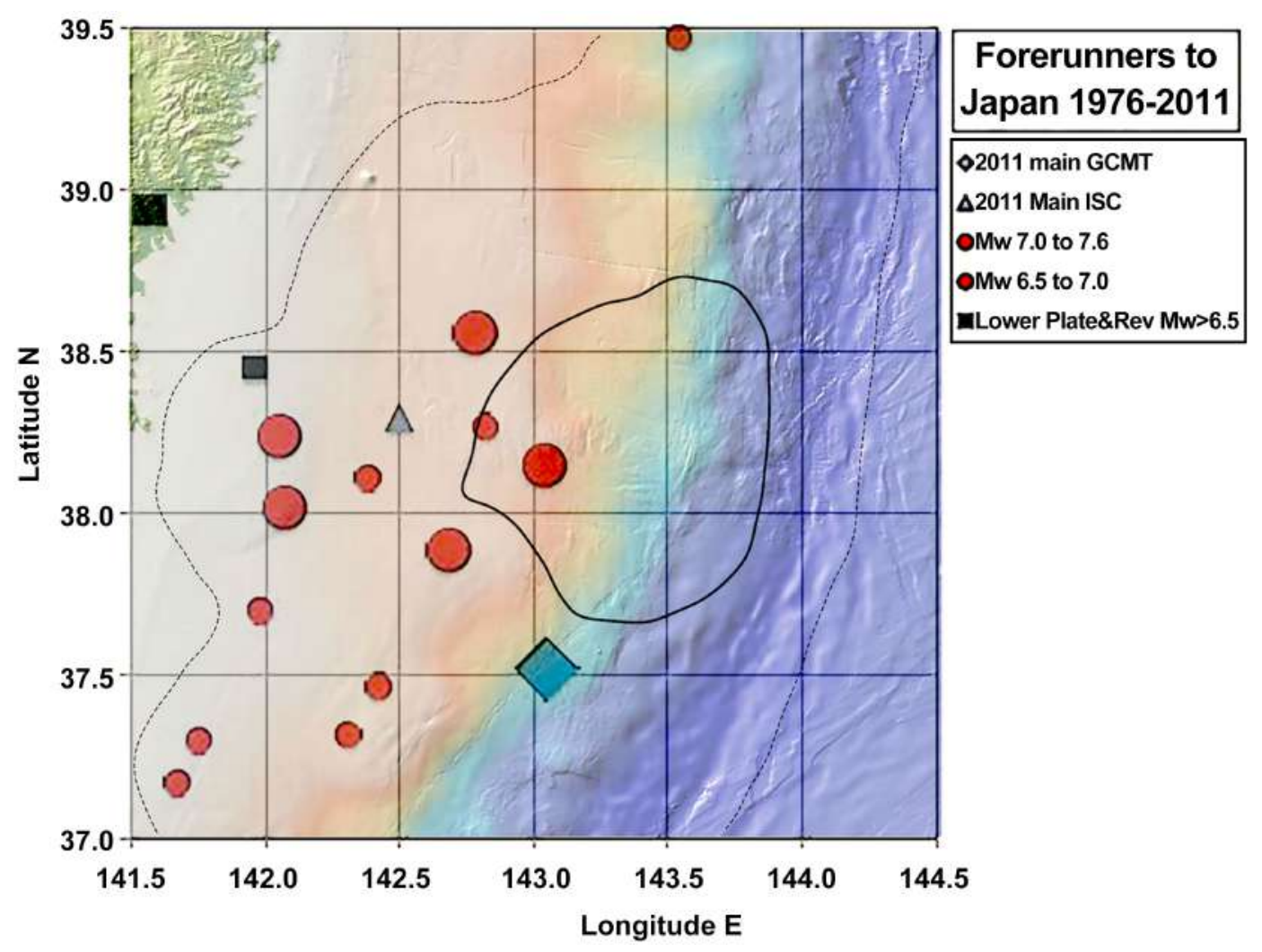

Figure 10. Locations of earthquakes of $\mathrm{Mw} \geq 6.5$ from 1976 through Tohoku-oki, mainshock of 2011. Large blue diamond is its long-period centroid location; blue triangle denotes its short-period epicenter. Red colors indicate sizes and thrust mechanisms of forerunning activity prior to the mainshock. Heavy solid and dashed lines same as in Figure 9.

four outside it but within the $4 \mathrm{~m}$ contour. The region ruptured previously in additional Miyagi-oki events of $M \geq 7.0$ in 1915, 1933, 1936 and 1939. Most of the $M \geq 7$ Miyagi-oki shocks broke separate asperities [17].

The locations of the five largest forerunning earthquakes since 1976 in Figure 10 surround the short-period hypocenter, the point of initial rupture in the 2011 mainshock (blue triangle). Rupture in 2011 expanded well beyond those five. The large magnitudes and numbers of those forerunning earthquakes are unique among the events studied in this paper. The dimensions of the main asperity broken in the largest, Mw 7.6 in 1978, was about 45 by $25 \mathrm{~km}$ [17]. The asperities of those five events were large enough for stresses to have interacted significantly with one another.

Ikuta et al. [37] conclude, ... "the plate boundary was accumulating the full slip deficit (i.e., it was totally locked) during at least the last 15 years [before 2011] in a very limited area with a diameter of a few 10s of kilometers, which overlaps with the maximum co-seismic slip area." They suggest this relatively small area, or asperity, was the last locked section of the plate boundary to fail in 2011. They show that M 7 class Miyagi-oki earthquakes of the previous 80 years only released part of the slip deficit that was being accumulated. They conclude that those M 7 rupture zones moved again in the mainshock. Apparently, the 
giant earthquake could not occur until several of the relatively large asperities associated with $\mathrm{Mw} \geq 7$ events ruptured and increased stresses on the last-to-break asperity [37].

The large foreshock of March 9 was followed two days later by additional moderate-size earthquakes whose locations approached the short-period epicenter of the coming giant shock (blue triangle in Figure 10). Many geophysicists now regard that forerunning sequence as a precursor to the giant earthquake. Nevertheless, until the mainshock occurred, those events do not seem to have been identified as precursors.

The 2011 mainshock was recorded by an exceptionally great number of seismograph stations and geodetic observation points both on and offshore. This permitted slip to be well calculated as far to the southeast as the deepest part of the Japan Trench. The average fault displacement over the entire area of rupture in 2011 was about $10 \mathrm{~m}$. Horizontal slip close to the trench was an extraordinary 50 to $80 \mathrm{~m}$. Loveless and Meade [38] used GPS data to calculate the percentage of locking (coupling) along the main plate boundaries of Japan. They found strong coupling in the zone that broke in 2011.

Forerunning thrust activity of $\mathrm{Mw}>5.5$ in Figure 10, however, did not extend to the deepest part of the trench. Very few shocks as small as Mw 5.0 (not shown) occurred nearer the trench than the centroid location. The rocks closest to the deepest part of the trench are inferred to be mostly in the velocity-strengthening slip regime. Displacements close to the trench in many other subduction zones have been poorly mapped. Some geophysicists concluded previously that those zones either creeped continuously with time or moved episodically in slow-slip events. Instead, that region ruptured more than $24 \mathrm{~m}$ in 2011 (Figure 9 and Figure 10).

Ikuta et al. state [37], “... suggest deeper fault sections played an important role in the accumulation of a large slip deficit near the trench, which is where the large co-seismic slip was reported in studies using seismic waves." They claim the M7-class asperities prevented large slip from occurring closer to the trench until the mainshock. In that sense, the latter region appears to be very unusual among subduction zones.

Several authors [39] [40] [41] [42] reported slow slip in the years to about a decade before the mainshock. Two of them placed it at depth along the plate boundary to the west of the centroid. The time interval between small repeating earthquakes decreased with time, another indication that slow slip was increasing downdip before 2011 [43].

Nanjo et al. [44] showed that $b$-values decreased from a normal value of about 1.1 in the 5 to 20 years before the giant 2011 earthquake. They found it then decreased further in the five years before 2011 to a very low value of 0.45 within the coming rupture zone. Such low $b$-values are often taken as an indicator of relatively high stress [16]. These are among several examples of intermediate-term (1 to 10 years) and long-term (10 to 30 years) precursors. 
Figure 11 shows cumulative seismic moment released between 1976 and the 2011 mainshock. If moment release had been occurring uniformly with time, the cumulative release would form a straight line of positive slope. Instead, it increased more rapidly starting between 2003 and 2005. It also increased at the time of the Mw 7.6 shock in 1978 but then decreased until 2003.

As stated earlier for Chile, the Japan subduction zone is divided into segments like the 2011 rupture zone that are characterized by strong coupling. Nishikawa et al. [45] and references therein] report that the regions to the north of $39^{\circ} \mathrm{N}$ and south of $37^{\circ} \mathrm{N}$ were the sites of numerous slow events on a variety of time scales. The region in between them was the main slip zone of the 2011 earthquake.

In summary, the 2011 mainshock was unusual in that it was preceded by abundant activity of magnitude 7 and greater, which did not extend as far toward the trench as the centroid of the mainshock. A great asperity that finally broke in the mainshock is inferred to have extended from the three large easternmost Miyagi-oki earthquakes to the outcrop of the plate boundary at the trench. Cumulative seismic moment accelerated between about 2004 and 2011. Others reported various precursory activity from several years to one or two decades before the mainshock.

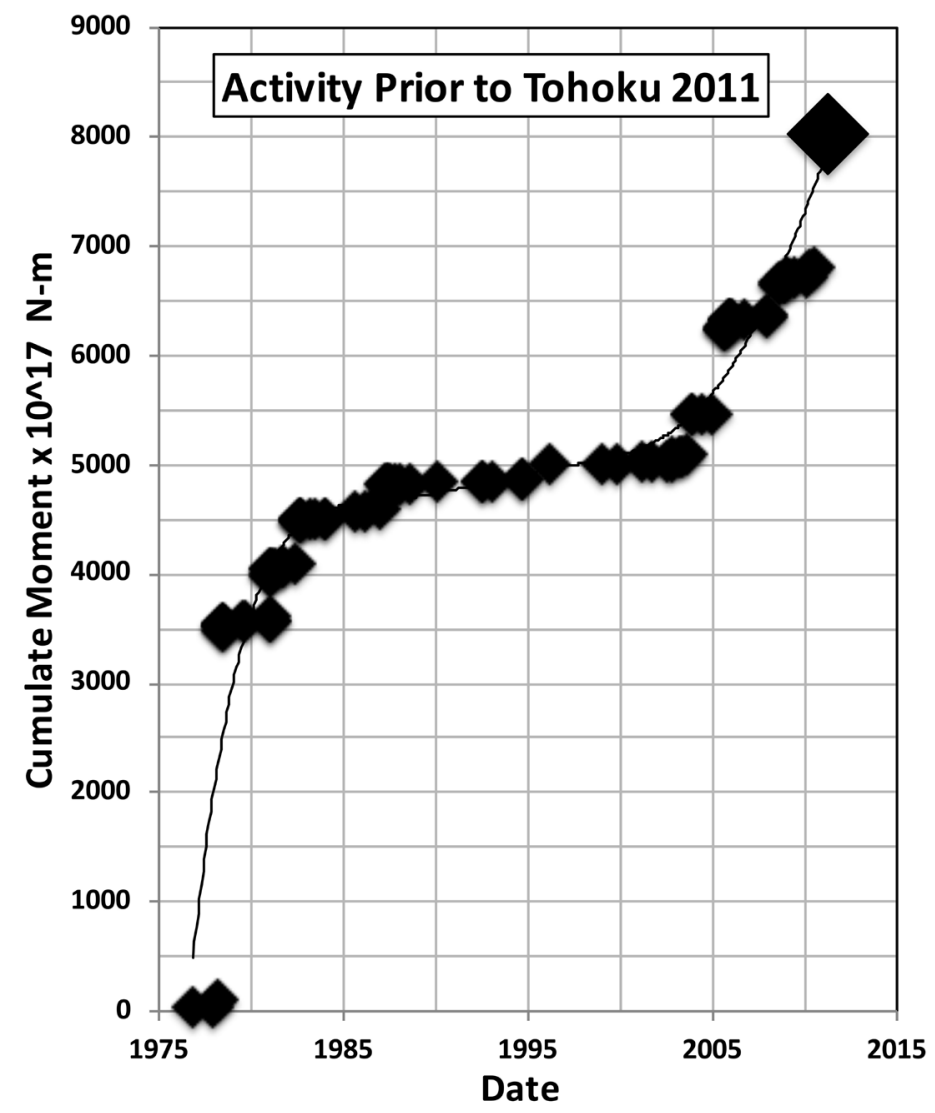

Figure 11. Cumulative seismic moment release before the 2011 Japanese earthquake for the area shown in Figure 9. Solid line is best-fitting polynomial of low degree. 


\subsubsection{Central Kuril Islands Earthquake of 2006, Mw 8.3}

The great Kuril Islands thrust earthquake of 2006 filled part of a major seismic gap between the 1952 Kamchatka shock of Mw 8.9 to the northeast and the 1963 Kuril earthquake of Mw 8.5 to the southwest. A smaller event of Mw 7.8 in 1915 likely broke part of the 2006 zone. Another shock of Mw 7.5 in 1918 probably ruptured to its southwest [2] [5]. A major seismic gap still exists between the rupture zones of the 2006 and 1952 earthquakes.

The depth of the moment tensor solution for the 2006 rupture was computed to be only $14 \mathrm{~km}$, an indication it occurred along the shallow part of the plate boundary. A similar conclusion was reached by [46] from their analysis of the codas of $\mathrm{P}$ waves. The 2006 event produced a tsunami of only moderate size [46]. The 2006 shock was followed two months later by a great normal-faulting event of Mw 8.1 just to its east within the down-bent Pacific plate. The 2006 earthquake triggered normal-faulting events before the great 2007 normal-faulting shock.

Maximum slip [47] was centered in the middle of that deduced by [46] in Figure 12. I do not think the result in [47] is as accurate since it was based on GPS observations to the southwest, (many in Hokkaido and one site in a southern

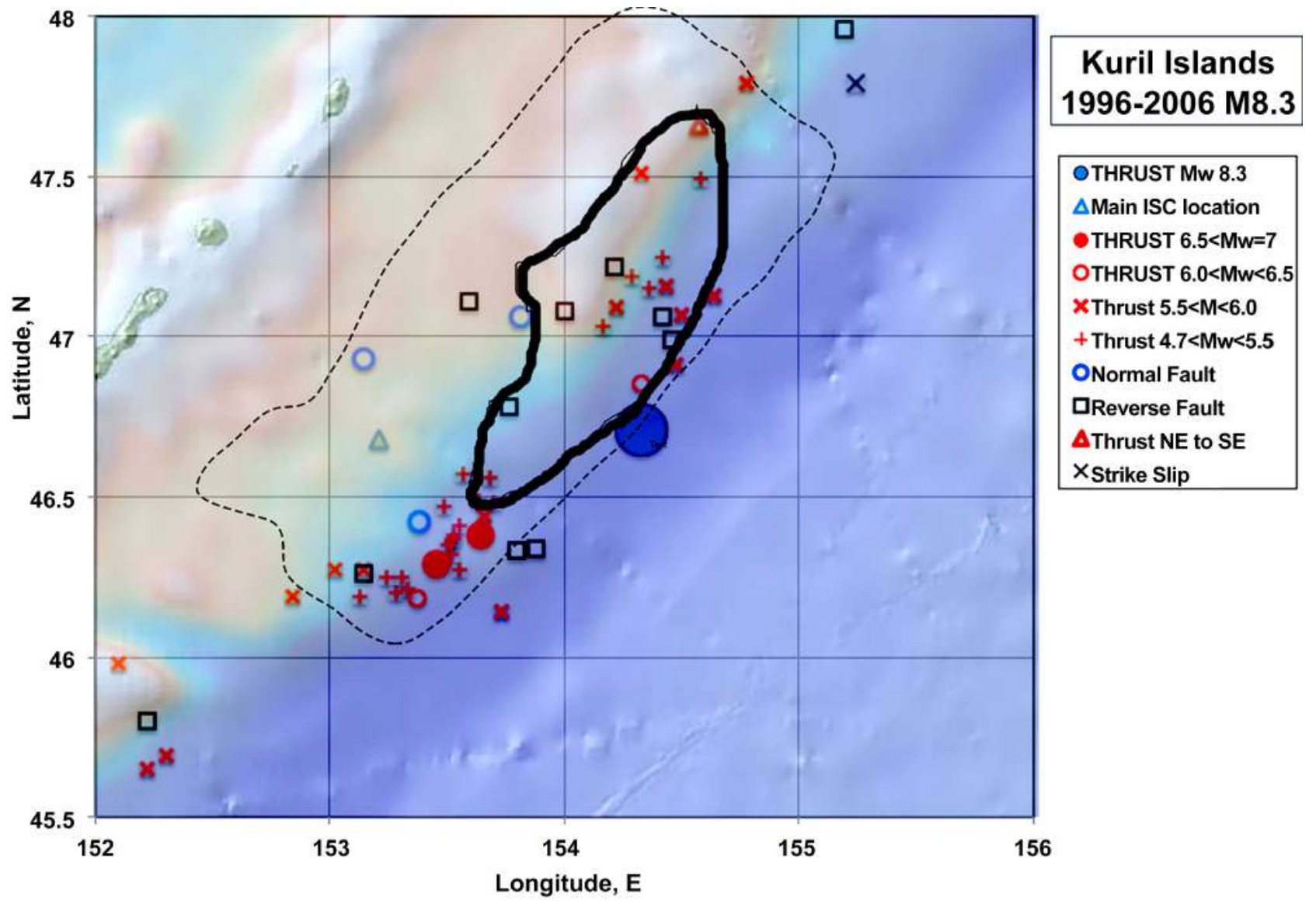

Figure 12. Locations of earthquakes of $\mathrm{Mw} \geq 5.0$ in the decade preceding the Kuril Islands mainshock of 2006. Large blue circle denotes long-period centroid; blue-green triangle, short period epicenter. Colors depict sizes and mechanisms of forerunning activity. Heavy solid and dashed lines enclose regions of computed slip greater than 7 and $1 \mathrm{~m}$ during the mainshock after [46]. 
Kuril Island). Steblov et al. [48] inferred that slip was concentrated at its southwestern end. They, however, used data from a few widely spaced new GPS stations in the Kuril Islands. I regard the maximum slip distributions computed by [46] as the most reliable and show them in Figure 12.

Forerunning activity (Figure 12) occurred southwest of the $7 \mathrm{~m}$ slip area but inside the one meter contour. Many of those events occurred as foreshocks in the few months before the 2006 main event. The southern half of the zone of $7 \mathrm{~m}$ slip in 2006 included few forerunning thrust shocks between 1996 and the mainshock. Many forerunning thrust events of $5<\mathrm{Mw}<6$ occurred in the northeastern half of the zone of $7 \mathrm{~m}$ slip along with four earthquakes with reverse-faulting mechanisms.

Rupture in 2006 propagated mainly to the northeast within the zone of high slip in Figure 12. Ref. [46] also states, "large secondary bursts are associated with two northeastern patches of enhanced slip." Fujii and Satake [49] deduced that the largest tsunami source occurred at its northeastern end. The Bulletin of the International Seismological Centre computed a short-period hypocenter at $46.68^{\circ} \mathrm{N}, 153.21^{\circ} \mathrm{E}$ and a shallow depth of $12 \mathrm{~km}$, which places it near the southern part of the zone of high slip but to its west. One possible explanation for forerunning activity in the northeastern half of the zone of maximum slip is that the southwestern half ruptured first and triggered somewhat slower slip and a tsunami in the northeastern half. If so, they appear to define two large asperities that broke in 2006.

In summary, forerunning thrust earthquakes occurred in the northeastern half of the zone of computed highest slip but not in its southwestern half. The southwestern half may be interpreted as a great asperity with slip initiating nearby. Estimates of magnitude and rupture length of the coming 2006 mainshock based solely on forerunning shocks of $\mathrm{Mw}>5.0$ would have been too small. The mainshock occurred in a long-standing seismic gap. Cumulative seismic moment release from 1976 until the mainshock was nearly constant except where it increased abruptly during the one-year period of precursory activity.

\subsubsection{Poorly Coupled Plate Boundary off Java, Indonesia}

Plate boundaries that are usually regarded as poorly coupled off Java, the Lesser Sunda Islands of Indonesia, the Marianas, Tonga and the Kermadec islands were examined to see if any of their few great earthquakes were preceded by significant forerunning activity. The answer was no. The data for Java are presented here; the other areas are described in the Supplement.

The plate boundary south of Java is very different from that to its west off Sumatra in that many known earthquakes of magnitude 8 and greater have occurred south of Sumatra but none off Java and the Lesser Sunda islands to its east. Only one known event greater than Mw 7.0 (it of 7.3) took place off Java between 1916 and 1977. Only a single moderate-size earthquake occurred from 1976 until 1994 within $150 \mathrm{~km}$ of the 1994 mainshock in Figure 13. Very low activity took place between 1994 and the 2006 mainshock. 


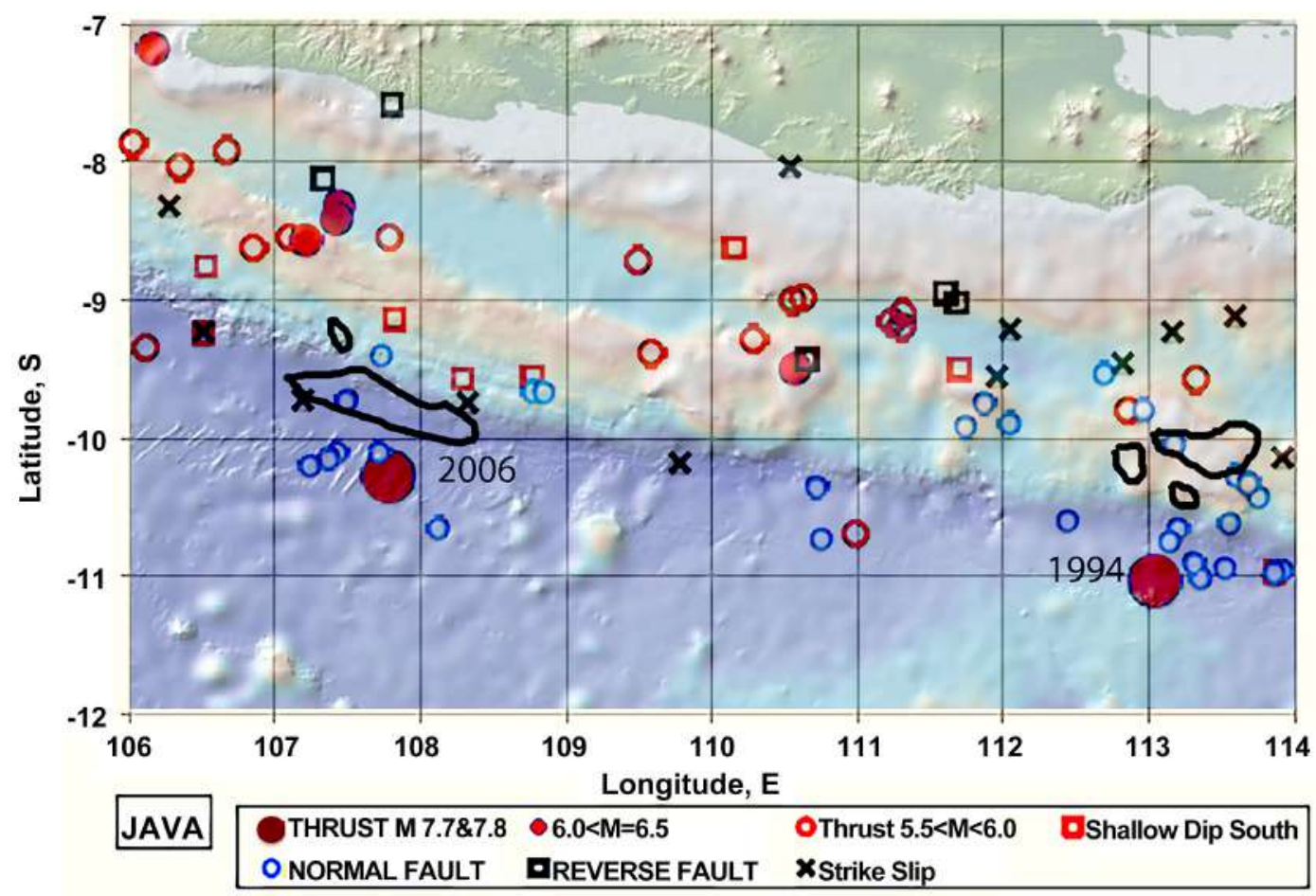

Figure 13. Locations of earthquakes near Java, Indonesia of Mw > 5.5 from 1976 through February 2019. Colors denote sizes and mechanisms of earthquakes. Heavy black lines enclose regions of computed slip greater than $1 \mathrm{~m}$ in mainshocks of 1994 after [50] [51] [52].

The thrust events of 1994 and 2006 of Mw 7.8 and 7.7 occurred very close to the Java trench. Their computed slip was small. Each was followed by aftershocks involving normal faulting, not thrust events. Their zones of maximum (one meter) slip were not sites of forerunning thrust earthquakes from 1977 through early 2019 but few other places in Figure 13 were.

Abercrombie et al. [50] report that the 1994 earthquake occurred near a seamount that is currently in the initial stage of being subducted. They interpret the 1994 event as occurring at a locked asperity in an otherwise largely decoupled subduction zone. They show that aftershocks surround the seamount, an indication that it was, in fact, a major asperity. The 2006 mainshock appears to be very similar to that of 1994. Each generated a large tsunami. A seamount along an otherwise decoupled plate boundary is well coupled [53].

In summary, nearly the entire plate boundary south of Java is poorly coupled. Forerunning thrust events prior to the 1994 and 2006 were nearly non-existent. Hence, asperities of future large events like them are unlikely to be identified ahead of time by long-term forerunning activity of moderate magnitude. Work is needed to identify them ahead of time using other techniques since their occurrence can generate damaging tsunamis.

\subsection{Other Great Earthquakes-Central and South America}

\subsubsection{Costa Rican Earthquake of 2012}

The Costa Rican mainshock of Mw 7.6 was smaller than the other events stu- 
died. Nevertheless, patterns of forerunning earthquakes and high slip [54] [55] are like those for the Iquique, Chilean shock in Figure 4. Most forerunning activity in Figure 14 occurred outside and updip of the slip zones of 0.5 and $2 \mathrm{~m}$ but not as far as the deepest part of the trench. Other forerunners took place along strike to the northwest and southeast. Larger aftershocks in 2014 (not shown) also occurred mainly updip of those high slip zones [55] [56].

The Costa Rican thrust earthquake of 2012 is nearly unique in that major slip (Figure 14) occurred beneath land, i.e., the Nicoya Peninsula, a thick ophiolitic accumulation of oceanic crust that was previously emplaced along that coast of Costa Rica. The Peninsula is only $60 \mathrm{~km}$ from the deepest part of the Central American trench. Thus, the two regions of high slip in Figure 14 were well-determined using GPS data from stations on land. Since large slip in 2012 did not extend as far as the trench, it is understandable that a significant tsunami was not generated [56]. The plate boundary beneath the central part of the Nicoya Peninsula was largely locked, i.e., tightly coupled as determined from GPS data, which commenced in 2000 [55] [56].

The 2012 zone ruptured previously in large earthquakes in 1950 (Mw 7.75, 1992 [11]) and 1853 [56]. The 2012 rupture zone had been identified as a major seismic gap for many years.

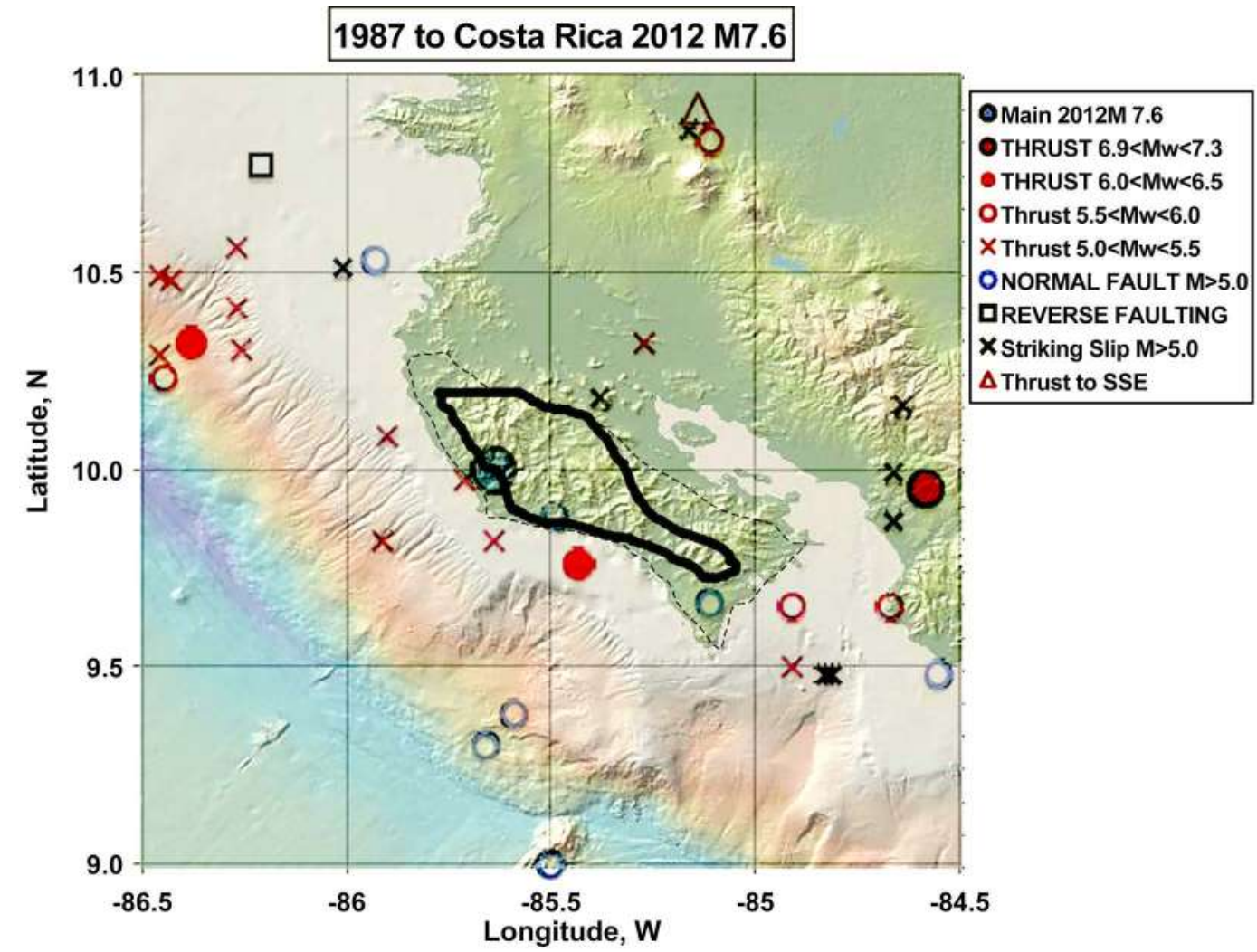

Figure 14. Moment tensor locations of earthquakes of $\mathrm{Mw} \geq 5.0$ from 1987 through Costa Rican mainshock of 2012 of Mw 7.6 (large blue circle). Colors depict sizes and mechanisms of forerunning activity prior to mainshock. Heavy solid and dashed lines enclose regions of slip greater than 2 and $0.5 \mathrm{~m}$ in mainshock from [55]. 
Seismic tremor and low-frequency earthquakes were observed at depths below the $\mathrm{M}$ discontinuity of the upper plate and most tremor occurred in adjacent areas of the megathrust that experienced little seismic slip in the 2012 mainshock [54].

In summary, forerunning thrust earthquakes nearly surround the rupture zone of the 2012 mainshock. The interior quiet zone is identified as a great asperity that broke in 2012. The zone was identified ahead of time as a major seismic gap.

\subsubsection{Pedenales, Ecuadorian Earthquake of 2016, Mw 7.8}

Forerunning activity of $\mathrm{Mw} \geq 5.0$ to the 2016 Ecuadorian mainshock occurred outside the zones of computed slip of 1 and $3 \mathrm{~m}$ (Figure 15). The main centroid was situated inside one of the two zones of $3 \mathrm{~m}$ slip, like the patterns for many mainshocks in this paper. Most forerunning events occurred on the northeastern and southwestern sides of the regions of maximum slip and mainly in two bands extending from the coast outward to the trench.

That zone is identified as a great asperity.

The 2016 rupture zone broke previously in the Ecuador-Colombia earthquake of 1906 of about Mw 8.5. The 1906 zone subsequently ruptured from south to north in the sequence 1942, 1958 and 1979 (Mw 7.7, 7.3 and 8.2 [11]). The 1958

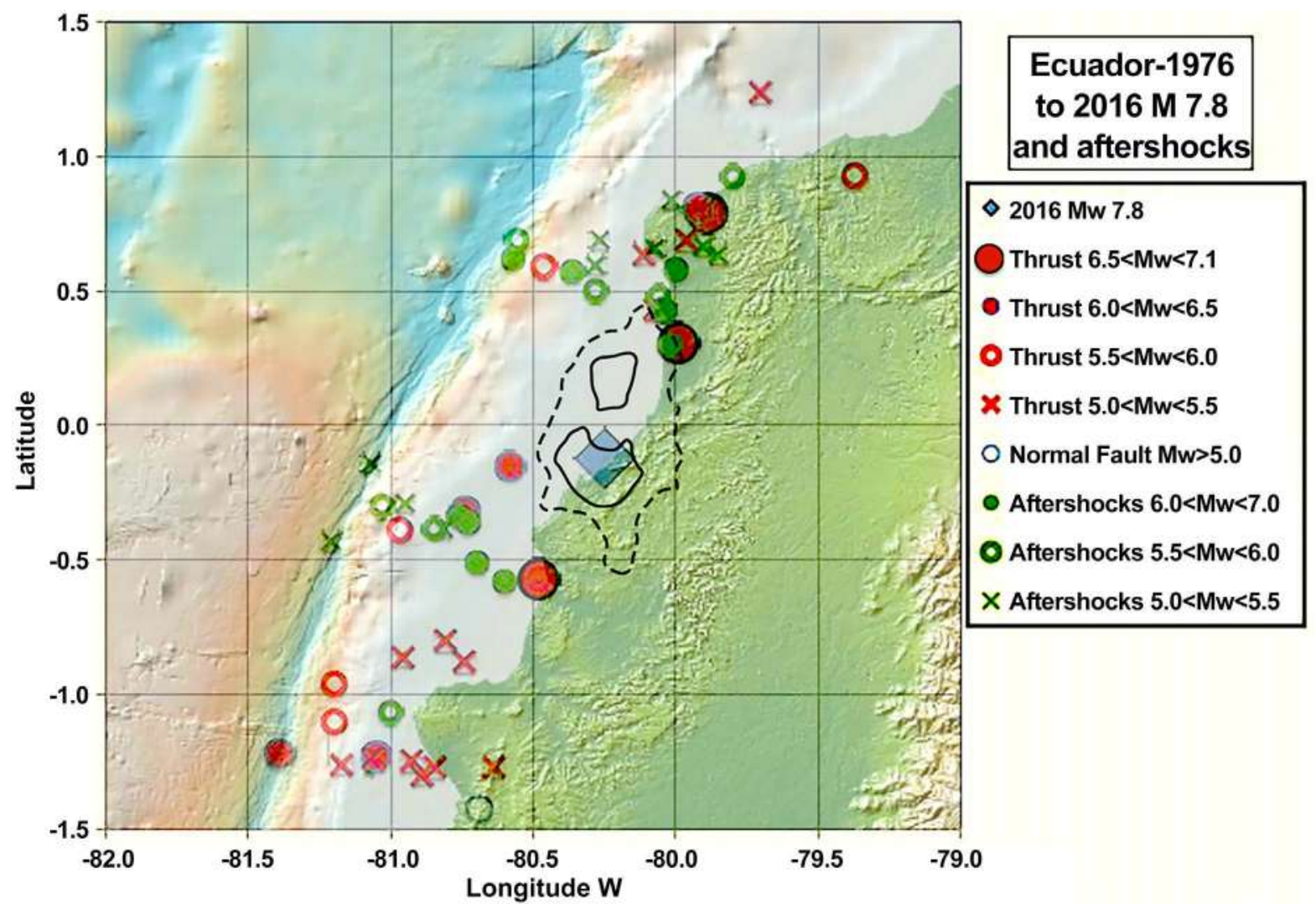

Figure 15. Locations of earthquakes of $\mathrm{Mw} \geq 5.0$ from 1976 through Ecuadorian mainshock of 2016 of Mw 7.8 (large blue diamond). Colors denote sizes and mechanisms of forerunning activity prior to mainshock; aftershocks indicated in green. Heavy solid and dashed lines indicate computed regions of slip larger than 3 and $1 \mathrm{~m}$ in mainshock from [57]. 
and 1979 shocks were located along strike to the northeast of the 2016 rupture area. The 1942 epicenter fell within the 2016 zone of high slip in Figure 15.

Mothes et al. [58] conclude that the 2016 shock broke two main asperities on either side of the 1942 rupture area. I do not think the 1942 earthquake is well enough located to claim it ruptured a separate, relatively small asperity. Its $\mathrm{Mw}$ is like that of 2016, indicating its rupture zone and that of 2016 probably were of similar size. The region to the northeast last broke in 1979. It is a likely place for a future great shock. The 2016 rupture zone was a seismic gap for many decades.

The 1958 and 1979 zones were well coupled out to the deepest part of the trench but the 1942 and 2016 segments were well coupled only about halfway to the trench [58]. The segments of the plate boundary south of the 2016 rupture, where the Carnegie Ridge is being subducted, are poorly coupled except between about $1.2^{\circ}$ and $1.4^{\circ} \mathrm{S}$ where significant relief occurs on the plate interface [59]. The latter region had significant seismic activity prior to the 2016 earthquake, as did the zone just to its north.

In summary, the 2016 Ecuadorian earthquake ruptured a quiet zone that was surrounded by forerunning and aftershock activity. That region is regarded to be a great asperity.

\subsubsection{Central Peru, 2007}

Most forerunning activity to the Mw 8.0 earthquake of 2007 offshore of Pisco in central Peru was situated either on the periphery of the slip contour of $2 \mathrm{~m}$ or to its southeast. Aftershocks also occurred either to its southeast or within its northwestern part. A zone about $75 \mathrm{~km}$ along strike was the site of no thrust forerunning or aftershock activity (Figure 16).

In summary, most of the thrust foreshocks were located outside the zone of slip larger than $2 \mathrm{~m}$. A zone about $75 \mathrm{~km}$ along strike can be regarded as a great asperity that broke in the mainshock.

\subsubsection{Peru 1996, Mw 7.7}

This was one of the smallest events studied, Mw 7.7. Forerunning and aftershock activity in Figure 17 were located entirely outside, but adjacent to, the computed $1 \mathrm{~m}$ slip contour. Most of that activity occurred updip and closer to the trench than the centroid of the mainshock. The main event generated a large tsunami.

In summary, the few forerunning events and aftershocks surround a quiet zone that can be identified as a large asperity.

\subsubsection{Earthquake off Arequipa, Peru of 2001, Mw 8.4}

The Peruvian shock of 2001 was one of the largest earthquakes studied. It broke a significant part of the seismic gap remaining from the giant shock of 1868 but well short of the rupture zone of the 2014 Iquique event to the southeast (Figure 4).

Rupture started at the short-period hypocenter (blue-green square in Figure 18) at the far northern side of the $1 \mathrm{~m}$ slip contour and progressed southeasterly where slip greater than $4 \mathrm{~m}$ took place in a second sub-event (Bulletin International Seismological Centre). Two forerunning shocks occurred within the north- 
ern $1 \mathrm{~m}$ sub-region zone and another on its northwestern-most side (Figure 18). Other forerunners were scattered throughout the rest of the rupture zone as well as in the area just to the southeast of the $1 \mathrm{~m}$ contour.

In summary, the patterns of forerunning activity to the Arequipa mainshock are like those of the great Kuril earthquake of 2006 described earlier (Figure 12) in that rupture started first in a sub-region with few forerunning events and progressed along strike where a second sub-event was part of the mainshock. The 2001 mainshock likely ruptured two great asperities. The 2001 region had been a significant seismic gap since it last ruptured in a giant shock in 1868 . The remainder of the 1868 zone to the southeast remains a seismic gap.

\subsubsection{Antofagasta Chile 1995. Mw 8.0}

Most forerunning and aftershock activity associated with the Antofagasta earthquake of 1995 was located either on the periphery or outside the $1 \mathrm{~m}$ slip contour in Figure 19. The centroid of the mainshock is located just inside the $4 \mathrm{~m}$ slip contour. A shock of Mw 7.5 occurred eight years earlier on the periphery inside the $1 \mathrm{~m}$ contour. Chlieh et al. [61] conclude that slip occurred "fairly uniformly" during the mainshock and that all slip inversions give a consistent picture of the distribution of displacements during the earthquake with a single asperity slipping 5 to $10 \mathrm{~m}$.

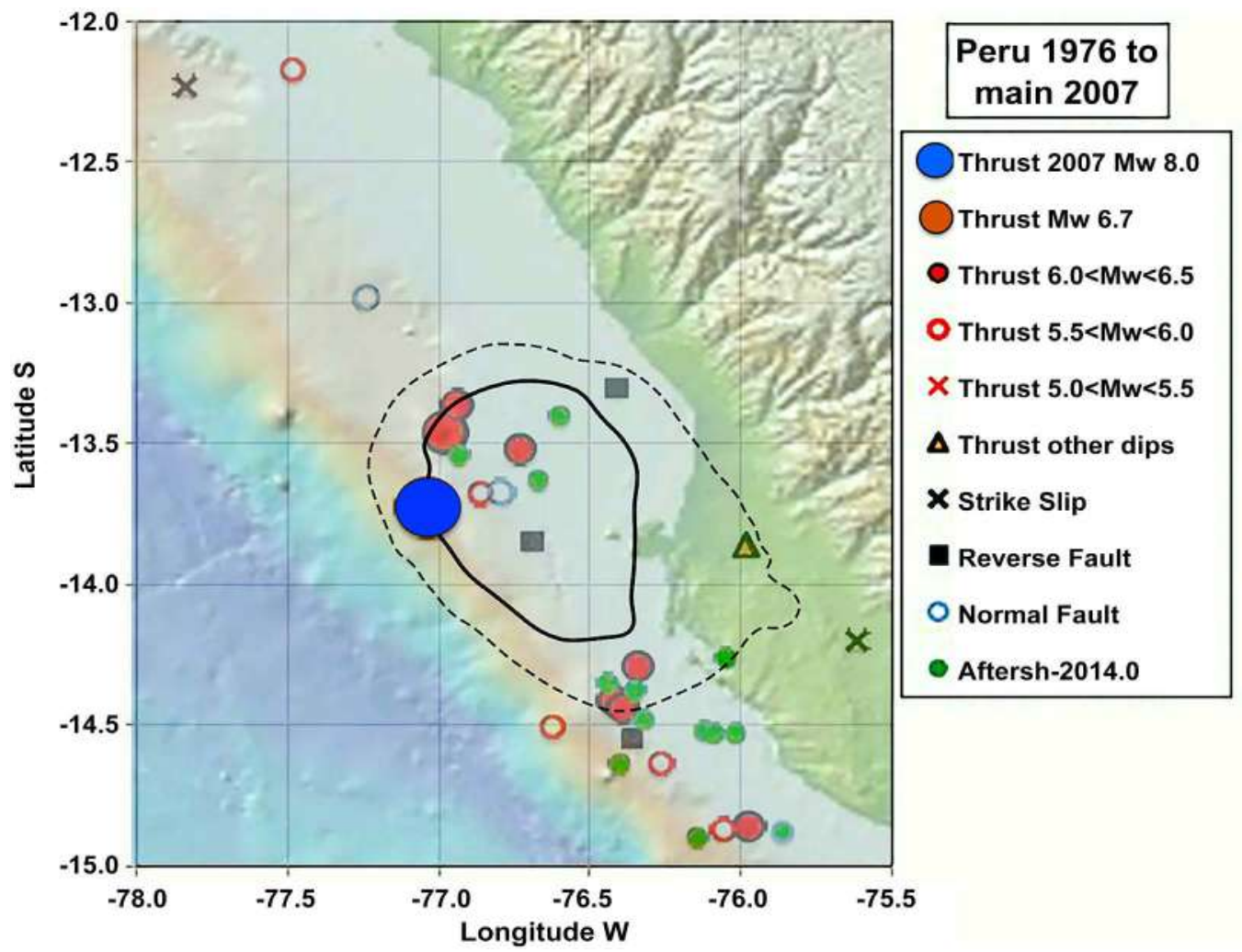

Figure 16. Locations of earthquakes of $\mathrm{Mw} \geq 5.0$ from 1976 through Pisco, Peru mainshock of 2007 of Mw 8.0 (large blue circle). Colors denote sizes and mechanisms of forerunning activity prior to mainshock; aftershocks through 2013, in green. Heavy solid and dashed lines indicate regions of slip larger than 2 and $1 \mathrm{~m}$ in mainshock [60]. 


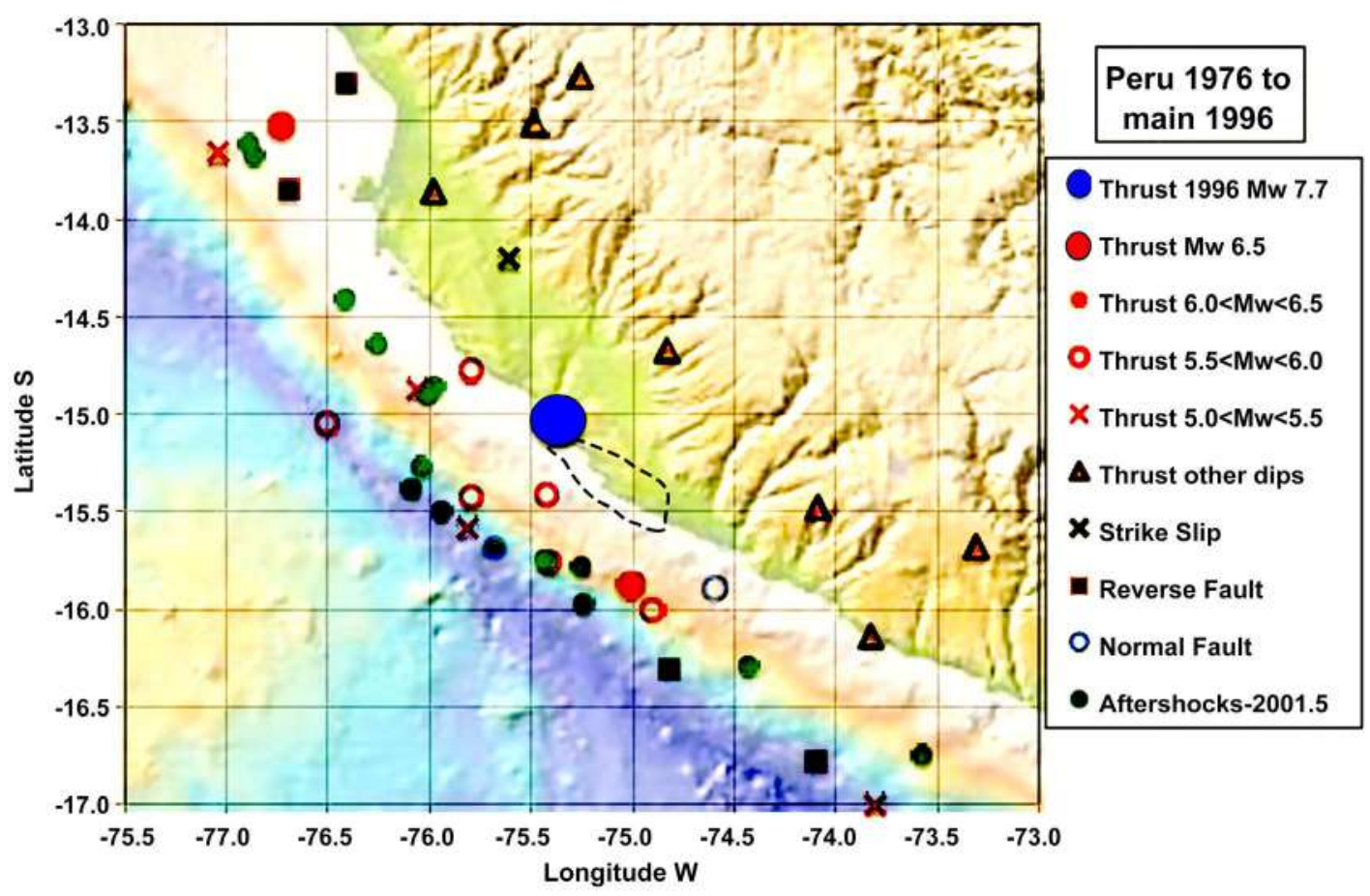

Figure 17. Locations of earthquakes of $\mathrm{Mw} \geq 5.0$ from 1976 through Peruvian mainshock of 1996 of Mw 7.7 (large blue circle). Colors denote sizes and mechanisms of forerunning activity prior to mainshock; aftershocks through June 2001 shown in green. Dashed line indicates regions of slip larger than $1 \mathrm{~m}$ in mainshock from $[60]$.

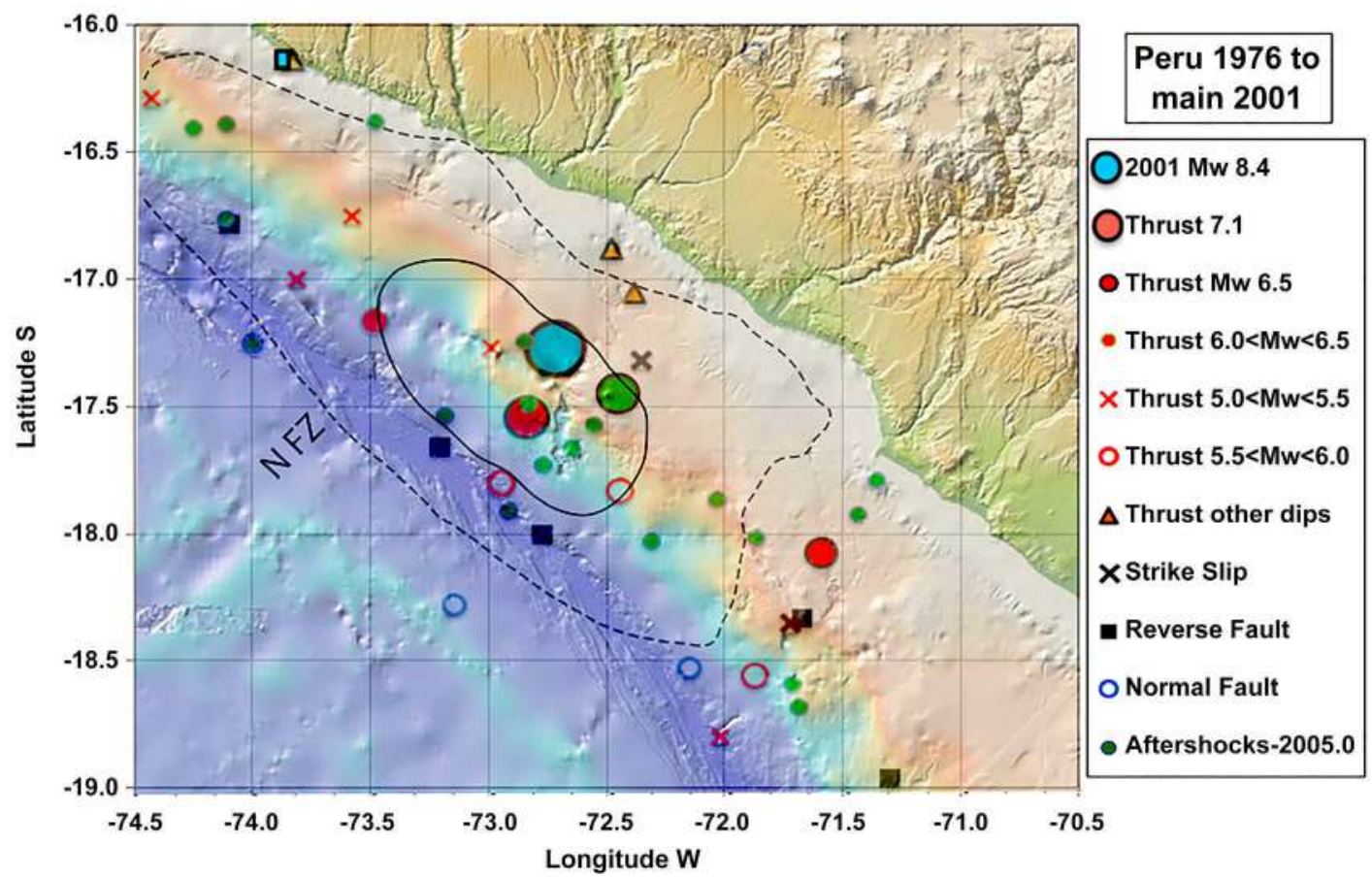

Figure 18. Locations of earthquakes of $\mathrm{Mw} \geq 5.0$ from 1976 through Arequipa, Peru mainshock of 2001 of Mw 8.4 (large blue circle). Solid blue square at top denotes short-period epicenter, the point of initial rupture. Colors indicate sizes and mechanisms of forerunning activity prior to mainshock. Aftershocks through December 2004 are colored green. Heavy solid and dashed lines indicate regions of slip larger than 4 and $1 \mathrm{~m}$ in mainshock from [60]. NFZ denotes Nasca fracture zone. 


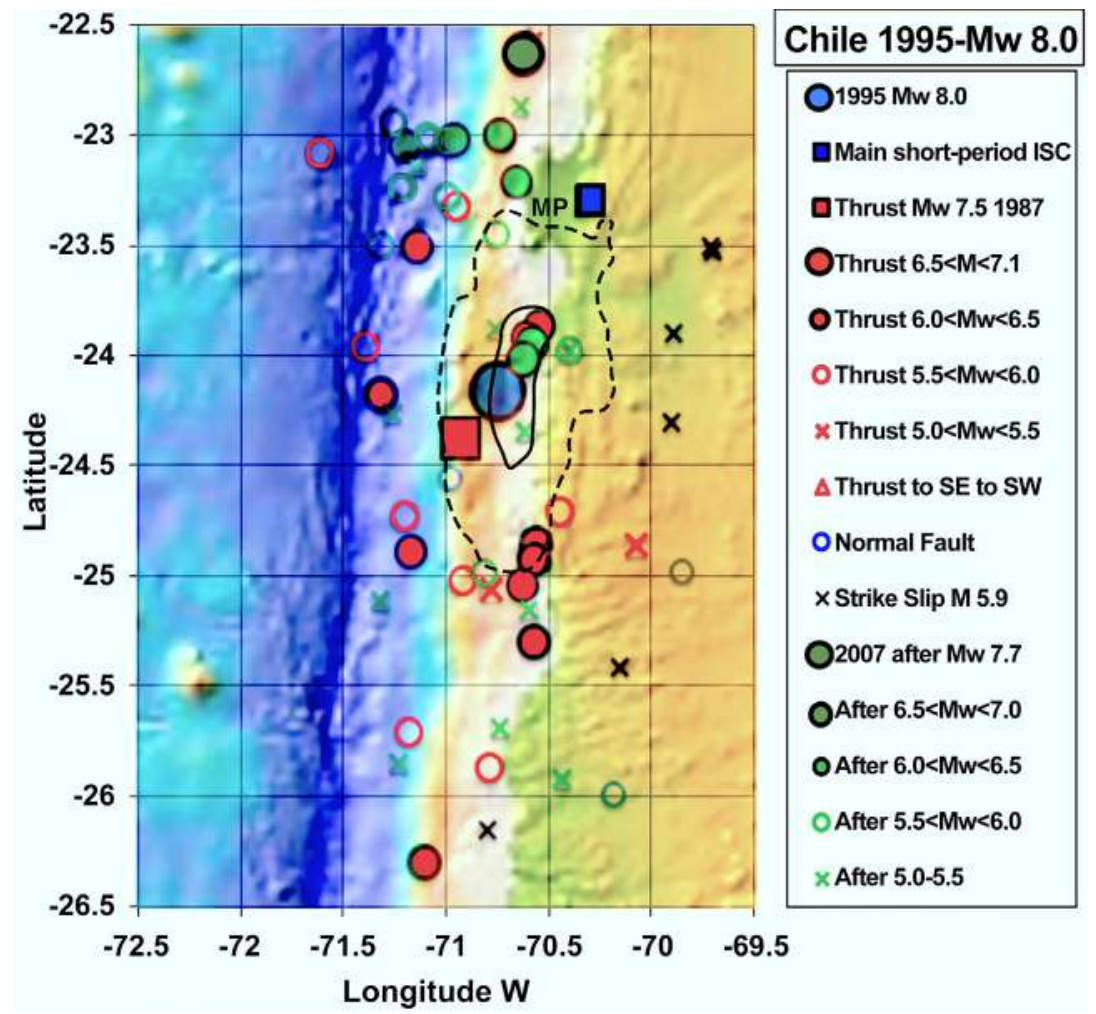

Figure 19. Locations of earthquakes of $\mathrm{Mw} \geq 5.0$ from 1976 through Antofagasto, Chilean mainshock of 1995 of Mw 8.0 (large blue circle). Solid blue square is short-period epicenter from the Bulletin of the International Seismological Centre. Colors denote sizes and mechanisms of forerunning activity prior to the mainshock. Aftershocks are indicated in green. Heavy solid and dashed lines indicate regions of computed slip larger than 4 and $1 \mathrm{~m}$ in mainshock from [62]. MP is Mejillones Peninsula.

Rupture started at the short-period location just to its north at the blue square near the Mejillones Peninsula (MP). The area offshore of the peninsula, between $23^{\circ}$ and $23.5^{\circ} \mathrm{S}$ in Figure 19, was identified [33] as a low-coupling zone (LCZ) much like that at the southern end of the Maule rupture zone (Figure 6). While the Mejillones LCZ was the site of little co-seismic slip in the mainshock, long-term aseismic slip within it is not known [33]. No known large earthquakes, however, have ruptured directly beneath the Peninsula [33].

In summary, forerunning activity to the 1995 mainshock as well as aftershocks occurred on the periphery of the $1 \mathrm{~m}$ slip contour. Two forerunners also took place within the central $4 \mathrm{~m}$ slip contour.

\subsubsection{Northern Chile 2007, Mw 7.7}

The 2007 mainshock, was one of the smallest examined. Forerunning thrust activity in Figure 20 was concentrated to the south of the centroid of the mainshock and southwest of the two zones where slip was calculated as one meter or greater. That activity was concentrated offshore beneath the Mejillones LCZ, which was described in the previous section. The small cumulative seismic moment of forerunning thrust events (not shown) exhibits upward curvature but is dominated by a single larger earthquake. 


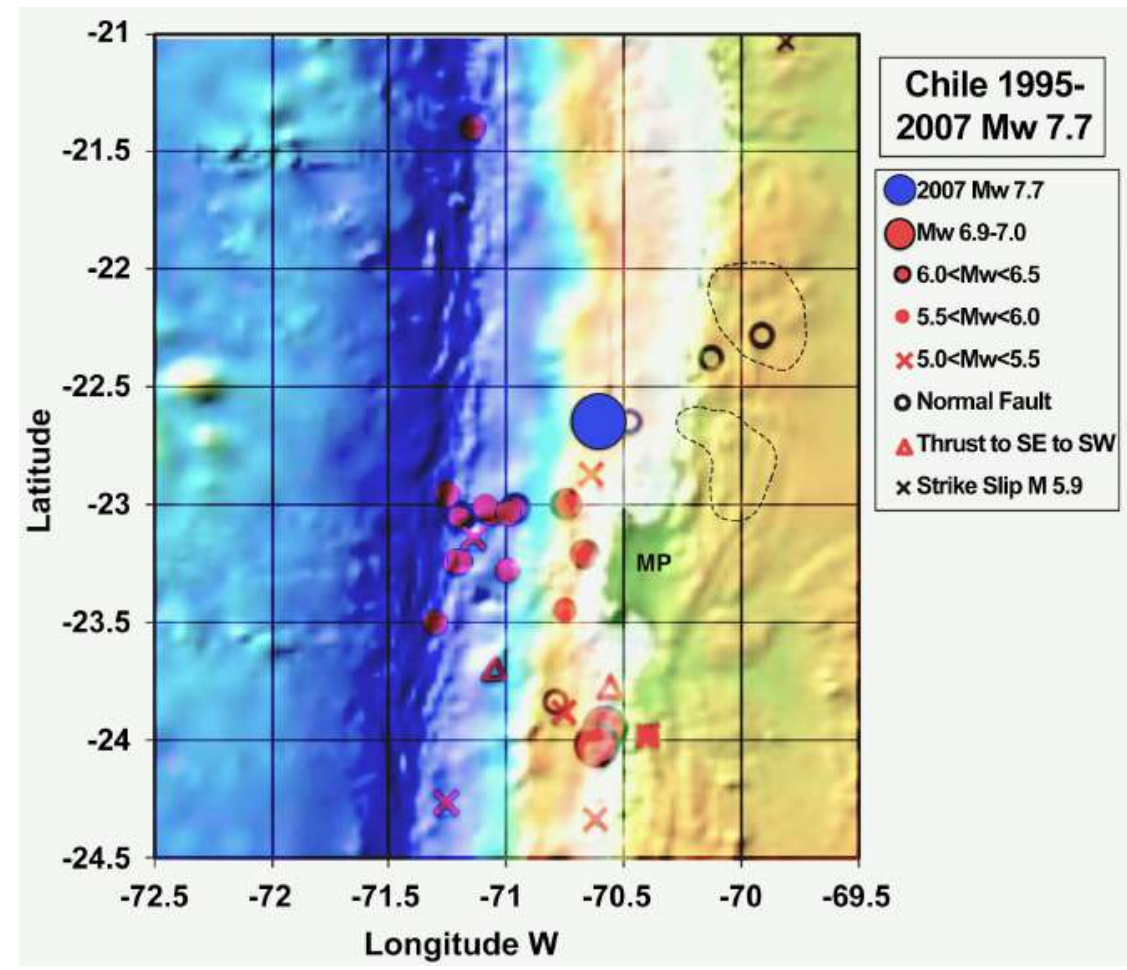

Figure 20. Locations of earthquakes of $\mathrm{Mw} \geq 5.0$ from 1976 through northern Chilean mainshock of 2007 of Mw 7.7 (large blue circle). Colors denote sizes and mechanisms of forerunning activity prior to mainshock. Heavy solid and dashed lines indicate two regions of slip larger than $1 \mathrm{~m}$ in mainshock from [63]. MP denotes Mejillones Peninsula.

In summary, forerunning activity was concentrated south of the regions of high slip beneath the Mejillones low-coupling zone. The rupture zone was quiet ahead of time and may be defined as a major asperity. The GCMT location farther west than the high slip contours indicates that slip likely extended farther west closer to the deepest part of the trench.

\subsubsection{Illapel Chilean Earthquake of 2015, Mw 8.3}

Many forerunning shocks of $M \geq 5.0$ from 1976 until the 2015 mainshock were located inside the 2 and $5 \mathrm{~m}$ slip contours of Figure 21. Slip was modeled using a combination of seismic and offshore tide gauge data to better constrain displacements near the trench [64]. Those authors concluded that slip between the 2 and $5 \mathrm{~m}$ maximum in Figure 21 extended out to nearly the outcrop of the plate boundary at the trench. The region inside the $5 \mathrm{~m}$ contour between the centroid and about $50 \mathrm{~km}$ to the north was the site of only one forerunning shock and no aftershocks. It might be picked from forerunning activity as the great asperity that broke in the mainshock.

The 2015 region previously broke in 1943, both in events of Mw 8.2 [11]. The Illapel rupture zone and the Atacama seismic gap to the north are separated by the Challenger fracture zone (not shown), which is being subducted at the trench. The two ends of the 2015 rupture were identified as low-coupling zones [33]. 


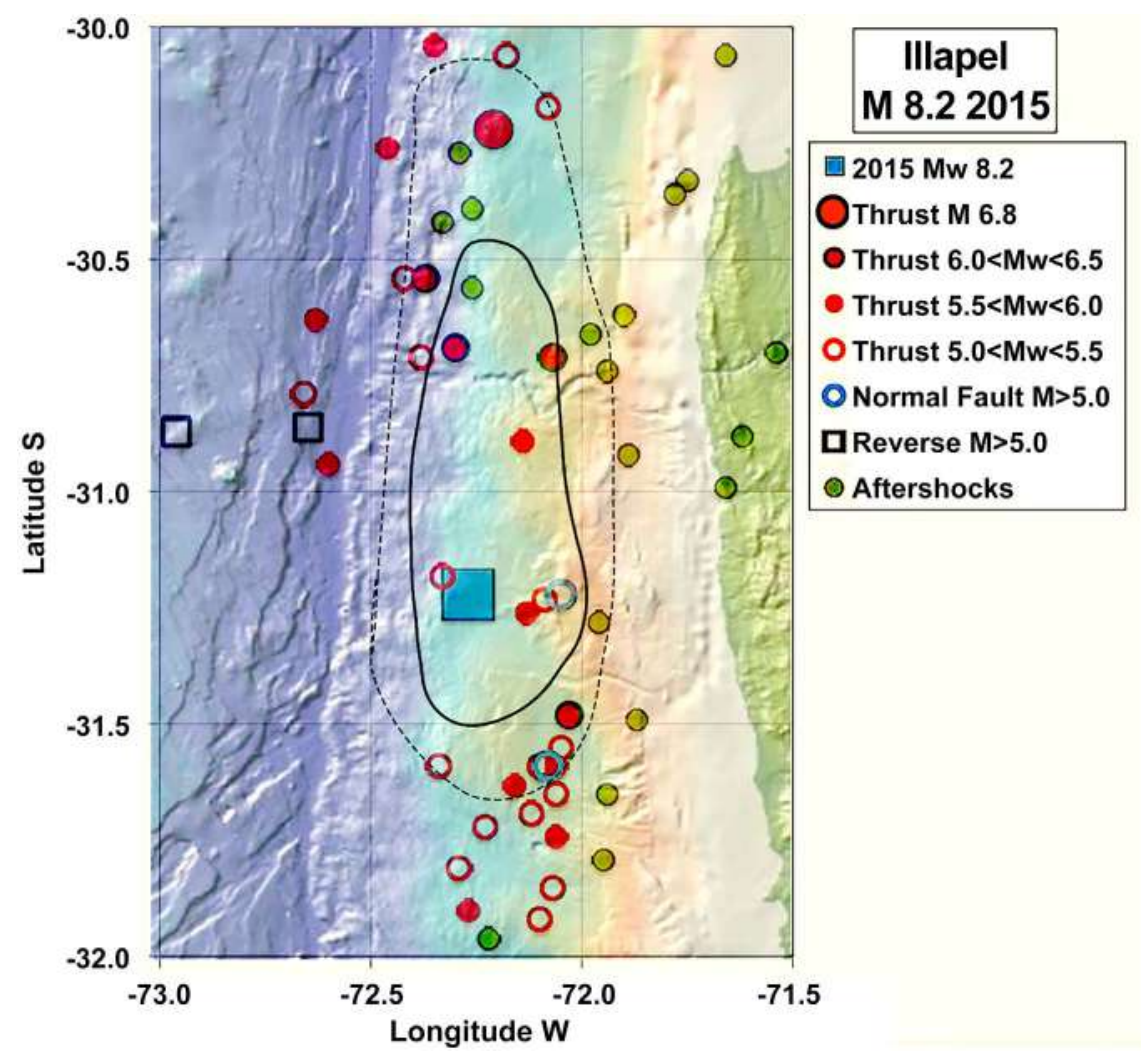

Figure 21. Locations of earthquakes of $\mathrm{Mw} \geq 5.0$ from 1976 through the great Illapel, Chilean mainshock of 2015 of Mw 8.2 (large blue square). Red symbols denote forerunning thrust activity prior to the mainshock; green circles indicate aftershocks of $\mathrm{Mw} \geq 5.5$. Heavy solid and dashed lines show regions of slip greater than 5 and $2 \mathrm{~m}$ in 2015 as computed by [64].

The region to the north of the Illapel shock last ruptured in the giant Atacama earthquake of about Mw 8.7 in 1922. Very little activity of even moderate size has occurred in that seismic gap to the north of $30.5^{\circ} \mathrm{S}$ from the start of the GCMT catalog in 1976 through 2019.

In summary, the distribution of forerunning activity to the 2015 earthquake is not clear with respect to the two regions of high computed slip. It is possible to pick a large region just to the north of the centroid of the mainshock that contained only a single forerunning shock within the $5 \mathrm{~m}$ contour as a great asperity. No aftershocks occurred in that region.

\subsubsection{Giant Chilean Earthquake of 1960}

The Mw 9.6 shock in south-central Chile was the largest earthquake between the start of instrumental seismology in the 1890s and August 2020. I use a combination of different types of locations to examine it: centroids since 1976 and short-period epicenters from 1920 to 1976.

Epicenters of forerunning activity of $\mathrm{mb} \geq 6.0$ from 1920 to the 1960 mainshock were all located outside of the three computed high-slip zones where displacements exceeded $20 \mathrm{~m}$ (Figure 22). The epicenter of the mainshock, which is not a centroid but a short-period location, marks the initial start of rupture. 
Rupture in the mainshock propagated to the south for nearly $900 \mathrm{~km}$ to the plate triple junction where the South Chile rise intersects of Chilean subduction zone. The 1960 sequence was initiated the day before the mainshock by an event of about Mw 8.1 [34] within the Araco low-coupling zone (LCZ). The Araco LCZ was the site of abundant forerunning activity as well as subsequent shocks between 1960 and 2020 (Figure 23 and Figure 24). Figure 24 shows abundant forerunners to the Maule shock of 2010 in the Araco LCZ between $37^{\circ}$ and $38.4^{\circ} \mathrm{S}$.

The 1960 event triggered many normal-faulting earthquakes (Figure 23 and Figure 24) just to the west of the plate boundary. Very little thrust activity occurred between 1999 and 2020. The earthquake of Mw 7.6 in 2016 broke outside the $196020 \mathrm{~m}$ slip contours but within the $5 \mathrm{~m}$ contour (Figure 23). While large, it was much smaller than the giant 1960 shock.

A considerably smaller moment release from displacements along the coast in the 1960 mainshock was calculated by Barrientos and Ward [65] than by Cifuentes and Silver [66] using teleseismic long-period data. The former speculated that greater slip occurred closer to the trench and accounted for the difference. The large number of normal-faulting events west of the plate boundary in Figure 23 and Figure 24 is in accord with that hypothesis. The 1960 event generated a huge tsunami.

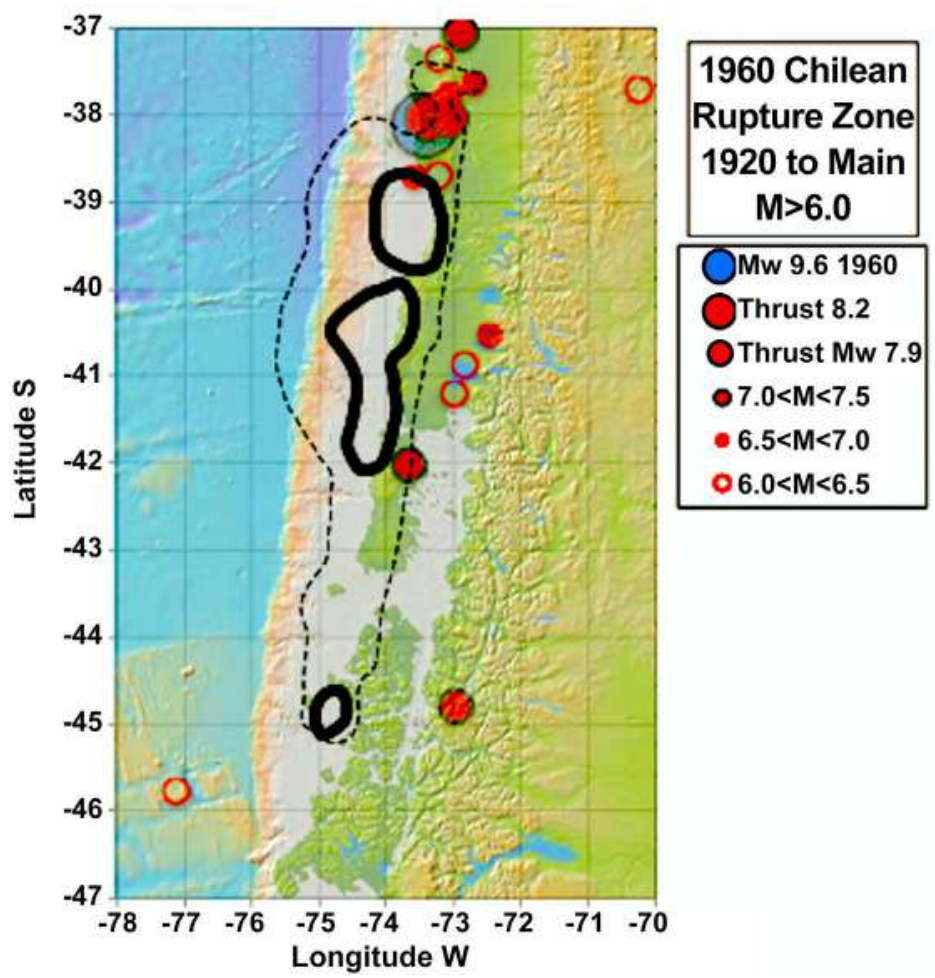

Figure 22. Locations from short-period body waves of earthquakes of Ms $\geq 6.0$ from 1920 through the giant Chilean mainshock of 1960. Red symbols denote thrust activity prior to mainshock. Heavy solid and dashed lines indicate regions of slip greater than 20 and $5 \mathrm{~m}$ in 1960 as computed by [65]. 


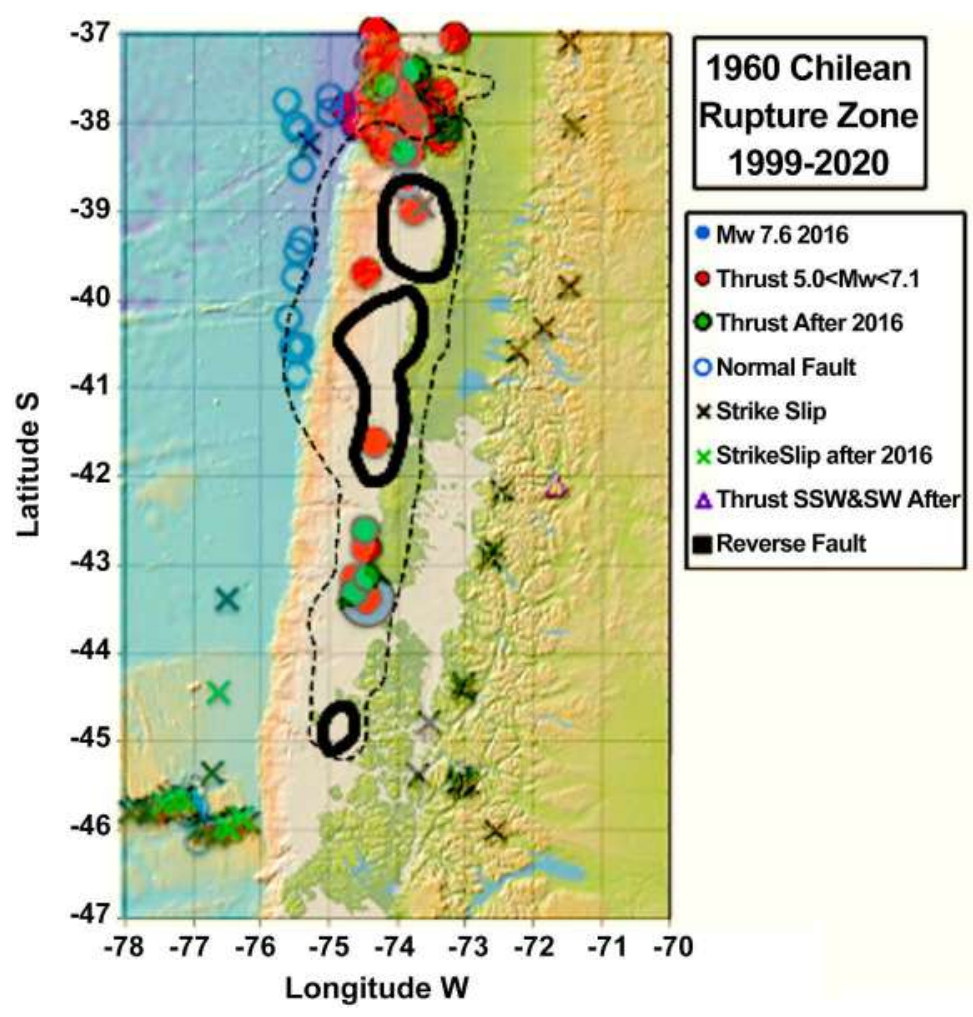

Figure 23. Centroid locations of earthquakes of $\mathrm{Mw} \geq 5.0$ from 1999 to mid-2020. Red symbols denote thrust activity. Heavy solid and dashed lines indicate regions of high slip in 1960 as in Figure 22.

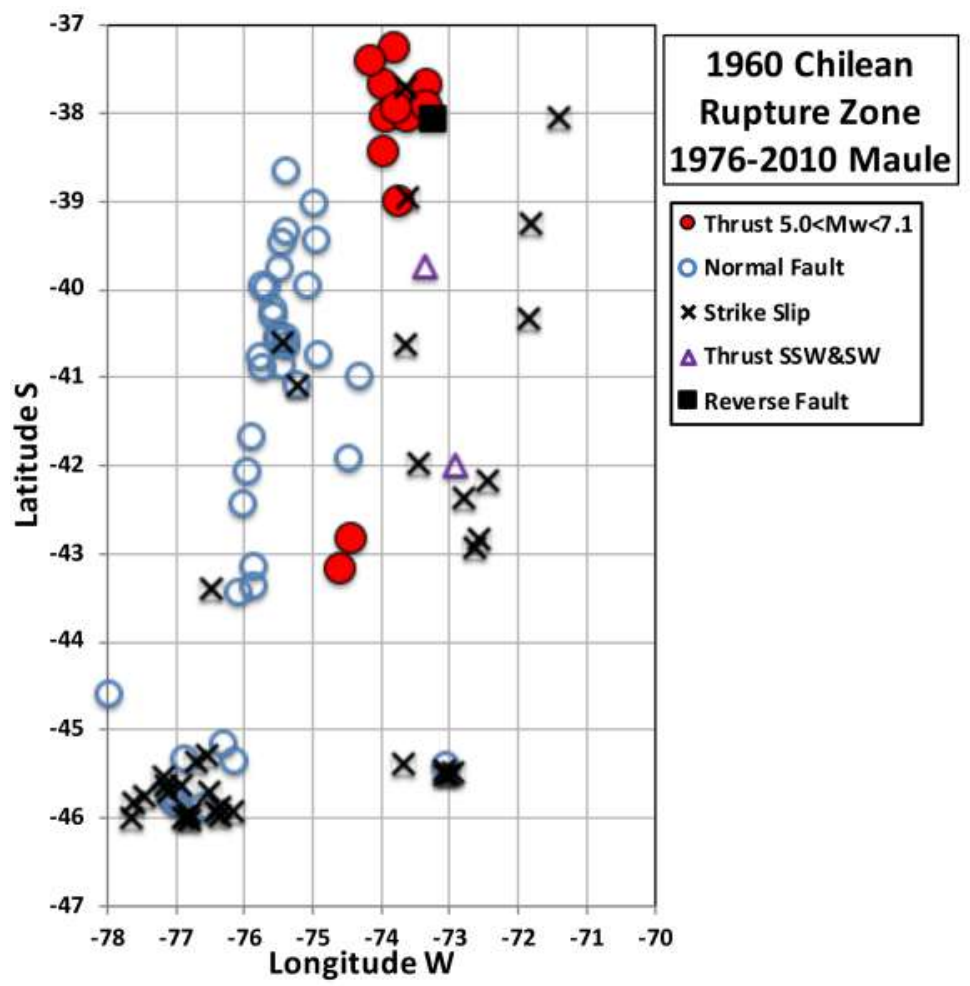

Figure 24. Centroid locations of earthquakes in and near the 1960 rupture zone from 1976 through the Maule mainshock of 2010. 
In summary, no forerunning thrust mechanisms of $\mathrm{Ms} \geq 6.0$ occurred from 1920 until the May 1960 mainshock within the three zones where computed slip exceeded $20 \mathrm{~m}$. Those three zones are identified as huge asperities. Forerunning activity was concentrated just to the north within the Aruco low-coupling region where several large shocks commenced the day before the giant earthquake. Forerunning shocks to the Maule earthquake of 2010 to the north also were concentrated in the Aruco LCZ. Precursory activity to future great events should be sought within the Aruco region and perhaps at the southern end of the 1960 rupture zones.

\subsection{Forerunning Activity to Indonesian Earthquakes}

\subsubsection{Giant Sumatran Earthquake of 2004}

The giant Sumatra-Nicobar-Andaman earthquake of 2004 ruptured from its southern end off the coast of Sumatra near $3^{\circ} \mathrm{N}$ to its northern end near $14^{\circ} \mathrm{N}$, one of the longest ruptures known (Figure 25 and Figure 26). Computed slip was greater than $10 \mathrm{~m}$ along several segments of the subduction zone, a common feature for giant earthquakes. I use the slip contours of [67] since they incorporated local and distant seismic and geodetic information in their computed displacements.

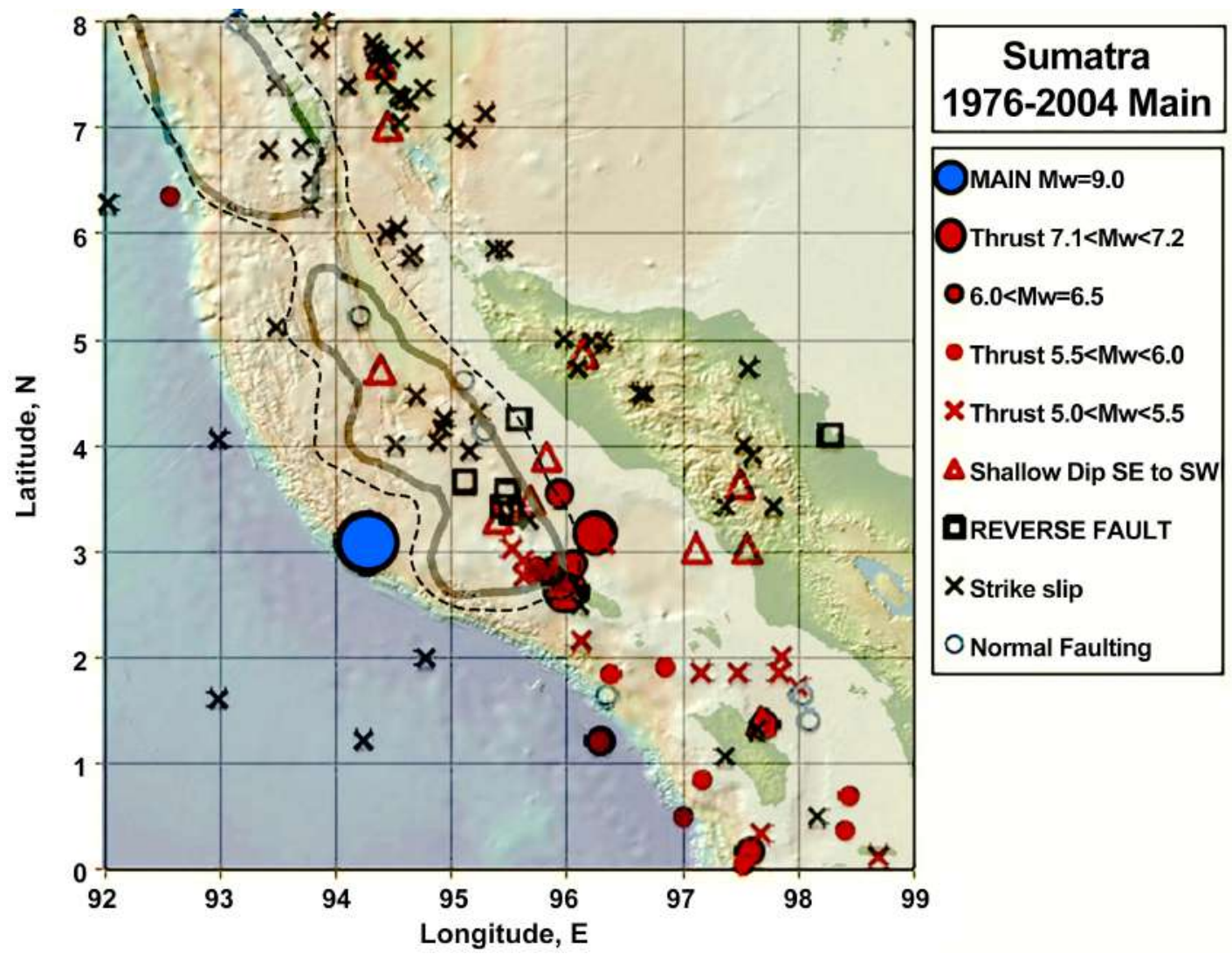

Figure 25. Locations of earthquakes of Mw > 5.0 from 1976 until the 2004 giant shock of Mw 9.0 (large blue circle) for the southern half of the rupture zone off northern Sumatra and the Nicobar Islands. Heavy and dashed lines denote computed slip of 10 and $5 \mathrm{~m}$ from [67]. 


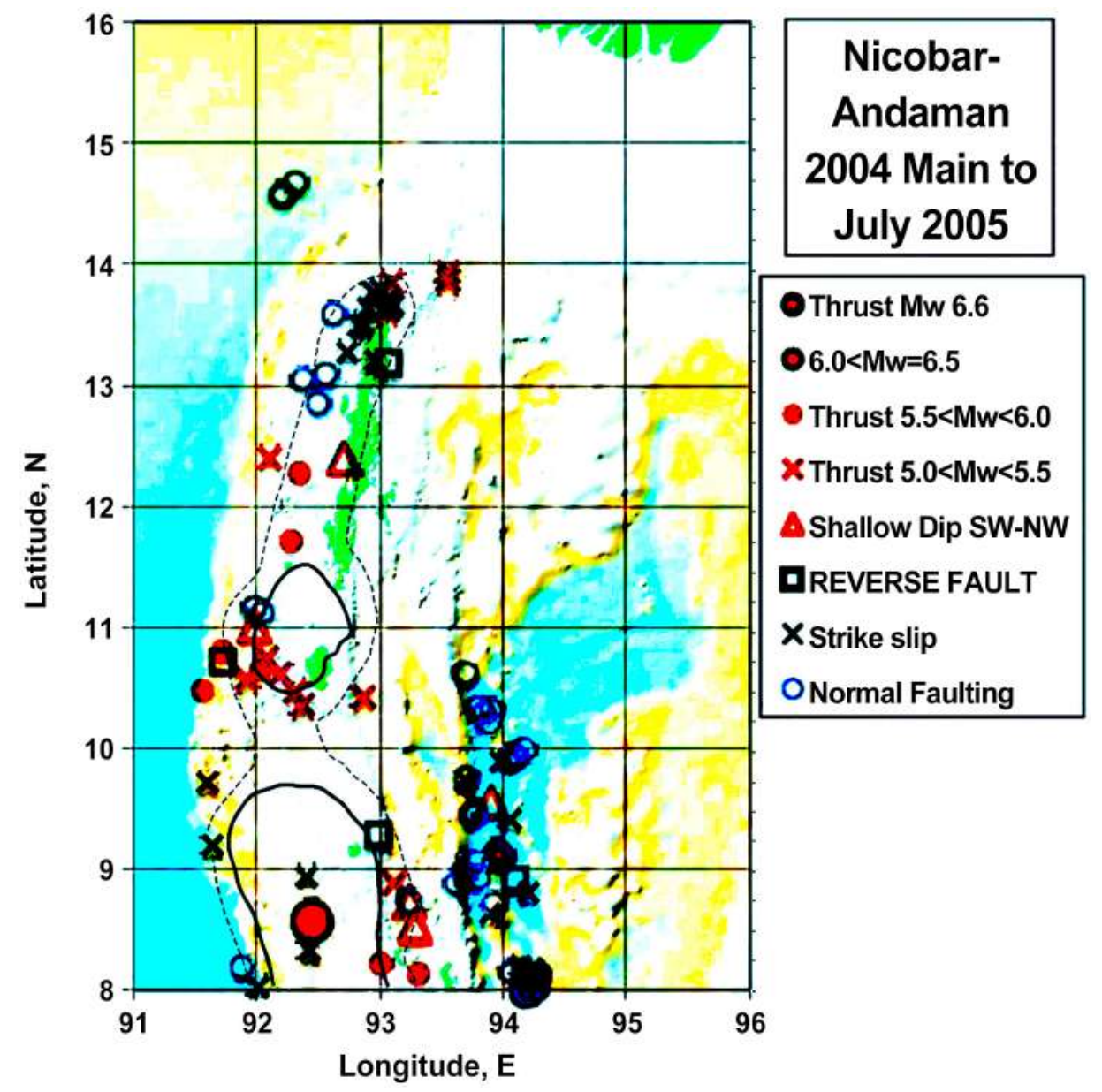

Figure 26. Locations of earthquakes of Mw > 5.0 from 1976 until 2004 giant shock of Mw 9.0 for northern half of rupture zone off the Nicobar and the Andaman Islands. Slip contours same as in previous figure.

Several forerunning earthquakes with thrust mechanisms occurred near the southern end of the rupture zone in Figure 25. Many strike-slip mechanisms occurred within the $10 \mathrm{~m}$ slip zones off Sumatra and the Nicobar Islands. A few thrust events occurred farther north (Figure 26) near the Andaman Islands. The $10 \mathrm{~m}$ slip zones off the Nicobar and Andaman Islands were the sites of only a single forerunning thrust earthquake. Several thrust mechanisms, however, can be seen in Figure 25 and Figure 26 with unusual dips to the southeast to west.

In summary, several large forerunning thrust shocks of $6.0<\mathrm{Mw}<7.2 \mathrm{oc}-$ curred near the southeastern end of the coming 2004 rupture zone. Otherwise, forerunning thrust shocks were rare. Reverse and strike-slip mechanisms and thrust solutions with unusual dips took place in and near the $10 \mathrm{~m}$ slip zone off Sumatra prior to the giant earthquake. The $10 \mathrm{~m}$ slip zones off the Nicobar and Andaman Islands were very quiet prior to the great shock. The entire 2004 rupture zone had been a seismic gap for many decades before 2004. The 2004 mainshock likely broke at least two great asperities. 


\subsubsection{Sumatran Earthquake off Nias and Simeulue Islands in 2005, Mw 8.6}

The giant Nias-Simeulue shock of 2005 occurred three months after the 2004 Sumatra-Andaman event. A number of forerunning thrust earthquakes of $\mathrm{Mw}>$ 6.9 occurred between them (Figure 27). The computed $6 \mathrm{~m}$ slip contour for the Nias-Simeulue shock, the site of its centroid of the mainshock, was nearly devoid of forerunning activity. Considerable forerunning thrust mechanisms can be seen in Figure 27 to the southeast of the $2.4 \mathrm{~m}$ slip contour. Figure 28 shows an abrupt termination of aftershocks of the 2004 giant shock about $150 \mathrm{~km}$ to the northwest of the 2005 centroid.

In summary, the region that slipped six or more meters in 2005 was nearly devoid of forerunning thrust activity. It can be regarded as a great asperity. Many thrust shocks occurred to the northwest and southeast of both the 2.4 slip zones.

\subsubsection{Northern Sumatran Earthquake of 2010, Mw 7.8}

The northern Sumatran earthquake of 2010 ruptured a 100-km length of the plate boundary between the giant shocks of 2004 and 2005 [69]. Using GPS data [69], it broke between the two northwestern regions of $2.4 \mathrm{~m}$ slip in the 2005 earthquake (Figure 27), i.e., a zone that remained unbroken in 2004 and 2005. The mainshock consisted of two large events about $12 \mathrm{~s}$ apart. Most forerunning thrust activity occurred seaward of the computed $1.75 \mathrm{~m}$ rupture contours. Its centroid and many aftershocks were located similarly (Figure 29). None took place within the $2.5 \mathrm{~m}$ contour.

In summary, all but one of the forerunning shocks to the north Sumatra earthquake of 2006 took place outside of its two zones of major displacement. Its slip contours define two major asperities that broke in 2010 .

\subsubsection{Southern Sumatran Shocks of Mw 7.9 and 8.5 in 2007}

The earthquakes of Mw 8.5 and 7.9 ruptured offshore of central Sumatra 12 hours apart in 2007 (Figure 30). They were preceded by a strike-slip shock of Mw 7.8 in 2000 (large black X, bottom right of Figure 30). Rupture started near the southeastern end and propagated to the northwest in the first and larger event. Feng et al. [71] deduce that the second shock of Mw 7.9 broke two zones: 1) within the northern end of the $5 \mathrm{~m}$ contour surrounding the $\mathrm{Mw} 8.5$ event and 2) another near $2^{\circ} \mathrm{S}$. The centroid of the Mw 7.8 earthquake being between the two is consistent with their interpretation of two separate patches of $5 \mathrm{~m}$ displacement.

The Mw 8.5 shock was nearly devoid of forerunning activity within either the $5 \mathrm{~m}$ slip contours and none within that of $15 \mathrm{~m}$. Abundant thrust forerunning activity occurred farther to the southeast along strike of the plate boundary. Two forerunning thrust and several high-angle reverse earthquakes occurred within the $5 \mathrm{~m}$ slip zone near $2^{\circ} \mathrm{S}$. The source time function consisted of two pulses [73]. The 2007 rupture zones broke previously in a giant mainshock in 1833. It had been a major seismic gap for many decades prior to 2007 . 


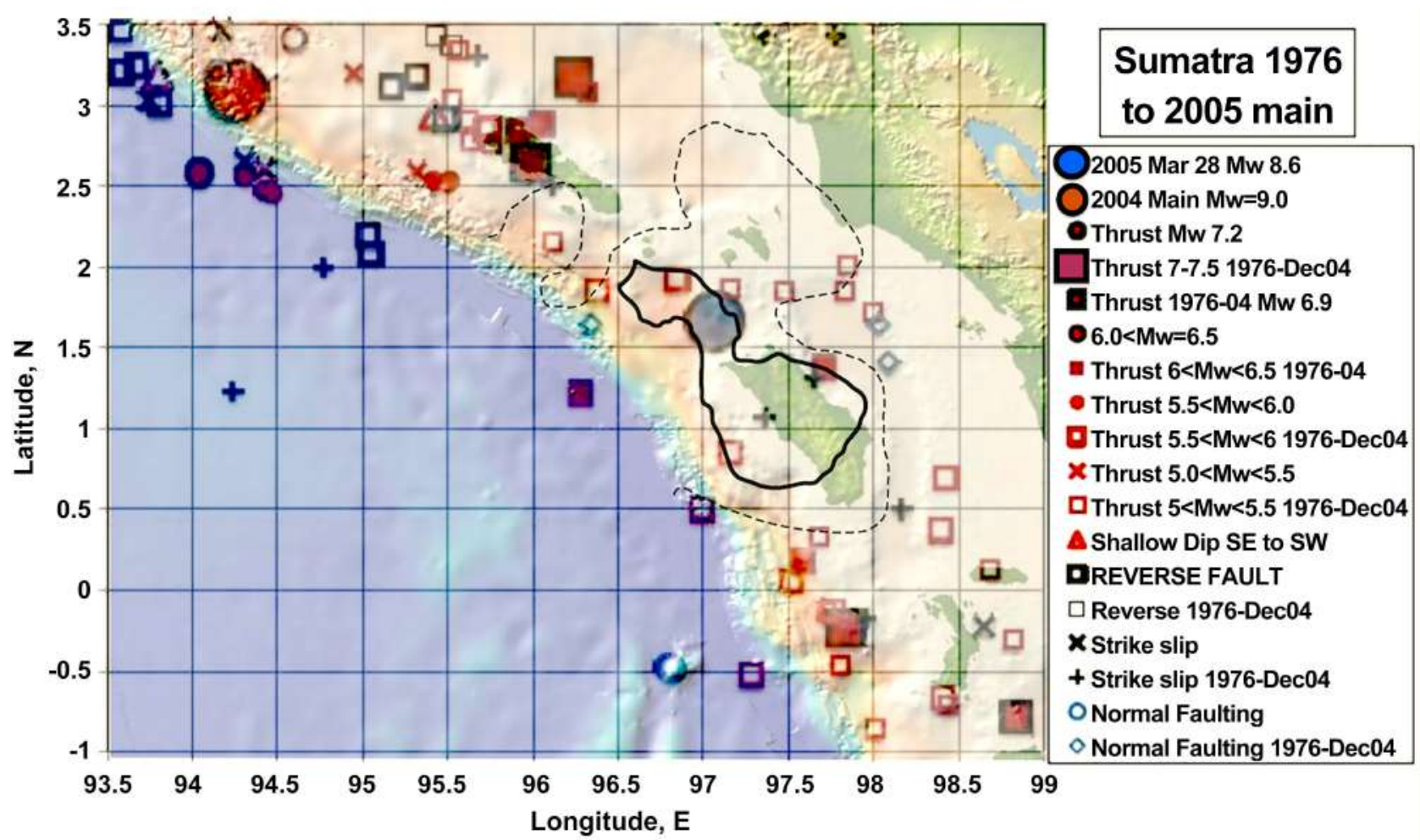

Figure 27. Locations of earthquakes of Mw > 5.0 from 1976 until Nias-Simeulue, Indonesian shock of March 2005 of Mw 8.6. Solid and dashed lines indicate computed displacements of 6 and $2.4 \mathrm{~m}$ from [68].

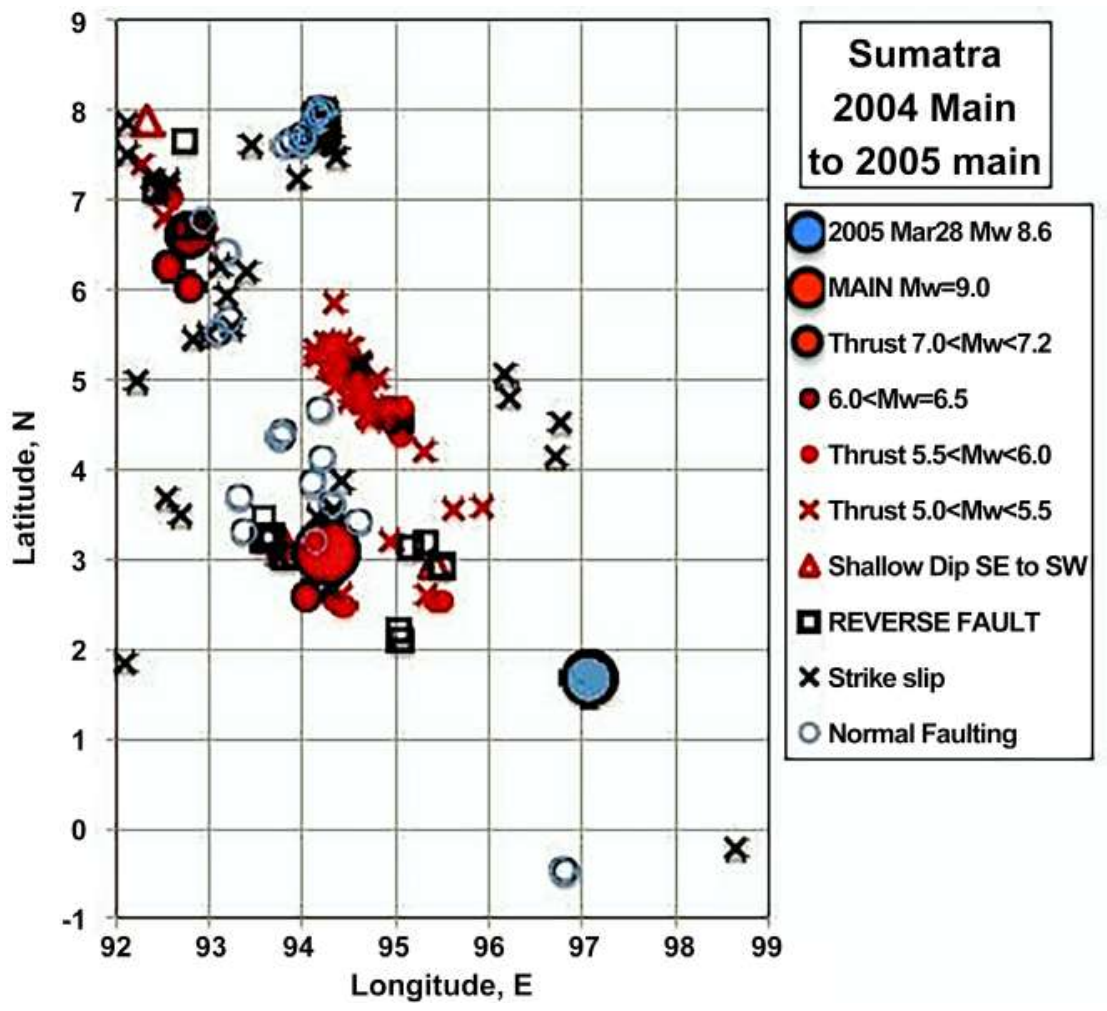

Figure 28. Locations of earthquakes of $\mathrm{Mw}>5.0$ from the 2004 giant Sumatran event (large red circle) until the Nias-Simeulue Indonesian shock of March 2005 of Mw 8.6 (large blue circle). 


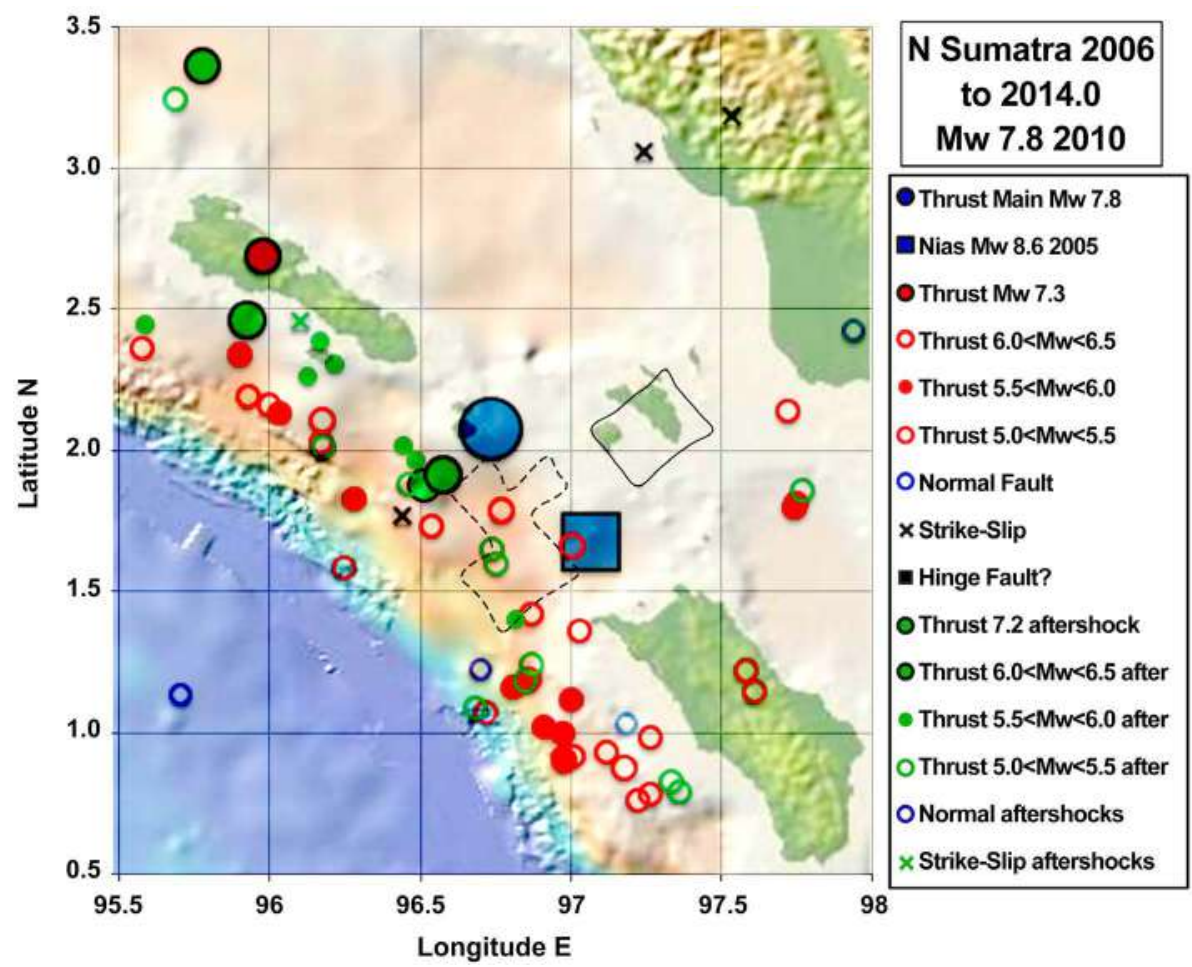

Figure 29. Locations of events of $\mathrm{Mw}>5.0$ between the Nias-Simeulue earthquake of 2005 (large blue square) and the Banyak shock of Mw 7.8 on April 6, 2010 (large blue circle). Events after the 2010 shock are shown in green through 2014. Calculated displacements larger than 2.5 and $1.75 \mathrm{~m}$ indicated by solid and dashed lines after [70].

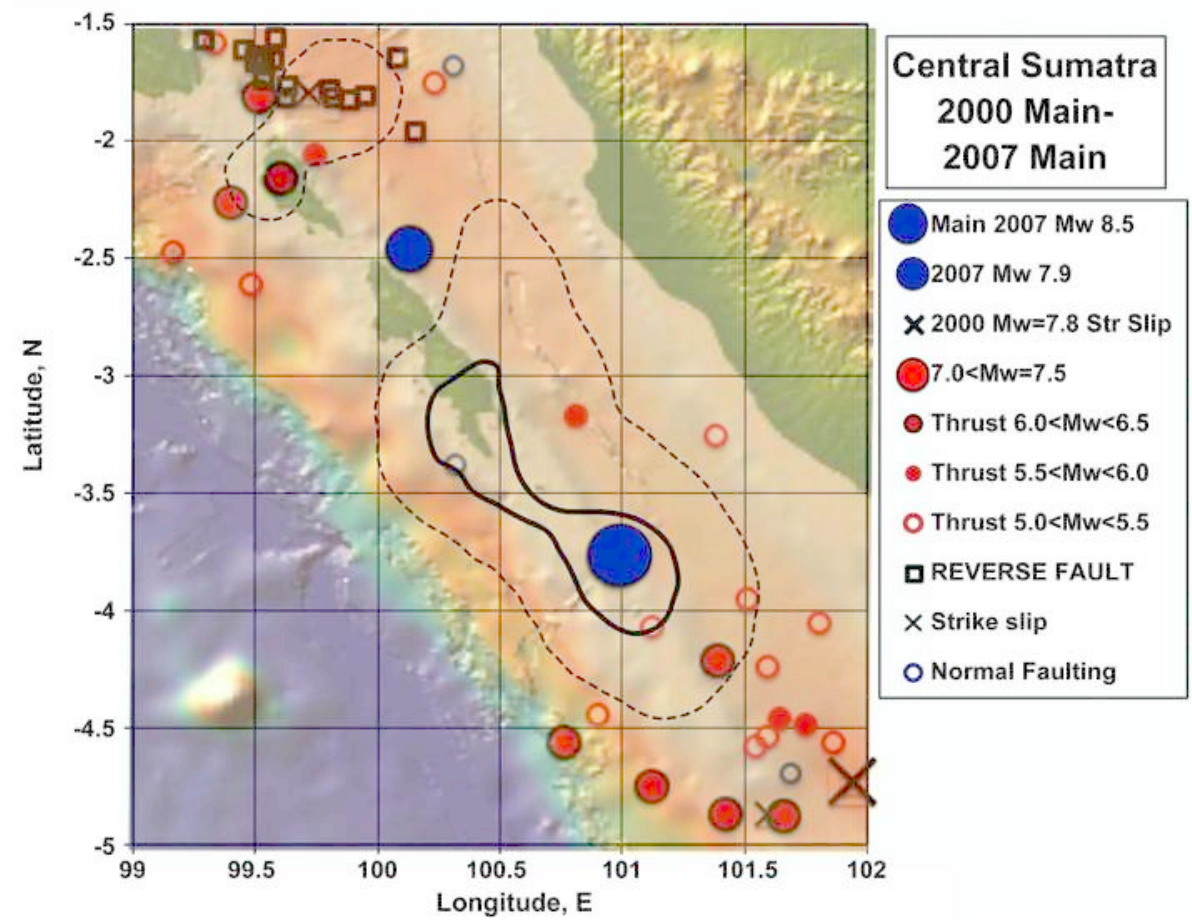

Figure 30. Locations of central Sumatran earthquakes of $\mathrm{Mw}>5.0$ between 2000 strike-slip event of Mw 7.8 (symbol X at lower right) and shocks in 2007 of Mw 7.9 and 8.5. Heavy and dashed lines denote calculated displacements of 15 and $5 \mathrm{~m}$ from [72]. 
In summary, forerunning thrust activity did not occur within the $15 \mathrm{~m}$ slip contour, consistent with its being a giant asperity associated with the Mw 8.5 earthquake.

\subsubsection{Sumatran Earthquake of 2010, Mw 7.8}

The 2010 shock ruptured seaward of the two events of 2007 along the shallowest part of the plate boundary seaward of the Mentawai Islands. It generated a large and destructive tsunami, like that off Java in 2006 [74]. Unlike the Java shock (Figure 13), several thrust foreshocks occurred on the periphery of the higher slip zone of Figure 31.

In summary, the 2010 earthquake, which occurred close to the trench, ruptured a quiet 5-m slip zone that was surrounded by forerunning thrust shocks. That zone is identified as a major asperity. The 2010 event generated a large tsunami.

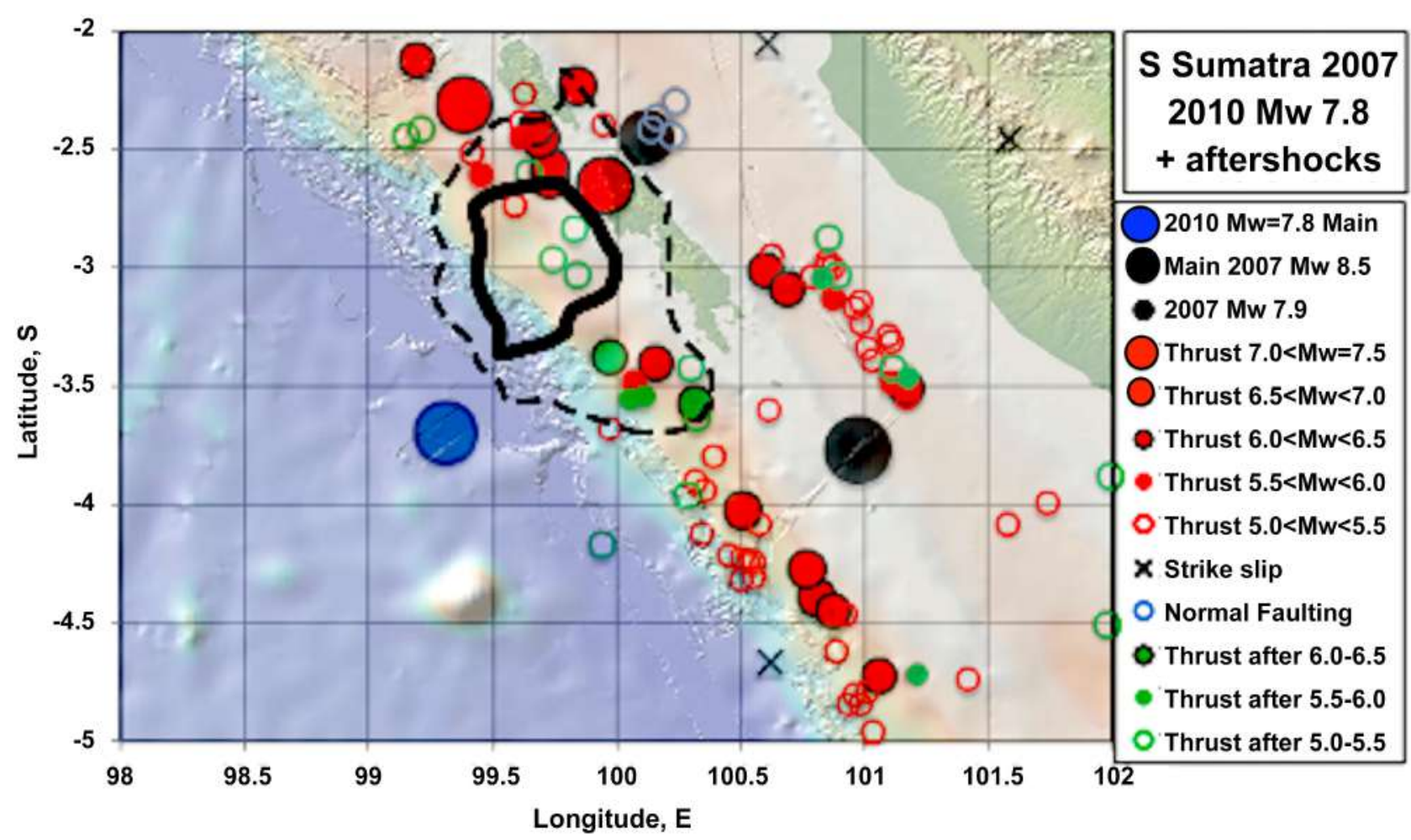

Figure 31. Locations of Sumatran earthquakes of $\mathrm{Mw}>5.0$ between September 2007 and mainshock of 2010 of Mw 7.8. Heavy and dashed lines denote calculated displacements of 5 and $1.5 \mathrm{~m}$ from [74].

\subsection{Earthquakes from New Guinea to New Zealand}

\subsubsection{West Irian, Indonesia 1996, Mw 8.2}

None of the few thrust foreshocks occurred within the solid line that indicates major computed slip in 1996 (Figure 32). Das and Henry [75], however, found that their well-located pre-events took place very close to their zone of maximum slip, which they did not find for the other great shocks they examined. The tsunami reached heights of $7 \mathrm{~m}$ in many areas (Bulletin International 
Seismological Centre). The mainshock consisted of a relatively simple pulse [73].

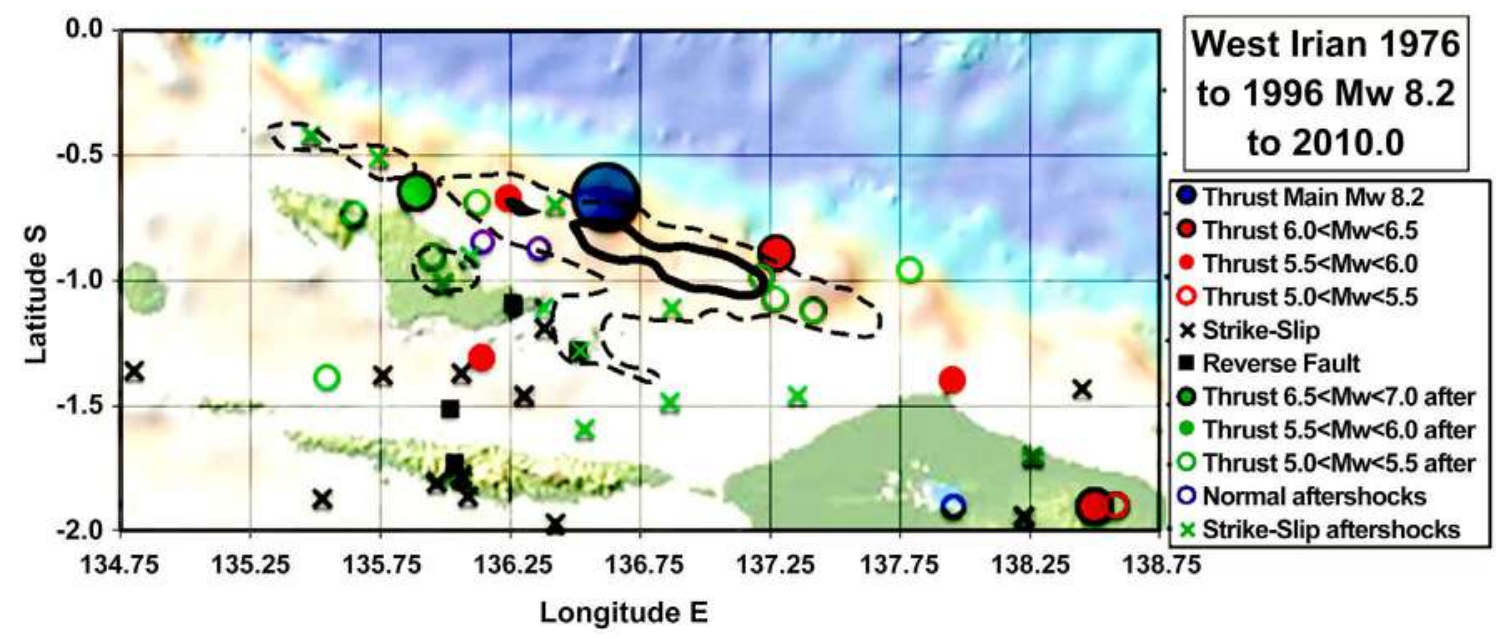

Figure 32. Locations of forerunning events starting in 1976 and aftershocks of $\mathrm{Mw}>5.0$ for West Irian (Biak), Indonesian mainshock of 1996, Mw 8.2 (large solid blue circle). Contours of seismic moment released in mainshock from 1 and $3 \times 10^{20} \mathrm{~N}-\mathrm{m}$ indicated by dashed and solid lines from [75].

In summary, a major asperity may be present near the centroid. The number of forerunning events was not sufficient for them to be used to map the coming rupture zone.

\subsubsection{Solomon Islands Earthquake of 2007, Mw 8.1}

Many thrust earthquakes of $\mathrm{Mw}>6.5$ occurred along a narrow band of the subduction zone in the Solomon Islands from 1977 through 2018. Events of Mw > 7.0 from 1915 to 1977, while likely not as well located, also were situated near that same zone.

Figure 33 is centered on the largest known shock in the Solomon Islands, that of 2007 of Mw 8.1. Little forerunning activity of Mw $\geq 5.5$ occurred from 1977 until the main event within either the western or eastern zones of large slip or between them. The moment tensor solution for the mainshock was situated just inside the western, i.e., the larger, zone of forerunning activity. Abundant forerunners occurred just to its northwest as well as trenchward.

A very young plate boundary formed to the south of the Solomon Islands along the north-south zone of rough topography [76] near $156.5^{\circ} \mathrm{E}$ (Figure 33). It now divides the Australian plate to the east from the Woodlark plate to its west. High slip in 2007 was concentrated on either side of where that zone intersects the subduction plate boundary. That triple junction, however, experienced significant uplift during the 2007 mainshock [76]. The region between the western and eastern zones of maximum slip in 2007 has not experienced a larger known earthquake than Mw 6.4 from 1977 to 2018 or $\mathrm{Mw}>7.0$ since 1915. That very young subduction region near the triple junction may not be capable of rupturing in a very large earthquake. Instead, it may move mainly aseismically. 


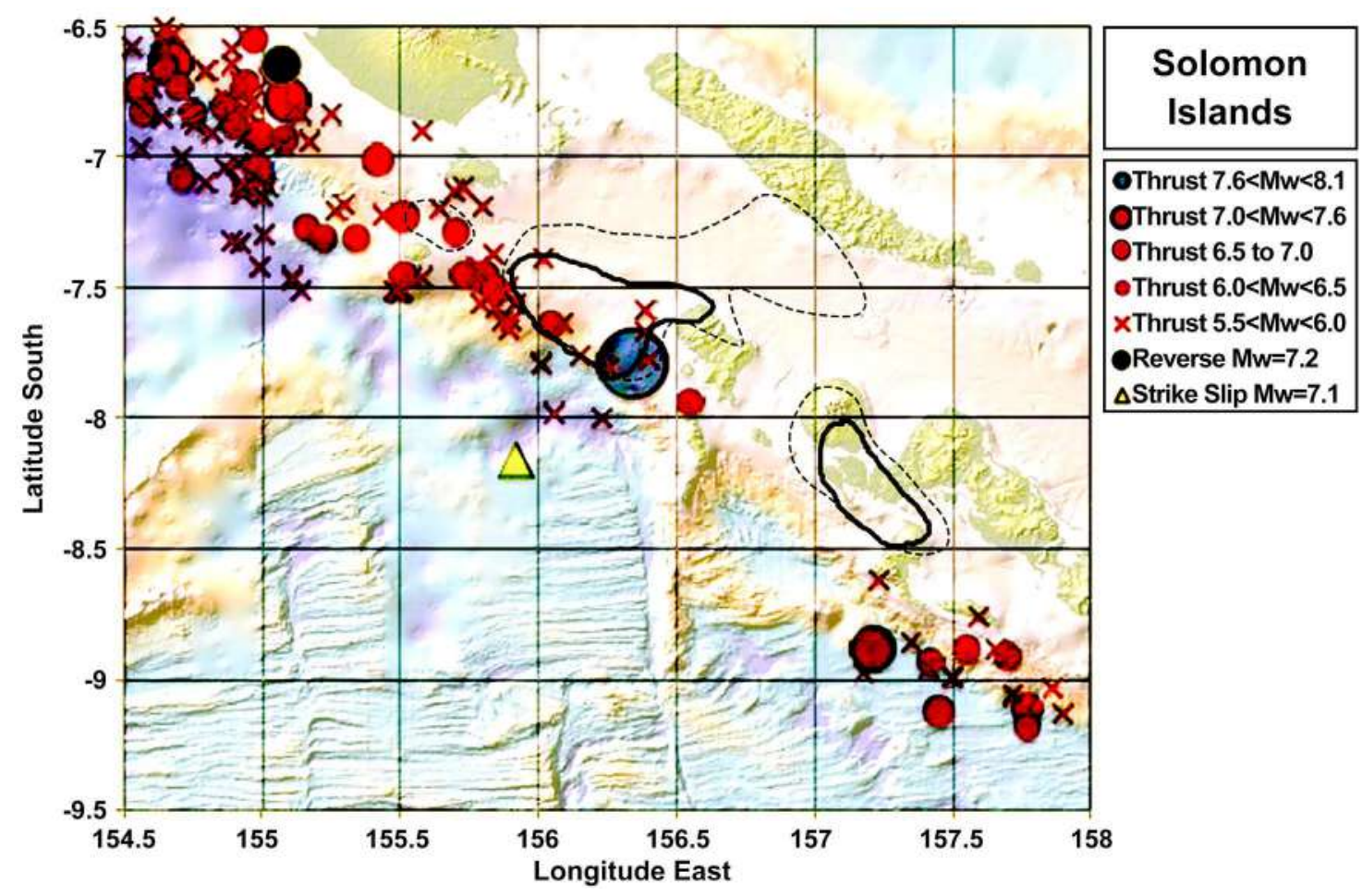

Figure 33. Locations of earthquakes along the central Solomon Islands of $\mathrm{Mw} \geq 5.5$ from 1976 through the 2007 mainshock of Mw 8.1. Large blue circle denotes long-period centroid location of mainshock. Colors depict sizes and mechanisms of seismic sources. Heavy and dashed lines enclose regions of slip greater than 2 and $1 \mathrm{~m}$ during mainshock from [76].

The rupture propagated mostly unilaterally to the northwest from the shortperiod epicenter, which was located just to the southwest of the eastern region of high slip in Figure 33 [76]. The greatest slip occurred in the western zone.

In summary, little forerunning activity occurred within either the western and eastern zones of high slip or between them. The two major asperities that broke in the mainshock could have been defined ahead of time using the forerunning shocks. The zone between them, the site of a young triple junction, may move aseismically.

\subsubsection{Southeastern Solomon Islands Earthquake of 2016, Mw 7.8}

The shock of 2016 off the west coast of the island of Guadalcanal at a centroid depth of about $46 \mathrm{~km}$ had a reverse-faulting mechanism. Thrust and reverse forerunning earthquakes in Figure 34 surround a quiet zone near the centroid of the mainshock. Rupture started at the southeastern end of that quiet zone near $10.79^{\circ} \mathrm{S}, 161.28^{\circ} \mathrm{E}$. To my knowledge no one has published a detailed slip distribution.

In summary, the forerunning activity surrounding the centroid of the mainshock appears to define a great asperity extending about 50 to $80 \mathrm{~km}$ along strike. That asperity itself was quiet for decades ahead of the 2016 mainshock. A detailed computation of slip is needed for it. 


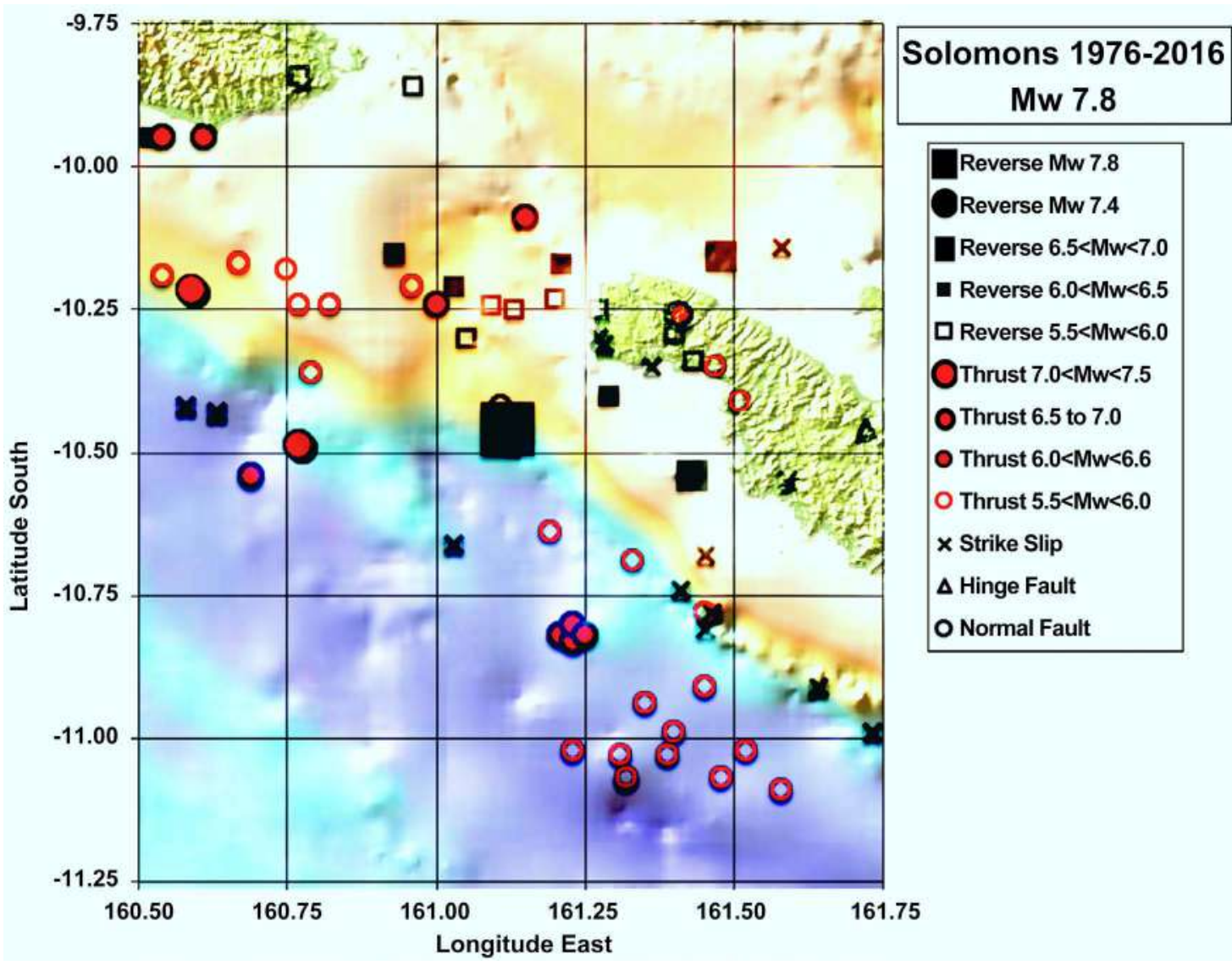

Figure 34. Forerunning activity from 1976 to the great Solomon Islands earthquake of 2016 (large black square) near Guadalcanal.

\subsubsection{Santa Cruz Earthquake of 2014, Mw 7.9}

The great Santa Cruz earthquake of 2014 ruptured two separate patches of high slip shown by the solid and dashed black lines in Figure 35 and Figure 36. Most foreshocks (Figure 35) in the year before the mainshock occurred between the two areas of higher computed slip not inside them. It is understandable that the centroid location of the entire mainshock is located between the two high-slip patches.

Figure 36 shows forerunning activity from 2003 to 2013 omitting the foreshocks in the previous figure. The regions of highest computed slip were devoid of thrust forerunning activity. Several thrust forerunning events occurred in the northwestern 2 to $7 \mathrm{~m}$ slip area. Activity in the southeast corner of Figure 36 may represent continuing aftershocks of the Mw 7.8 shock of 2009 .

In summary, the two zones of highest slip in the 2014 mainshock were devoid of forerunning activity. They are taken as defining two great asperities that ruptured in 2014. Foreshocks occurred between the two high slip zones.

\subsubsection{Off South Island New Zealand 2009, Mw 7.8}

The 2009 event took place along a subduction zone that extends from the southern South Island of New Zealand southwestward to Macquarie Island (Figure 37) and dips to the southeast. Much forerunning thrust activity in the decades 
before the 2009 mainshock took place to its northeast and southwest beyond the computed slip contours [78]. Aftershocks took place closer to those contours and to the centroid of the mainshock.

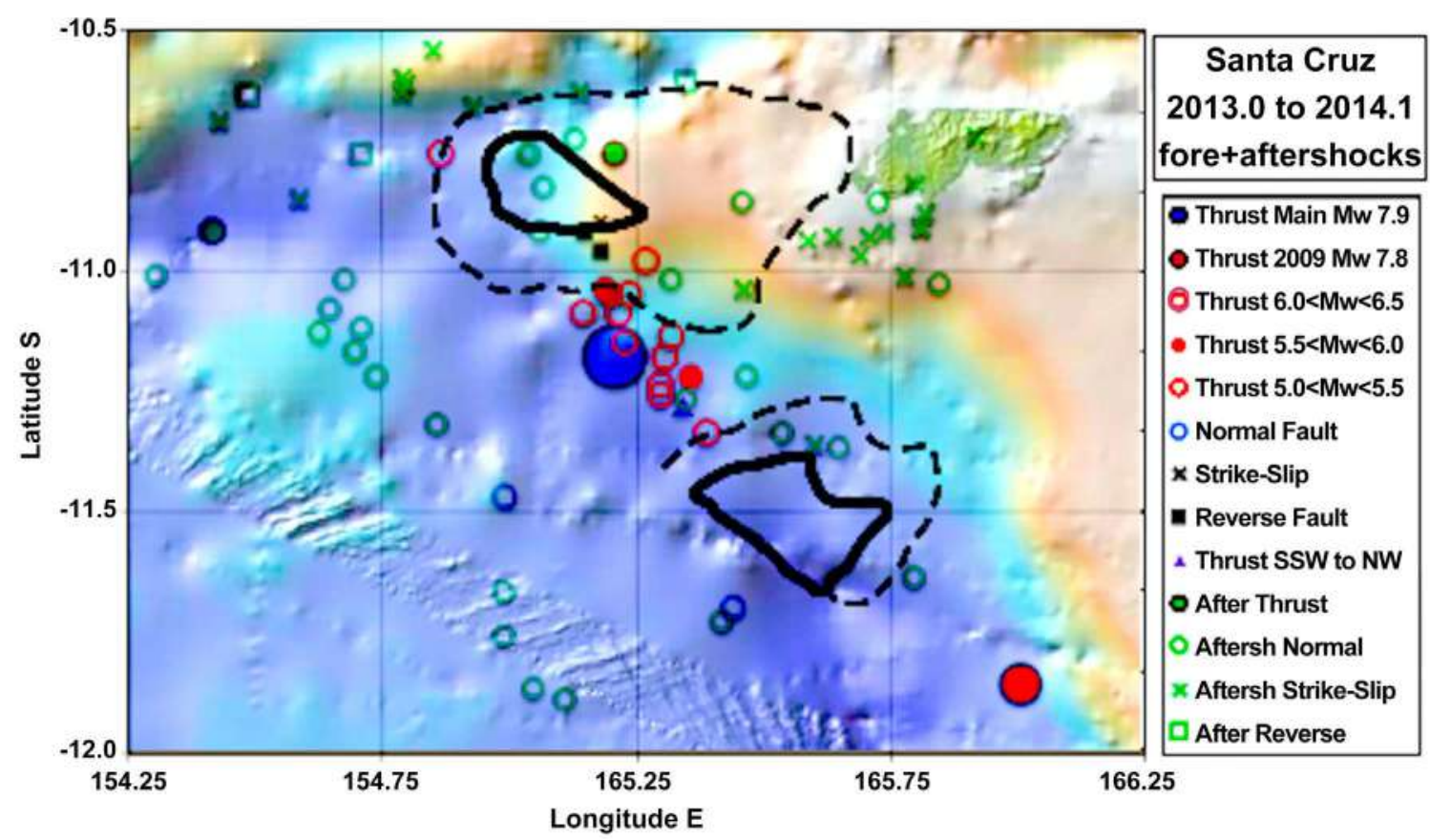

Figure 35. Locations of earthquakes in the Santa Cruz Islands of Mw $\geq 5.0$ from January 2013 through early 2014 showing foreshocks and aftershocks of the mainshock of February 6 of Mw 7.9 (large blue circle). Heavy and dashed lines denote computed displacements of 7 and 2 m modified from [77].

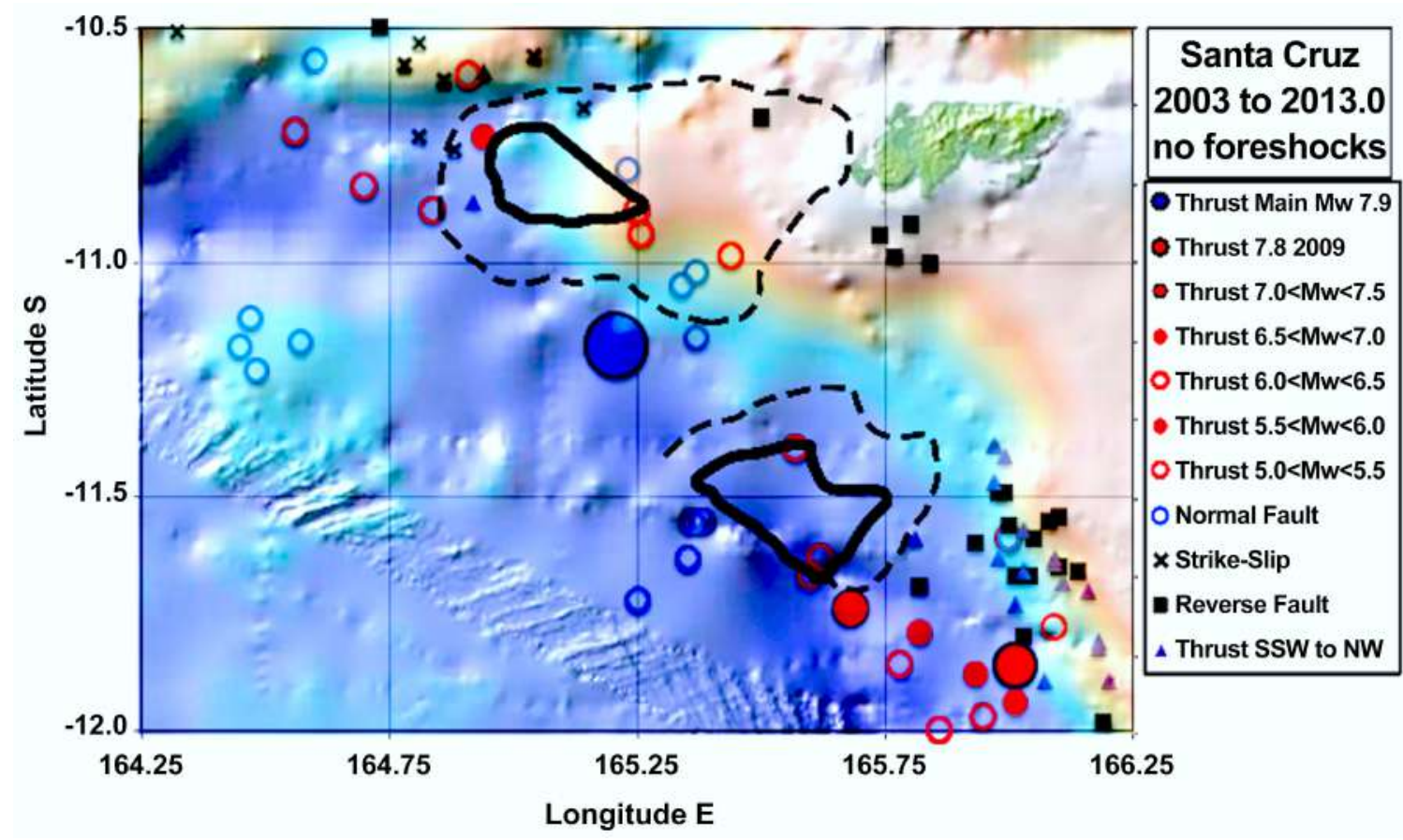

Figure 36. Locations of earthquakes in the Santa Cruz Islands of $M w \geq 5.0$ from 2003 to January 2013 prior to the mainshock of February 6 of Mw 7.9 (large blue circle). Foreshocks in previous figure are omitted. 


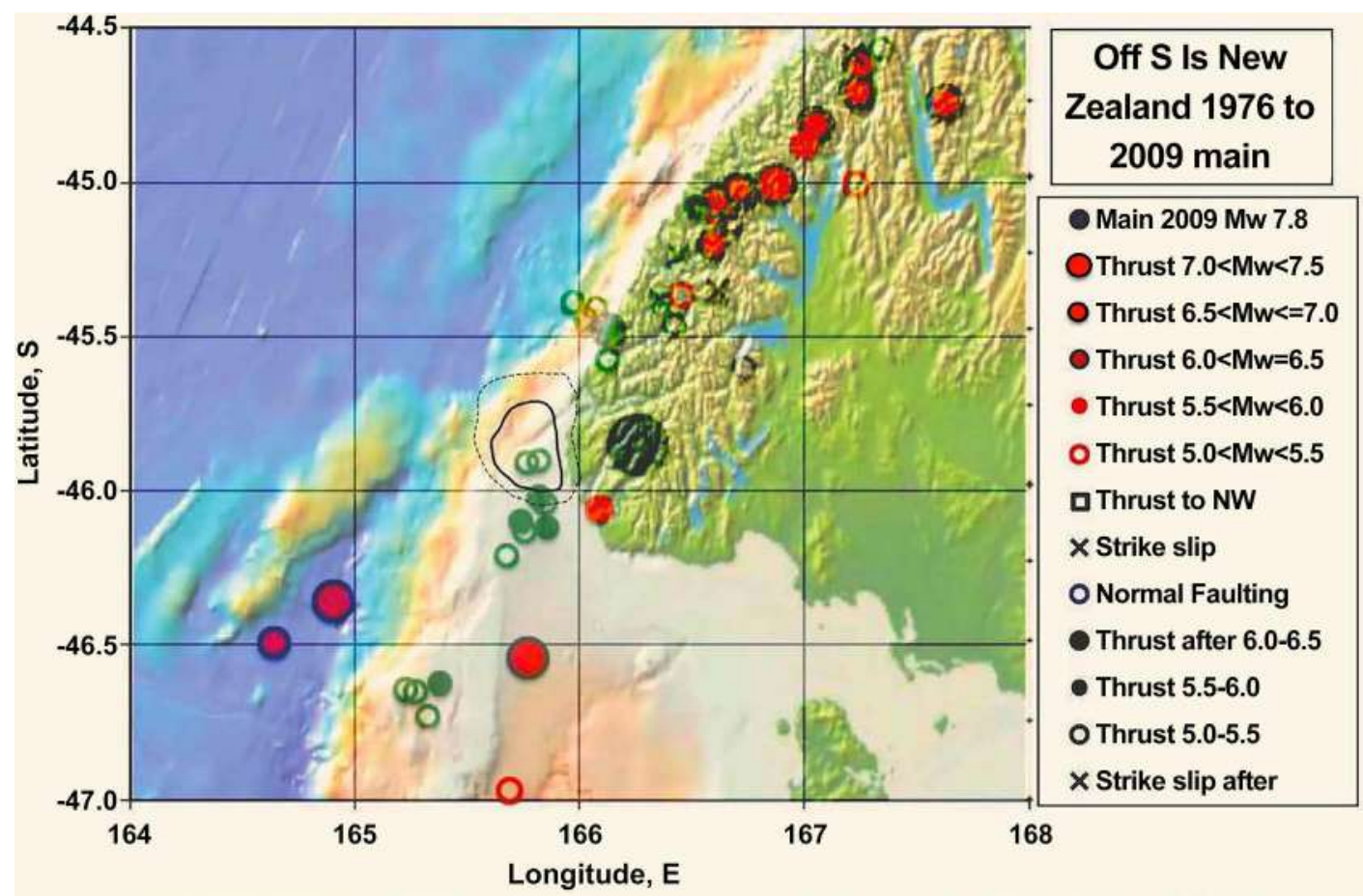

Figure 37. Locations of earthquakes near southwestern coast of the South Island of New Zealand of Mw $\geq$ 5.0 from 1976 through the mainshock of 2009 (large blue circle). Heavy and dashed lines indicate computed slip of 5 and $2 \mathrm{~m}$ in the mainshock from [78].

In summary, a quiet zone of forerunning activity was centered near the high-slip area and the centroid of the mainshock. The forerunning activity in the figure occurred beyond them. The rupture zone itself likely was the site of a great asperity.

\subsection{Earthquakes along Plate Boundaries of the North Pacific}

\subsubsection{Southern Kuril Earthquake of 1994, Mw 8.3}

Forerunning activity of $\mathrm{Mw} \geq 6.0$ from 1976 until the great Kuril Islands earthquake of 1994 surrounds a very quiet inner zone in Figure 38 (i.e., it defines a very elongated shape or "Mogi donut" [23]. The location of the centroid of the mainshock was situated within that elongate zone of forerunners. The short-period locations (not shown) for the same events also outline a similar donut shape but about $25 \mathrm{~km}$ to the northwest, probably an artifact of not considering properly the velocity structure of the downgoing plate.

Modelling of seismological and geodetic data for the 1994 mainshock indicates it consisted of two main sub-events [79]. Since those geodetic observations were all to the southwest in Hokkaido except for a single observation on the nearby Kuril Island of Shikotan, they were not certain a shallow-dipping plane parallel to the strike of the subduction zone could be excluded. Nevertheless, they favored a steeply dipping fault (solid black line in Figure 38) extending from a depth of 40 to $60 \mathrm{~km}$ within the downgoing lithospheric plate. They called it a lithospheric earthquake. Their model of the rupture zone lies in the southwestern half of the quiet part of the donut. 
The centroid depths of the two reverse faulting aftershocks in Figure 39 were 54 and $60 \mathrm{~km}$. The depths of thrust aftershocks within $100 \mathrm{~km}$ of the 1994 mainshock were 33 to $60 \mathrm{~km}$, in general agreement with the depth estimates of [79].

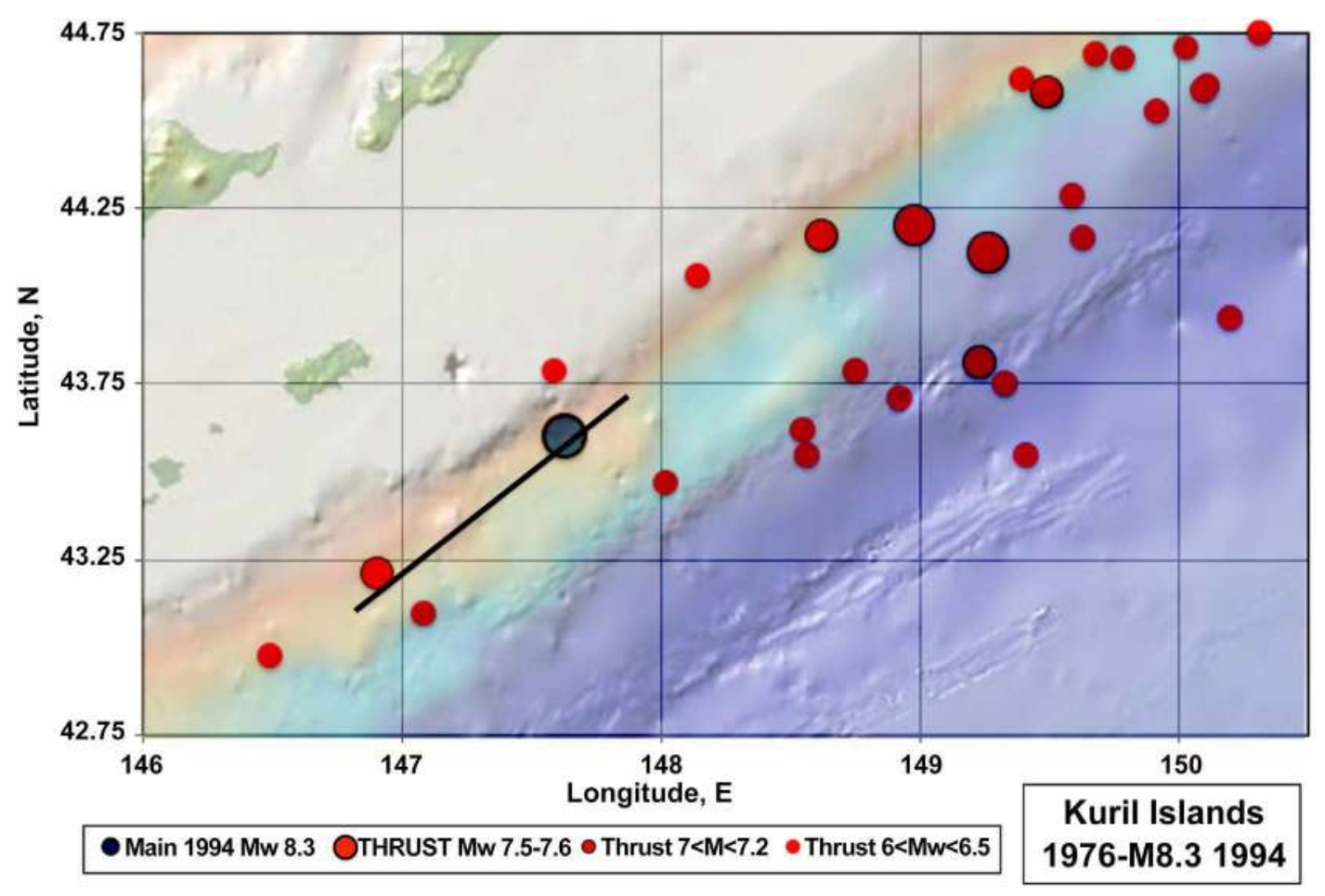

Figure 38. Locations of thrust earthquakes in the southern Kuril Islands of magnitude $\mathrm{Mw} \geq 6.0$ (red dots) from 1976 until the great shock of 1994 (large blue dot). They surround what is interpreted as the great asperity that broke in the coming mainshock. Black line is rupture length of the steeply-dipping nodal plane of [79].

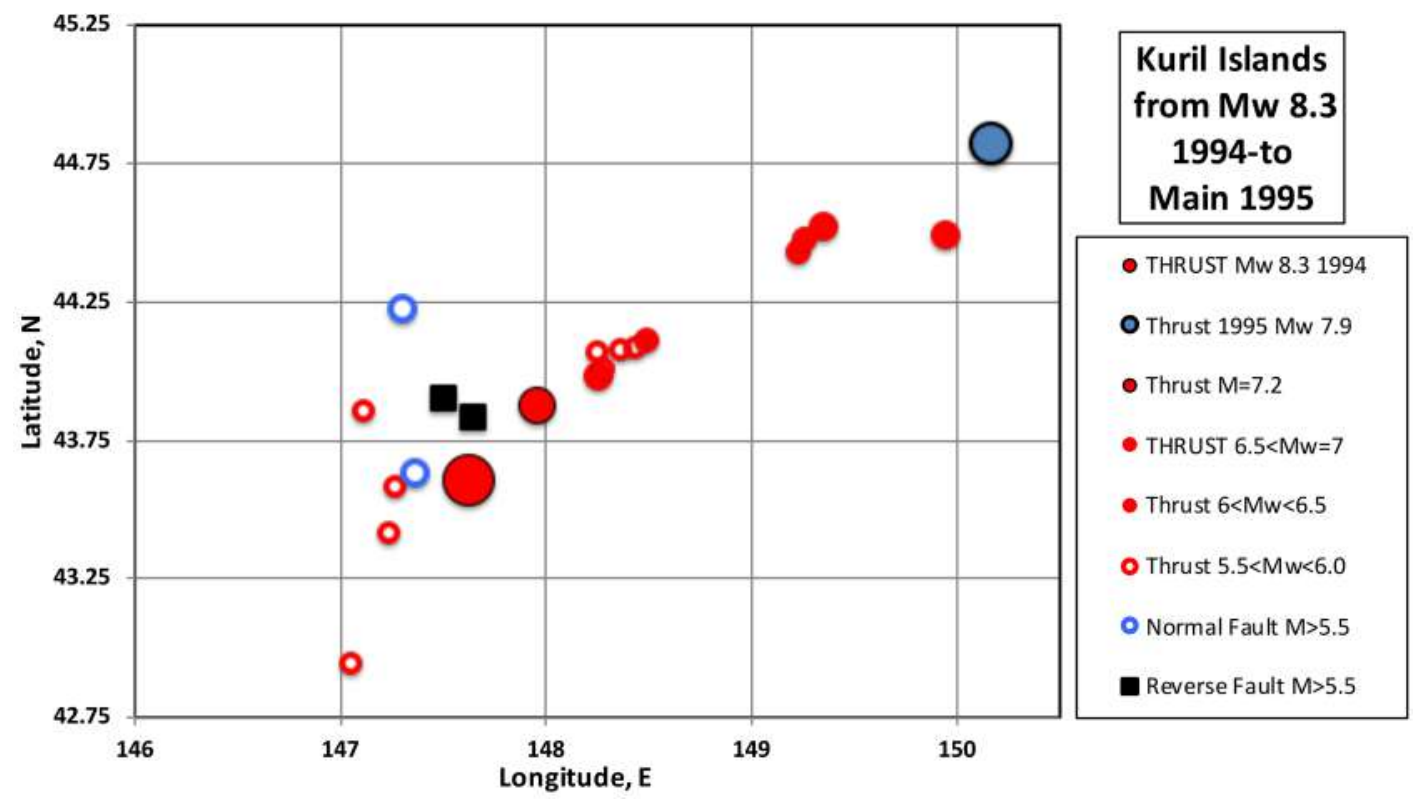

Figure 39. Locations of seismic activity between Kuril Islands great earthquake of 1994 (large red circle) and nearby mainshock of 1995 (large blue circle). 
Thus, rupture in the 1994 mainshock appears to have been either within the downgoing Pacific plate, a complex event with varying dips and depths or both.

Most aftershocks of Mw $\geq 5.5$ from the main event of 1994 until the 1995 adjacent shock occurred just to the northwest of the seismic centroid (Figure 39) and outside the quiet zone (i.e., the hole of the donut) in Figure 38. Few aftershocks occurred along the southeast side of the donut. The distribution of aftershocks favors rupture along a fault parallel to the plate boundary, albeit one of steep dip.

The 1994 earthquake did not occur on the plate boundary but instead on a northwesterly striking fault according to [80] [81]. I think they placed too much emphasis on a possible connection between the 1994 shock and an event at a depth of about $100 \mathrm{~km}$ farther to the northwest in 1978 of $\mathrm{Mw}$ 7.8. I conclude they each picked the wrong nodal plane as the causative fault.

In summary, forerunning thrust events outline an elongate donut that was free of such shocks in its interior. The centroid of the mainshock was inside, indicating it likely defines a great asperity that broke in 1994. More work is needed to resolve whether the mainshock, in fact, ruptured within the downgoing Pacific plate, including double-difference computations for the centroid data of the events in Figure 38. A rupture within the lithosphere, as advocated by [79], is like that in the great Tongan earthquake of 2006 as described in the Supplement. Great earthquakes within the downgoing lithosphere, however, are uncommon compared to great plate boundary events. The 1994 event probably did not reruptured part of the plate boundary that broke in the Mw 8.2 event of 1969 just 25 years earlier and hence did not violate the seismic gap hypothesis. That part of the plate boundary itself likely remains a seismic gap.

\subsubsection{Kuril Island Earthquake of 1995, Mw 7.9}

Forerunning activity to the great Kuril earthquake of 1995 surrounds a quiet zone that includes the centroid of the mainshock (Figure 40). The 1995 mainshock took place to the northeast of the 1994 event (Figure 38). Rupture in 1995 consisted of a simple pulse according to [73] but the Bulletin of the International Seismological Centre states it broke in two main pulses $22 \mathrm{~s}$ apart. Schwartz [82] computed the distribution of slip for the mainshock along strike but not with depth. Schwartz found that computed high slip in 1995 overlapped that of the giant shock of 1963 but with rather large uncertainties.

In summary, forerunning thrust activity defines a quiet zone that is interpreted to be a great asperity that broke in 1995. The amount of overlapping slip in the 1963 giant and 1995 great earthquakes is uncertain.

\subsubsection{Rat Island Aleutian Earthquake of 2003, Mw 7.7}

Abundant forerunning activity with thrust mechanisms occurred on all sides of the centroid of the Aleutian mainshock of 2003 (Figure 41). The mainshock was one of the smallest events studied. Foreshocks were prominent (Figure 42) from January 2003 until the main event in November. Aftershocks occurred solely to 


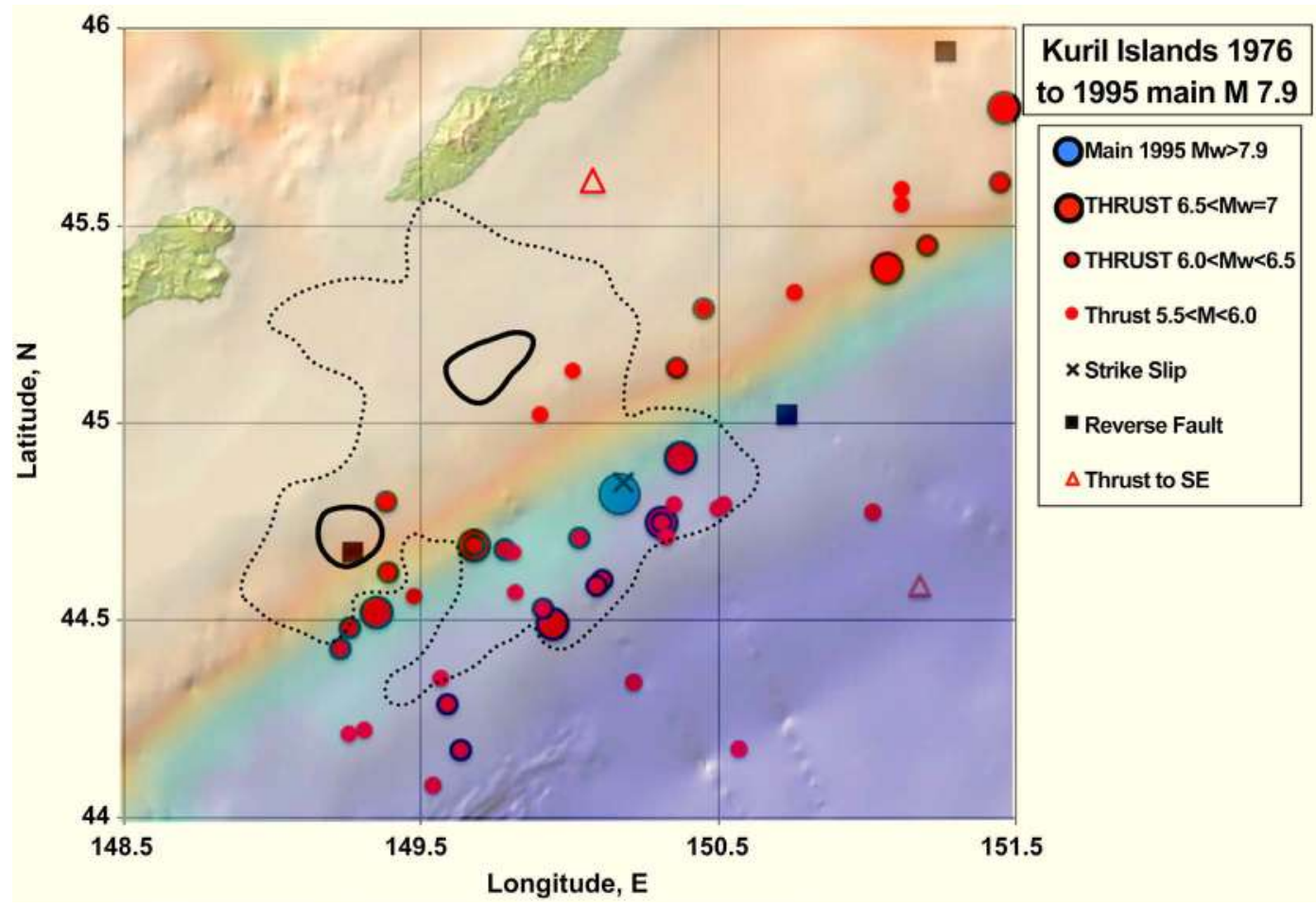

Figure 40. Locations of earthquakes of Mw > 5.5 from 1976 until 1995 Kuril Islands mainshock, Mw 7.9. Solid and dashed lines indicate computed rupture zones of high and moderate slip from [83].

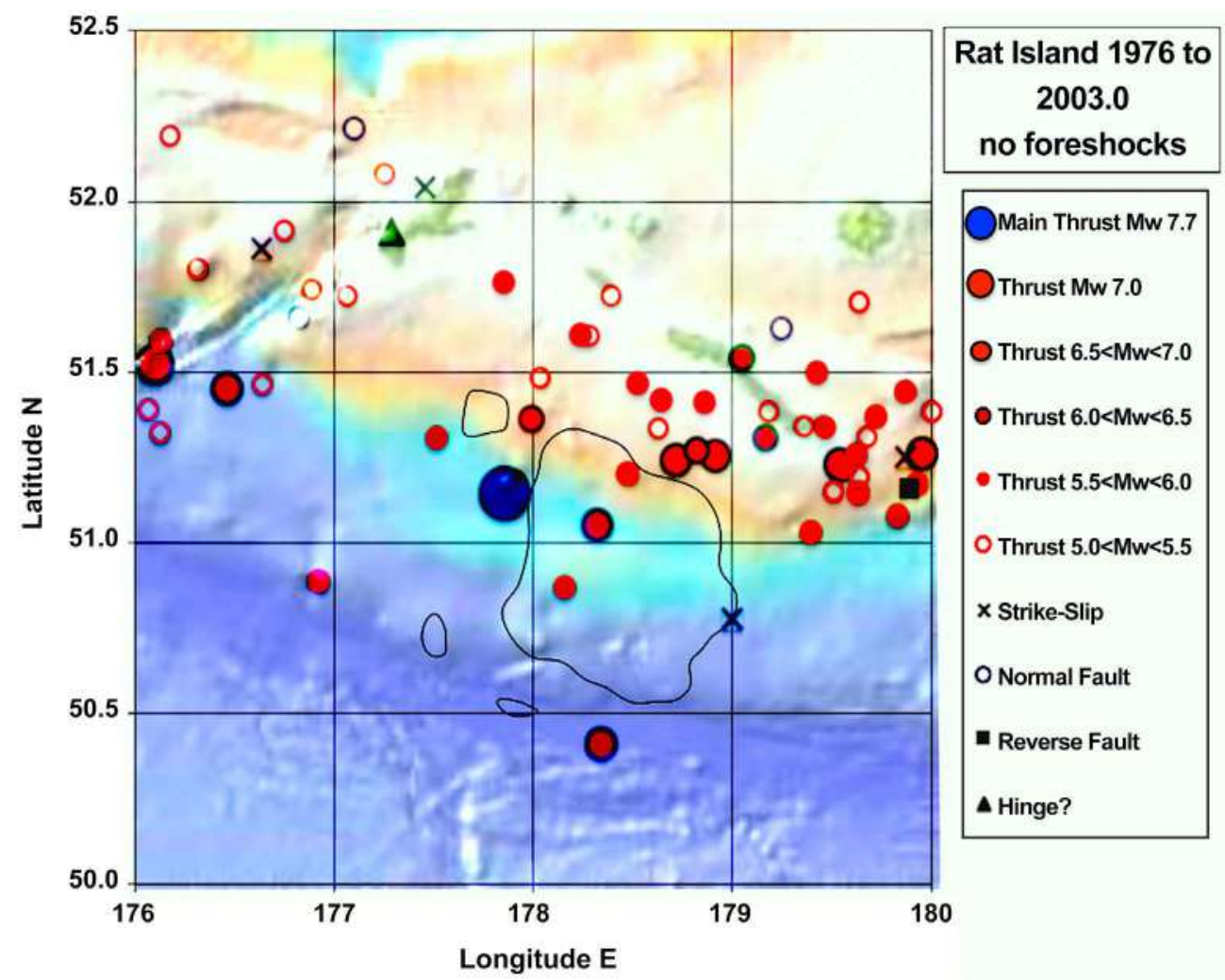

Figure 41. Forerunning activity from 1976 until Rat Island, Aleutians mainshock of 2003. Large blue circle denotes centroid of main event. Solid black lines indicate regions of high computed slip from [83]. 


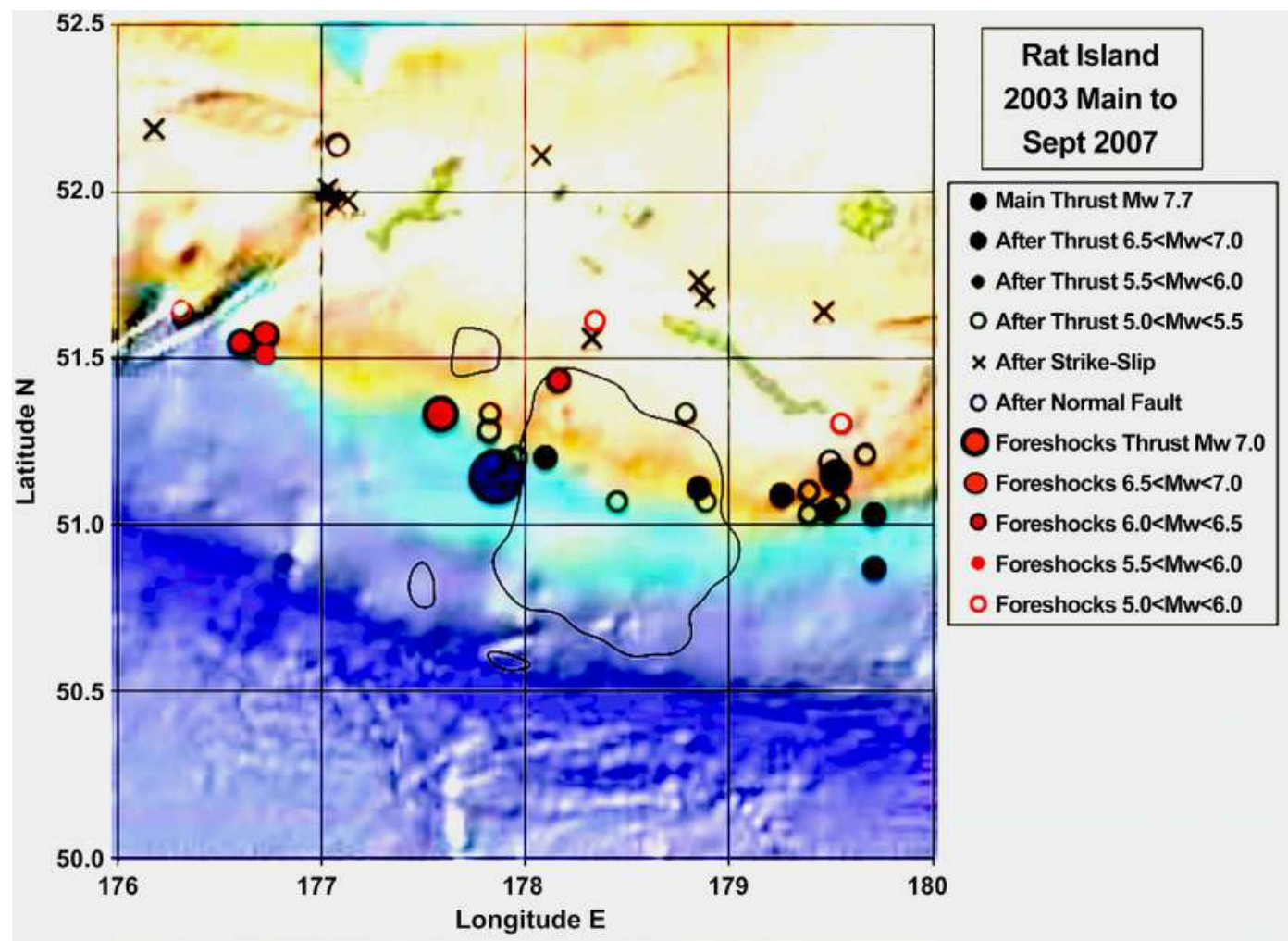

Figure 42. Foreshocks and aftershocks of Rat Island, Alaska event of 2003. Large dark blue circle is centroid of mainshock.

the east of the mainshock. Its short-period epicenter as determined by the Bulletin of the International Seismological Centre was located about $50 \mathrm{~km}$ east of the centroid, indicating the mainshock ruptured from east to west. Amchitka Island, the site of three U.S. underground nuclear tests is located near $51.5^{\circ} \mathrm{N}, 179^{\circ} \mathrm{E}$.

Rupture in 2003 consisted of a large simple pulse followed by later smaller slip pulses [73]. Most forerunning thrust earthquakes occurred outside the areas of high computed slip but three forerunning event took place within the larger slip contour.

In summary, much forerunning thrust activity to the 2003 mainshock occurred closer to the Aleutian Islands than the centroid and zones of computed high slip. Three thrust events occurred within the main high-slip contour. All but one foreshock took place outside.

\subsubsection{Central Aleutian Island Earthquake of 1996, Mw 7.9}

Almost all forerunning thrust events (Figure 43) of the Aleutian earthquake of 1996 occurred on the island side of its centroid. Abundant forerunning activity took place to the west of the centroid and of Adak Canyon (near $177.3^{\circ} \mathrm{W}$ ).

Tanioka and Gonzalez [84] modelled tsunami data for the 1996 and 1986 earthquakes. They concluded that the downdip width of the mainshock of 1996 was $30 \mathrm{~km}$ or less. The 1986 and 1996 rupture areas were well coupled seismically but the region to the east of $174^{\circ} \mathrm{W}$ was not [85]. Displacements were modelled for the 1996 mainshock [83]. The zone containing 50\% of moment release 


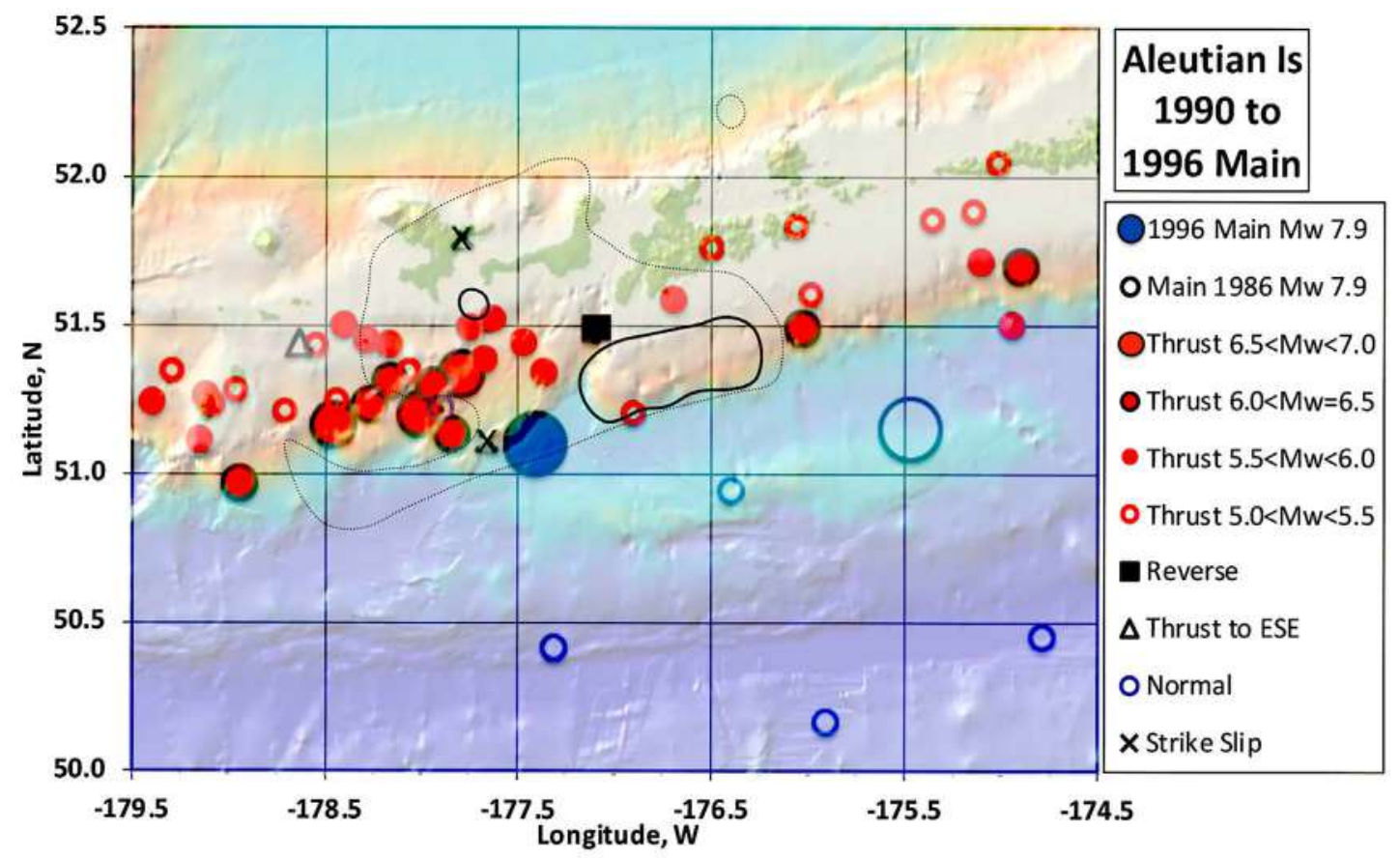

Figure 43. Forerunning events to the mainshock of 1996 in the Aleutian Islands. Large blue circle is centroid of mainshock; large open blue circle denotes centroid of 1986 great event. Heavy and dotted lines are contours enclosing 50\% and $85 \%$ of the estimated slip in the 1996 mainshock from [83].

is devoid of forerunning activity in Figure 43. All but one of the forerunning events occurred trenchward of that contour. This is consistent with the finding that the 1996 shock generated a tsunami that propagated across the Pacific [85].

Modelling the distribution of slip along strike for the 1986 shock, Boyd and Nábêlek [86] found it consisted of two zones of high moment release to the east of the 1986 centroid (Figure 43) and a zone of smaller release about $23 \mathrm{~km}$ to its west. Thus, high slip in the two mainshocks does not appear to overlap. The average slip from the seismic moment over the entire rupture 1986 zone was close to that calculated assuming full plate coupling since the 1957 giant earthquake [86]. Their estimates for the two zones of highest slip in 1986, however, were greater than those calculated for the potential slip built up since 1957 assuming full coupling.

The occurrence of the 1986 and 1996 earthquakes so soon after 1957 led several earth scientists to claim the seismic gap hypothesis was false. Since most great earthquakes have occurred in long-standing seismic gaps where sufficient potential displacement could have built up by plate motion, I sought other explanations for the occurrence of the 1986 and 1996 Aleutian events only 29 and 39 years after the giant 1957 mainshock. The centroids of the 1986 and 1996 shocks were located farther south and more trenchward than nearly all of the 1996 aftershocks and possibly those of 1986 (Figure 44). Thus, slip in 1996 and possibly 1986 may have ruptured more trenchward than the 1957 earthquake. Boyd and Nábêlek [86] did not estimate how the release of seismic moments varied in the dip direction; nor did Johnson et al. [87] for the 1957 earthquake. 


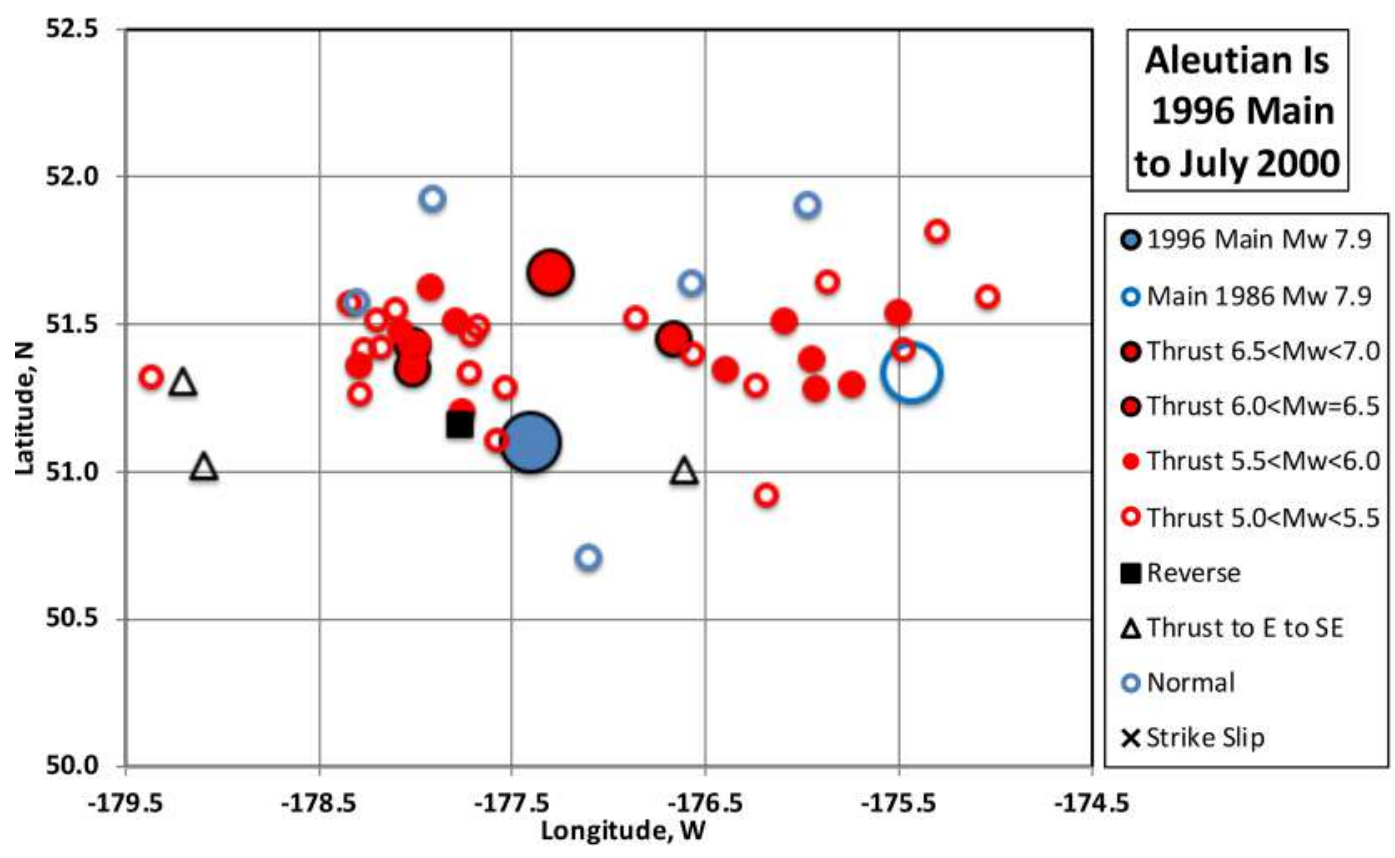

Figure 44. Aftershocks of 1996 mainshock in the Aleutian Islands. Large blue circle is centroid of 1996 mainshock; large open blue circle denotes centroid of 1986 event.

Moment release was small in 1957 to the east of the 1986 rupture zone [87]. Thus, we do not know how much areas of significant moment release in 1957 overlapped or not with those in 1986 and 1996. The short-period epicenter of the 1957 shock near $51.63^{\circ} \mathrm{N}, 175.41^{\circ} \mathrm{W}$ was close to that for 1986 and about $45 \mathrm{~km}$ north of the 1986 centroid.

Another explanation is that the 1957 shock did not release the stress that had been built up earlier. By that hypothesis, the 1986 and 1996 earthquakes released stresses that had been stored up for longer than 29 and 39 years.

In summary, forerunning and aftershock activity to the 1996 earthquake occurred mainly north of its centroid and the zone of highest slip, indicating the asperity that broke in it may have been located farther south. Detailed information on slip in the 1957 mainshock is needed to ascertain if the occurrence of the 1986 and 1996 events violated the seismic gap hypothesis by rupturing so soon.

\subsubsection{Kamchatka Earthquake of 1997, Mw 7.8}

The great Kamchatka mainshock of 1997 was a thrust event along this well-studied subduction zone. The event was unusual in that the highest slip region was situated beneath land of the Kronotsky peninsula. Neither the forerunning thrust nor aftershock activity in Figure 45 and Figure 46 occurred within the two computed regions of high slip. The forerunners surround the quiet zone on three sides.

The plate boundary to the north of $53^{\circ} \mathrm{N}$ is only moderately well coupled according to [88] [89] compared to that to the south, which includes a great shock in 1923 and the giant earthquake of 1952 [90]. The 1997 mainshock took place in a long-standing seismic gap between the 1923 event and that of 1971 to the 


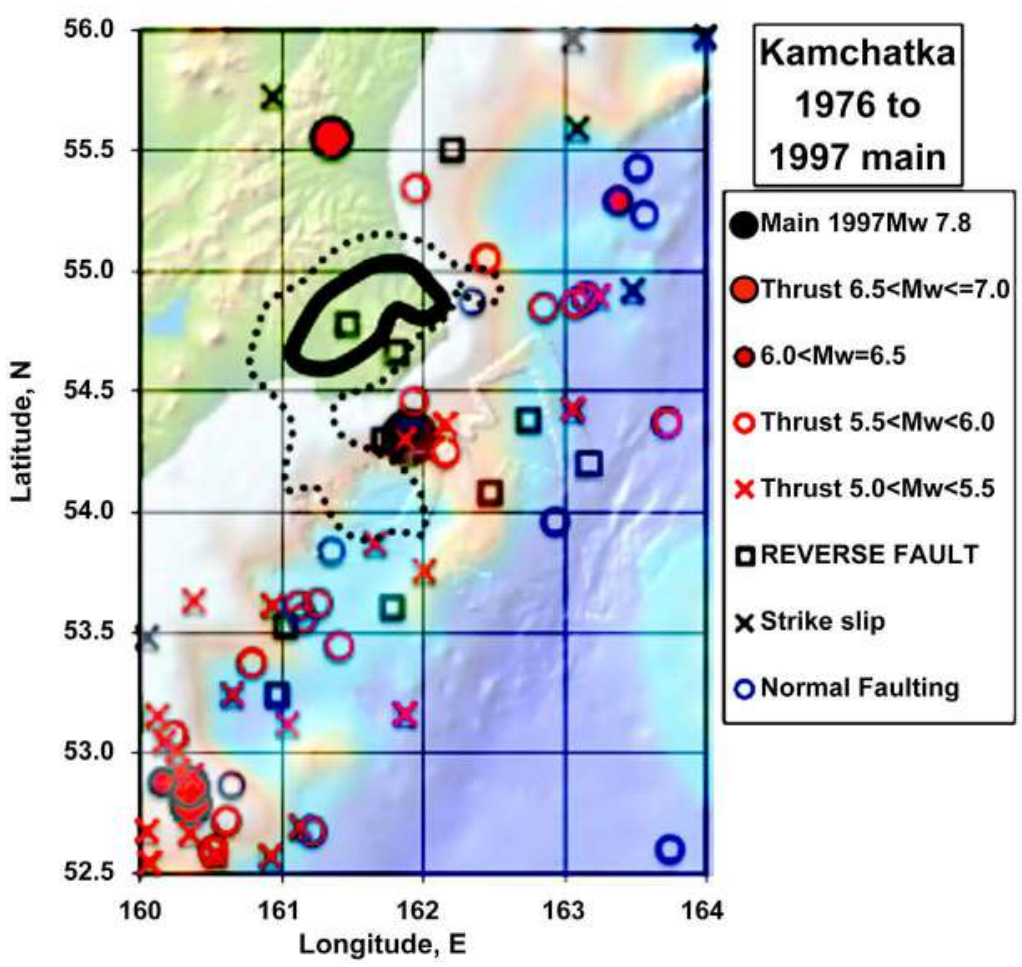

Figure 45. Locations of earthquakes of $\mathrm{Mw} \geq 5.0$ from 1976 until the Kamchatka shock of 1997 of Mw 7.8. Solid and dotted lines denote areas of computed highest and next highest slip from [83] [91].

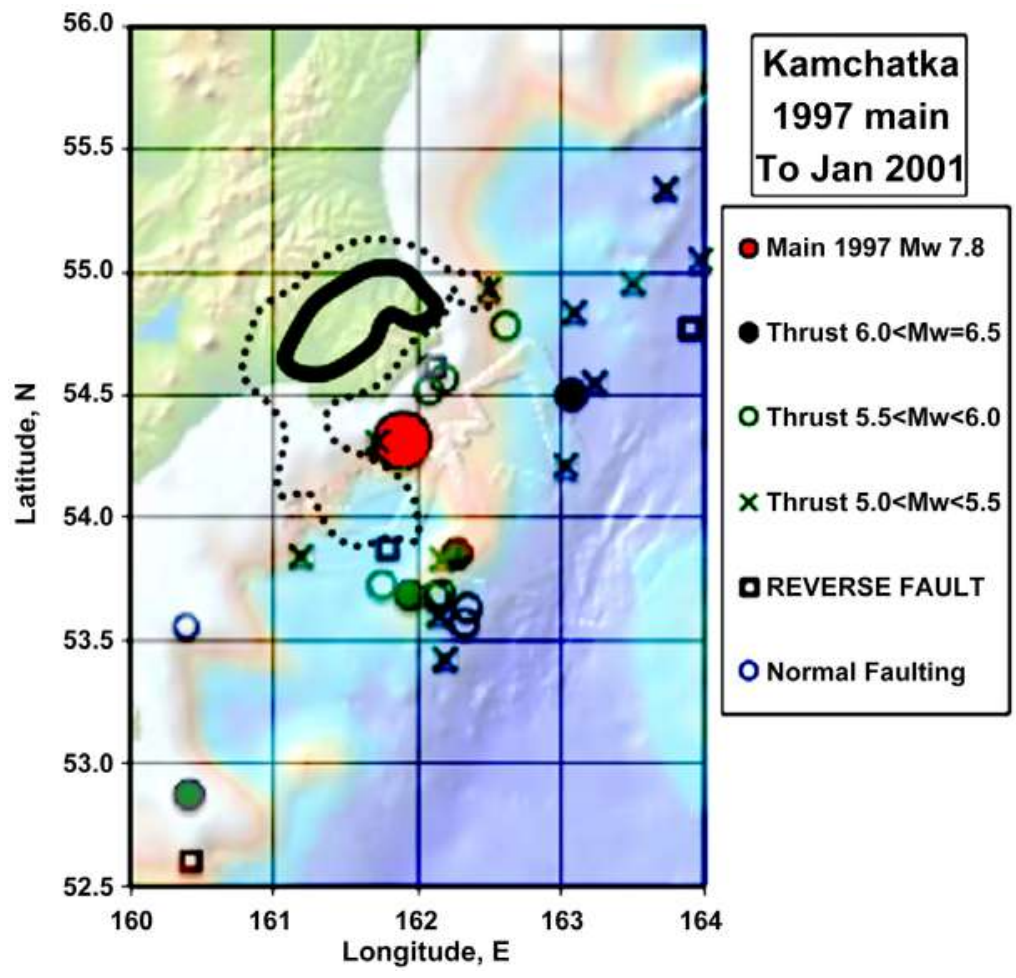

Figure 46. Locations of aftershocks of $\mathrm{Mw} \geq 5.0$ from the Kamchatka mainshock of 1997 of Mw 7.8 until January 2001. Two zones of high slip are same as in previous figure. 
northeast. The two papers find that small foreshocks and postseismic slip in the two months after the 1997 mainshock occurred outside of the main asperity that ruptured co-seismically. They report that aseismic afterslip during the next two months released as much seismic moment as the mainshock. The rupture in 1997 consisted of a simple pulse [73].

In summary, forerunning activity did not occur within the computed high slip region but was concentrated along its periphery on three sides. It defines a great asperity that likely broke in the mainshock. The mainshock took place in a well-defined seismic gap.

\section{Discussion and Conclusion}

Forerunning earthquakes of moderate to large size occurred during the 5 to 45 years before many recent great and giant thrust mainshocks at subduction zones. While the patterns and numbers of those events varied, several common patterns can be observed in the figures.

The rupture zones of 17 out of 47 mainshocks at subduction zones consisted of quiet zones surrounded by decadal forerunning activity on 3 to 4 of their sides. These include the following earthquakes: Kuril Islands 1994 and 1995, western Aleutians 1996, Vanuatu 1997, Kamchatka 1997, Tokachi-oki 2003, Nias 2005, Peru 2007, central Sumatra 2007, Solomon Islands 2007, New Zealand 2009, northern and southern Sumatra 2010, Tohoku 2011, Costa Rica 2012, Ecuador 2016 and eastern Solomon Islands 2016. This number is enough to make further work on them and future large subduction zone earthquakes worth pursuing. Many were identified in the literature as occurring in well-coupled segments of plate boundaries and long-standing seismic gaps.

Quiet zones surrounded by forerunning seismic activity are common. Quiet zones are taken to define major asperities that then ruptured in those mainshocks. The locations of surrounding seismic activity are interpreted as sites of small to moderate-size asperities of various numbers and sizes.

Forerunning events of $\mathrm{Mw} \geq 5$ occurred mainly updip of the centroids and computed zones of highest displacement for the Iquique and Tocopilla earthquakes of 2014 in northern Chile (Figure 4). Schurr et al. [22] found that smaller prior earthquakes than those used in this paper also occurred to the east and downdip of the centroid of the coming great shock. Thus, the totality of activity encircled a quiet zone, forming a well-developed Mogi donut. With the addition of those data, the entire size of the coming rupture zone was identifiable beforehand. The rupture length along strike of the coming 2014 mainshocks also could be estimated beforehand; it was not as long as that of the preceding 1877 giant earthquake. The Iquique plate boundary had been a seismic gap since 1877 . The Iquique shock also was preceded by several types of forerunning and precursory activity. In a sense it is a "poster child" for work on earthquake prediction for time scales of months to decades.

The giant Maule earthquake of 2010 broke two seismic gaps that had pre- 
viously ruptured separately in 1835 and 1906. Forerunning activity was largely concentrated near the two ends of the 2010 rupture zone, which coincides with two low-coupling zones (LCZ). Those and other LCZ described in the literature behaved differently from the two great asperities that ruptured together in 2010 . Many LCZ have been described as sites of slow-slip seismic events. The Araco LCZ at the southern end of the rupture zone of the 2010 shock was very active prior to and after the giant Chilean earthquake of 1960. Work on detecting forerunning and precursory activity needs to pay particular attention to those and other LCZ's.

Another low-coupling zone appears to be present off the southern coast of Kodiak Island (Figure 47) near the southwestern end of the rupture zone of the giant Alaskan shock of 1964. Aftershocks of the 1938 and 1964 earthquakes overlapped in what may be a LCZ. Slip in 1964 was small in that area [92]. An event of Mw 7.1 occurred six weeks before the 1964 earthquake along with other somewhat smaller events. Other LCZ have yet to be mapped and defined.

The zones of computed high slip for the great 2001 Arequipa and 2006 Kuril earthquakes were larger than the regions of forerunning activity shown in Figure 12 and Figure 18. One explanation is that rupture in each mainshock started in a quiet zone and then continued outside of it along strike. Forerunning activity surrounded a large quiet zone in the southwestern half of the coming rupture zone of the 2006 Kuril shock. Foreshocks occurred on its southwestern boundary. Rupture in the Arequipa mainshock began in the north in a quiet zone of forerunning activity and progressed into a southeastern area of more activity, much like the Kuril shock. Both mainshocks were large enough that they each likely broke a great asperity and then ruptured into a lower-coupling zone along strike.

Forerunning activity to the giant 2011 Japanese earthquake was distinct in that many Miyagi-oki shocks of $\mathrm{Mw} \geq 7.0$ occurred in the decades to more than a century beforehand between its computed regions of slip of 4 to $24 \mathrm{~m}$. Slip larger than $24 \mathrm{~m}$ in the mainshock occurred close to the trench where many had incorrectly surmised slipped took place aseismically. The large Miyagi-oki asperities apparently needed to rupture before the final one would be sufficiently stressed to break in 2011. Large co-seismic rupture then spread to the shallowest part of the plate boundary where slip exceeded $50 \mathrm{~m}$. Stresses associated with the unusually large Miyagi-oki asperities apparently prevented the plate boundary closest to the trench from moving aseismically at significant rates until the 2011 giant shock.

Rupture zones of several other great shocks were not well defined by forerunning activity. That was particularly so for some of the smallest shocks, those of $\mathrm{Mw} \leq 7.8$. Their rupture zones were small compared to uncertainties in the centroid locations of forerunning events. In addition, some had few forerunning shocks of $\mathrm{Mw} \geq 5$. The use of double-difference relocations for them as well as the addition of smaller forerunning events could be useful. 


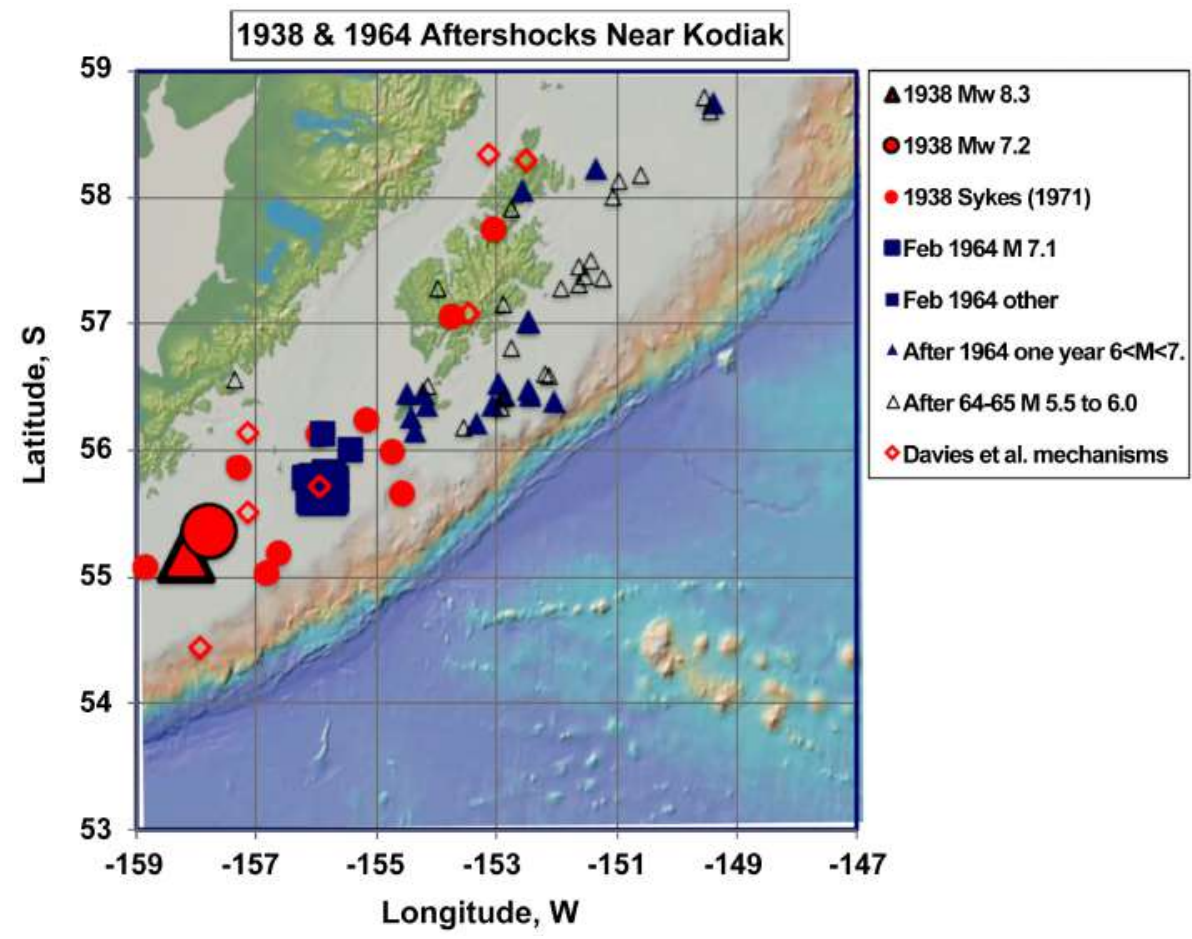

Figure 47. Overlap of aftershocks of the 1938 great and March 1964 giant earthquakes near the southern coast of Kodiak Island, Alaska. Events in February 1964 occurred prior to the giant earthquake.

A few great thrust earthquakes occurred along subduction zones that are widely regarded as being poorly coupled. Forerunning events were largely or totally missing for mainshocks offshore of Java, Tonga and the Marianas. The great events described for Tonga and the southern Marianas likely occurred within the downgoing plates, not at plate interfaces. The two Java shocks took place along the plate boundary very close to its outcrop at the Java trench. Each triggered normal faulting, not thrust, aftershocks even though the mainshocks involved thrust faulting.

Identifying regions that are capable of rupturing in shocks like the two off Java will need to employ other techniques. The use of forerunning activity to identify asperities that are capable of rupturing in great and giant earthquakes appears to be limited to well-coupled segments of subduction zones and their adjacent low-coupling zones.

Pérez and Scholz [6] studied forerunning activity and aftershocks of six giant earthquakes from 1952 and 1965 using events of magnitude 7 and larger extending back to 1900 . They sought to identify "seismicity patterns" associated with the entire seismic cycle of giant events. They report that once a mainshock-aftershock sequence occurred, the focal region entered a period of relative quiescence for large $(\mathrm{Ms} \geq 7)$ earthquakes. Significant activity of those magnitudes took place during many decades prior to each mainshock and clustered in space around the ends of the forthcoming rupture and/or in the vicinity of the short-period epicenter. They found that large aftershocks were localized at the places where prior 
seismicity had occurred. They also report that the nucleation and ends of the rupture often coincide with recognizable geometrical and/or geological inhomogeneities, or "barriers". They did not recognize any statistically significant "quiescent" or "doughnut" patterns in the preceding seismicity. They state, "in no case have we found any 'quiescence' (i.e., a rupture or study area in general that is seismically active and then becomes quiet) that can be qualitatively or quantitatively interpreted as significant and hence precursory to the main shock."

Several similarities to those of Pérez and Scholz were found in this paper but at the $\mathrm{Mw} \geq 5$ level including activity at the ends of rupture zones of mainshocks and the general distribution of aftershocks with respect to forerunning activity. Another similarity was that quiescence does not commence some time during the cycle of stress buildup to great earthquakes. The reason for this is that great asperities remain quiet during the long period of stress accumulation and then rupture suddenly in great and giant shocks. Differences found here were that forerunning activity occurred down and up dip as well as along strike. Prominent donut patterns of forerunning activity were found before some great earthquakes.

The rupture zone of the giant 1906 Ecuador-Colombia earthquake subsequently re-broke in large but not giant shocks in 1942, 1958 and 1979. The 2016 Ecuadorian earthquake of Mw 7.8 appears to have begun the next cycle of great shocks for the whole zone by re-rupturing the 1942 area (Figure 15). Most giant earthquakes-like 1952 Kamchatka [90], 1960 Chile [93], 1964 Alaska [94] and 2004 Sumatra-Andaman [95] - likely ruptured two or more great asperities. Each probably broke separately in moderate to great shocks at other times. This is a common pattern at subduction zones.

Earthquakes along several oceanic transform faults behaved in similar ways to those at subduction zones. Moderate-size shocks occurred and recurred along some segments of the Gofar transform fault at $4^{\circ} \mathrm{S}$ on the East Pacific Rise while other segments moved even without moderate-size earthquakes [96]. Some segments of the Eltanin transform fault system farther south were sites of repeating moderate-size earthquakes whereas other segments were poorly coupled for shocks of Mw > 5.5 [14] [97].

The Parkfield segment of the San Andreas Fault in central California is poorly coupled since it is known to have ruptured in earthquakes of only moderate size. It is the site of substantial fault creep and numerous small earthquakes. The adjacent main fault segments farther south and southeast, however, ruptured in the great earthquake of 1857. Several moderate-size events occurred in the general vicinity of Parkfield in the hours before the great 1857 shock [98]. Parkfield and vicinity could be a good place to seek forerunning activity to the next great shock farther south along the San Andreas Fault. The Parkfield zone is much like low-coupled zones along subduction zones.

The 1906 great earthquake in northern California was preceded by an unusual 
sequence of forerunning shocks of magnitude greater than 5 [99]. Most of them occurred off the San Andreas fault, the main fault that ruptured in 1906. Similar forerunning activity and accelerating seismic moment release took place with time prior to the 1868 Hayward, 1948 Desert Hot Springs and 1989 Loma Prieta earthquakes in California [99]. These patterns are like forerunning activity before many great earthquakes at subduction zones. Decadal forerunning activity to great strike-slip faults is described further in [8].

Cumulative seismic moment accelerated on time scales of about a decade before the 2011 Tohoku-oki and the 2014 Iquique earthquakes. Whether increase in moment was, in fact, casually related to the two coming earthquakes is uncertain. Aa firmer connection will require knowledge from additional great events. This paper examined mainly the distribution of forerunning activity with latitude and longitude, only a few instances of how it varied with time or depth. That is an area of obvious future research.

Several other types of possible precursors-increases in the frequency of small repeating earthquakes, slow slip events and changes in $b$ values-are described briefly along with descriptions of forerunning seismicity and great asperities. We need to understand if precursors of those types occur most often just before great and giant earthquakes.

All quiet zones and sites of forerunning activity in this paper were identified in hindsight. Is it possible to map similar distributions of forerunning activity ahead of time to better determine the slip regions of coming great and giant earthquakes and their magnitudes? This will not be easy since hundreds of quiet zones exist today for the subduction zones of the world. Observations and calculations could be used to narrow the search for those great events that are well advanced in time compared to their average repeat interval. Did those regions rupture previously in great or giant events; approximately what percentage of their rupture interval has already expired? For example, much of the 1964 rupture zone is presently quiet at the $\mathrm{Mw} \geq 5.0$ level, in accord with it consisting of two or more great asperities. Since displacements during 1964 were very large in those asperities, most of its rupture zone is very likely to be in the early stages of buildup of stresses to a giant event. Similarly, much of the 1960 Chilean rupture zone is not far advanced. An earthquake of Mw 7.6 in 2016 broke outside the 20 $\mathrm{m}$ but within the $5 \mathrm{~m}$ contour of the 1960 rupture zone (Figure 23). It obviously was not a repeat of the giant shock of 1960. Thus, earthquakes of Mw 7.5 to 8.0, but much smaller than those of 1960 and 1964, could well break smaller parts of the zones that ruptured in giant shocks of the last 100 years.

Changes in rates of aseismic deformation prior to several earthquakes are described in [100] [101]. For the days before the great 1944 and 1946 Nankaido earthquakes in Japan, geodetic observations and sea level changes have been interpreted as precursory slow slip at depths below those two rupture zones [102]. Slow slip at longer time scales occurred before the 2011 Tohoku-oki earthquake. Slow slip events of a variety of time scales are an important and exciting area of 
present study. Whether they can be used for intermediate-term and long-term predication is being assessed.

The work here on forerunning activity and identification of asperities of various sizes should be considered merely one aspect of earthquake prediction. The recent paper by [103] indicates strong new interest in the United States in monitoring and studying earthquake precursors. Forerunning activity also needs to be included as well as shorter-term precursors. We also need to know better where and when shorter-term precursors occur prior to very large events. I advocate moving from longer to short-term precursory studies.

Future work needs to include many subduction zones and transform faults worldwide instead of concentrating on just a single or a few areas, as happened in the United States decades ago with Parkfield. In addition to operating more local seismic networks, deployments of permanent GPS observations are needed for additional segments of subduction zones, including sites on the seafloor. Double-difference relocations need to be performed for forerunning shocks, including older earthquakes. Computer processing of seismic data to possibly identify forerunning and precursory activity could be done on a continuing basis using probabilistic approaches as new earthquakes occur.

\section{Acknowledgements}

I thank Göran Ekström, Bill Menke, Paul Richards and Chris Scholz for critical reading the manuscript; William Ryan, for advice on bathymetric data. Much of the data and calculations I used were collected and published by many authors-a very international effort.

\section{Conflicts of Interest}

The author declares no conflicts of interest regarding the publication of this paper.

\section{References}

[1] Mogi, K. (1962) Study of Elastic Shocks Caused by the Fracture of Inhomogeneous Materials and Its Relations to Earthquake Phenomena. Bulletin of the Earthquake Research Institute, 40, 125-173.

[2] Fedotov, S.A. (1965) Regularities of the Distribution of Strong Earthquakes in Kamchatka, the Kurile Islands and Northeastern Japan. Trudy Institute Fizika Zemli Akadimiki Nauk SSSR, 36, 66-93. (In Russian)

[3] Mogi, K. (1969) Relationship between the Occurrence of Great Earthquakes and Tectonic Structures. Bulletin of the Earthquake Research Institute, 47, 429.

[4] Sykes, L.R. (1971) Aftershock Zones of Great Earthquakes, Seismicity Gaps and Earthquake Prediction for Alaska and the Aleutians. Journal of Geophysical Research, 76, 8021-8041. https://doi.org/10.1029/JB076i032p08021

[5] Kelleher, J., Sykes, L. and Oliver, J. (1973) Possible Criteria for Predicting Earthquake Locations and Their Application to Major Plate Boundaries of the Pacific and the Caribbean. Journal of Geophysical Research, 80, 2547-2485. 
https://doi.org/10.1029/JB078i014p02547

[6] Pérez, O.J. and Scholz, C.H. (1997) Long-Term Seismic Behavior of the Focal and Adjacent Regions of Great Earthquakes during the Time between Two Successive Shocks. Journal of Geophysical Research, 102, 8203-8216. https://doi.org/10.1029/96JB02932

[7] Nishenko, S.P. (1985) Seismic Potential for Large and Great Interplate Earthquakes along the Chilean and Southern Peruvian Margins of South America: A Quantitative Reappraisal. Journal of Geophysical Research, 90, 3589-3615. https://doi.org/10.1029/JB090iB05p03589

[8] Sykes, L.R. (2021) Decadal Seismicity before Great Earthquakes-Strike-Slip Faults and Plate Interiors: Major Asperities and Low-Coupling Zones. International Journal of Geosciences. https://doi.org/10.4236/ijg.2021.129044

[9] Dziewonski, A.M., Chou, T.-A. and Woodhouse, J.H. (1981) Determination of Earthquake Source Parameters from Waveform Data for Studies of Global and Regional Seismicity. Journal of Geophysical Research, 86, 2825-2852. https://doi.org/10.1029/JB086iB04p02825

[10] Ekström, G., Nettles, M. and Dziewonski, A.M. (2012) The Global CMT Project 2004-2010: Centroid-Moment Tensors for 13,017 Earthquakes. Physics of the Earth and Planetary Interiors, 200-201, 1-9. https://doi.org/10.1016/j.pepi.2012.04.002

[11] Pacheco, J.F. and Sykes, L.R. (1992) Seismic Moment Catalog of Large, Shallow Earthquakes, 1900-1989. Bulletin of the Seismological Society of America, 82, 1306-1349. https://doi.org/10.1785/BSSA0820031306

[12] Haxby, W.F. and Ryan, W.B.F. (2019) GeoMapApp. http://www.geomapapp.org

[13] Ekström, G., Tromp, J. and Larson, E.W.F. (1997) Measurements and Global Models of Surface Wave Propagation. Journal of Geophysical Research, 102, 8137-8157. https://doi.org/10.1029/96JB03729

[14] Howe, M.J. (2019) Improving Estimates of Seismic Source Parameters Using Surface-Wave Observations: Applications to Earthquakes and Underground Nuclear Explosions. PhD, Columbia University, New York.

[15] Lay, T., Kanamori, H., Ammon, C.J., Koper, K.D., Hutko, A.R., Ye, L., Yue, H. and Rushing, T. (2012) Depth-Varying Rupture Properties of Subduction Zone Megathrusts Faults. Journal of Geophysical Research, 117, B04311. https://doi.org/10.1029/2011JB009133

[16] Scholz, C.H. (2019) The Mechanics of Earthquakes and Faulting. Third Edition, Cambridge University Press, Cambridge, 493 p.

[17] Yamanaka, Y. and Kikuchi, M. (2004) Asperity Map along the Subduction Zone in Northeastern Japan Inferred from Regional Seismic Data. Journal of Geophysical Research, 55, e21-e24. https://doi.org/10.1029/2003JB002683

[18] Satake, K., Hirata, K., Yamaki and Tanioka, Y. (2006) Re-Estimation of Tsunami Source of the 1952 Tokachioki Earthquake. Earth Planets Space, 58, 535-542. https://doi.org/10.1186/BF03351951

[19] Lay, T. and Rhode, A. (2019) Evaluating the Updip Extent of Large Megathrust Ruptures Using P Coda Levels. Geophysical Research Letters, 46, 1-21. https://doi.org/10.1029/2019GL082774

[20] Gusman, A.R., Murotani, S., Satake, K., Heidarzadeh, M., Gunawan, E., Watab, S. and Schurr, B. (2015) Fault Slip Distribution of the Iquique, Chile, Earthquake Estimated from Ocean-Wide Tsunami Waveforms and GPS Data. Geophysical Research Letters, 42, 1053-1060. https://doi.org/10.1002/2014GL062604 
[21] Hayes, G.P., Herman, M.W., Barhart, W.D., Furlong, K.P., Riquelme, S., Benz, H.M., Bergman, E., Barientos, S., Earle, P.S. and Samsonov, S. (2014) Continuing Megathrust Earthquake Potential in Chile after the 2014 Iquique Earthquake. Nature, 512, 295-298. https://doi.org/10.1038/nature13677

[22] Schurr, B., Moreno, M., Tréhu, A.M., Bedford, J., Kummerow, J., Li, S. and Oncken, O. (2020) Forming a Mogi Donut in the Years Prior to and Immediately before the 2014 M8, Chile, Earthquake. Geophysical Research Letters, 47, e2020GL088351. https://doi.org/10.1029/2020GL088351

[23] Mogi, K. (1969) Some Features of Recent Seismic Activity in and near Japan (2) Activity before and after Great Earthquakes. Bulletin of the Earthquake Research Institute, 47, 395-417.

[24] Socquet, A., Valdes, J.P., Jara, J., Cotton, F., Wallpersdorf, A., Cotte, N., Specht, S., Ortega-Culaciati, F., Carrizo, D. and Norabuena, E. (2017) An 8 Month Slow Slip Event Triggers Progressive Nucleation of the 2014 Megathrust. Geophysical Research Letters, 44, 4046-4053. https://doi.org/10.1002/2017GL073023

[25] Kato, A. and Nakagawa, S. (2014) Multiple Slow-Slip Events during a Foreshock Sequence of the 2014 Iquique, Chile Mw 8.1 Earthquake. Geophysical Research Letters, 41, 5420-5427. https://doi.org/10.1002/2014GL061138

[26] Ruiz, S., Metois, M., Fuenzalida, A., Ruiz, J., Leyton, F., Grandin, R., Vigny, C., Madariaga, R. and Campos, J. (2014) Intense Foreshocks and a Slow Slip Event Preceded the 2014 Iquique Mw 8.1 Earthquake. Science, 345, 1165-1169. https://doi.org/10.1126/science.1256074

[27] Aden-Antóniow, F., Satriano, C., Bernard, P., Poiata, N., Aissaoui, E.-M., Vilotte, J.-P. and Frank, W.B. (2020) Statistical Analysis of the Preparatory Phase of the Mw 8.1 Iquique Earthquake, Chile. Journal of Geophysical Research: Solid Earth, 125, e2019JB019337. https://doi.org/10.1029/2019JB019337

[28] Lay, T., Yue, H., Brodsky, E.E. and An, C. (2014) The 1 April 2014 Iquique, Chile, Mw 8.1 Earthquake. Geophysical Research Letters, 41, 3818-3825.

https://doi.org/10.1002/2014GL060238

[29] Schurr, B., Asch, G., Hainzl, S., Bedford, J., Hoechner, A., Palo, M., Wang, R., Moreno, M., Bartsch, M., Zhang, Y., Oncken, O., Tilmann, F., Dahm, T., Victor, P., Barrientos, S. and Vilotte, J.-P. (2014) Gradual Unlocking of Plate Boundary-Controlled Initiation of the 2014 Iquique Earthquake. Nature, 512, 299-302.

https://doi.org/10.1038/nature13681

[30] Moreno, M., Haberland, C., Oncken, O., Rietbrock, A., Angiboust, S. and Heidbach, O. (2014) Locking of the Chile Subduction Zone Controlled by Fluid Pressure before the 2010 Earthquake. Nature Geoscience, 7, 292-296.

https://doi.org/10.1038/ngeo2102

[31] Yue, H., Lay, T., Rivera, L., An, C., Vigny, C., Tong, X. and Soto, C.B. (2014) Localized Slip to the Trench in the 2010 Maule Chile $\mathrm{Mw}=8.8$ Earthquake from Joint Inversion of High-Rate GPS, Teleseismic Body Waves, InSar, Campaign GPS, and Tsunami Observations. Journal of Geophysical Research, 119, 7786-7804. https://doi.org/10.1002/2014JB011340

[32] Delouis, B., Nocquet, J.-M. and Vallée, M. (2010) Slip Distribution of the February 27, $2010 \mathrm{Mw}=8.8$ Maule Earthquake, Central Chile, from Static and High-Rate GPS, InSAR, and Broadband Teleseismic Data. Geophysical Research Letters, 37, L17305. https://doi.org/10.1029/2010GL043899

[33] Métois, M., Vigny, C. and Socquet, A. (2016) Interseismic Coupling, Megathrust Earthquakes and Seismic Swarms along the Chilean Subduction Zone $\left(38^{\circ}-18^{\circ} \mathrm{S}\right)$. 
Pure and Applied Geophysics, 173, 1431-1440. https://doi.org/10.1007/s00024-016-1280-5

[34] Cifuentes, I. (1989) The 1960 Chilean Earthquakes. Journal of Geophysical Research, 94, 665-680. https://doi.org/10.1029/JB094iB01p00665

[35] Olsen, K.M., Bangs, N.L., Tréhu, A.M., Han, S., Arnulf, A. and Contreras-Reyes, E. (2018) Thick, Strong Sediment Subduction off South-Central Chile and Its Role in Great Earthquakes. Abstract, American Geophysical Union, Washington DC.

[36] Satake, K., Fujii, Y., Harada, T. and Namegaya, Y. (2013) Time and Space Distribution of Coseismic Slip of the 2011 Tohoku Earthquake as Inferred from Tsunami Waveform Data. Bulletin of the Seismological Society of America, 103, 1473-1492. https://doi.org/10.1785/0120120122

[37] Ikuta, R., Satomura, M., Fujita, A., Shimada, S. and Ando, M. (2012) A Small Persistent Locked Area Associated with the 2011 Mw9.0 Tohoku-Oki Earthquake, Deduced from GPS Data. Journal of Geophysical Research, 117, B11408. https://doi.org/10.1029/2012JB009335

[38] Loveless, J.P. and Meade, B.J. (2015) Kinematic Barrier Constraints on the Magnitudes of Additional Great Earthquakes off the East Coast of Japan. Seismological Research Letters, 86, 202-209. https://doi.org/10.1785/0220140083

[39] Sato, M., Fujita, M., Matsumoto, Y., Ishikawa, T., Saito, H., Mochizuki, M. and Asada, A. (2013) Interplate Coupling off Northeastern Japan before the 2011 Tohoku-Oki Earthquake, Inferred from Seafloor Data. Journal of Geophysical Research, 118, 3860-3869. https://doi.org/10.1002/jgrb.50275

[40] Mavrommatis, A.P., Segall, P. and Johnson, K.M. (2014) A Decade Scale Deformation Transient Prior to the 2011 Mw 9.0 Tohoku-Oki Earthquake. Geophysical Research Letters, 41, 4486-4494. https://doi.org/10.1002/2014GL060139

[41] Ohtani, M., Hirahara, K., Hori, T. and Hyodo, M. (2014) Observed Change in Plate Coupling Close to the Rupture Initiation Area before the Occurrence of the 2011 Tohoku Earthquake: Implications from an Earthquake Cycle Model. Geophysical Research Letters, 41, 1899-1906. https://doi.org/10.1002/2013GL058751

[42] Yokota, Y. and Koketsu, K. (2015) A Very Long-Term Transient Event Preceding the 2011 Tohoku Earthquake. Nature Communications, 6, 1-5. https://doi.org/10.1038/ncomms6934

[43] Mavrommatis, A.P., Segall, P., Uchida, N. and Johnson, K.M. (2015) Long-Term Acceleration of Aseismic Slip Preceding the Mw 9 Tohoku-Oki Earthquake, Constraints from Repeating Earthquakes. Geophysical Research Letters, 42, 9717-9725. https://doi.org/10.1002/2015GL066069

[44] Nanjo, K.J., Hiata, N., Obara, K. and Kasahara, K. (2012) Decade-Scale Decrease in b Value Prior to the M9-Class 2011 Tohoku and 2004 Sumatra Quakes. Geophysical Research Letters, 39, L20304. https://doi.org/10.1029/2012GL052997

[45] Nishikawa, T., Matsuzawa, T., Ohta, K., Uchida, N., Nishimura, T. and Ide, S. (2019) The Slow Earthquake Spectrum in the Japan Trench Illuminated by the S-Net Seafloor Observatories. Science, 365, 808-813. https://doi.org/10.1126/science.aax5618

[46] Lay, T., Kanamori, H., Ammon, C.J., Hutko, A.R., Furlong, K. and Rivera, L. (2009) The 2006-2007 Kuril Islands Great Earthquake Sequence. Journal of Geophysical Research, 114, B11308. https://doi.org/10.1029/2008JB006280

[47] Takahashi, H. and Kasahara, M. (2007) Geodetic Constraint on the Slip Distribution of the 2006 Central Kuril Earthquake. Earth Planets Space, 59, 1095-1098. https://doi.org/10.1186/BF03352052 
[48] Steblov, G.M., Kogan, M.G., Levin, B.V., Vasilenko, N.F., Prytkov, A.S. and Frolov, D.I. (2008) Spatially Inked Asperities of the 2006-2007 Great Kuril Earthquakes Revealed by GPS. Geophysical Research Letters, 35, L22306. https://doi.org/10.1029/2008GL035572

[49] Fuji, Y. and Satake, K. (2008) Tsunami Sources of the November 2006 and January 2007 Great Kuril Earthquakes. Bulletin of the Seismological Society of America, 98, 1559-1571. https://doi.org/10.1785/0120070221

[50] Abercrombie, R.E., Antolik, M., Felzer, K. and Ekström, G. (2001) The 1994 Java Tsunami: Slip over a Subducting Seamount. Journal of Geophysical Research, 106, 6595-6607. https://doi.org/10.1029/2000JB900403

[51] Ammon, C.J., Kanamori, H., Lay, T. and Velasco, A.A. (2006) The 17 July 2006 Java Tsunami Earthquake. Geophysical Research Letters, 33, L24308. https://doi.org/10.1029/2006GL028005

[52] Fan, W., Bassett, D., Jiang, J., Shearer, P.M. and Chen, J. (2017) Rupture Evolution of the 2006 Java Tsunami Earthquake and Possible Role of Splay Faults. Tectonophysics, 721, 143-150. https://doi.org/10.1016/j.tecto.2017.10.003

[53] Scholz, C.H. and Small, C. (1997) The Effect of Seamount Subduction on Seismic Coupling. Geology, 25, 487-490. https://doi.org/10.1130/0091-7613(1997)025<0487:TEOSSO >2.3.CO;2

[54] Yue, H., Lay, T., Schwartz, S.Y., Rivera, L., Protti, M., Dixon, T.H., Owen, S. and Neuman, A.V. (2013) The 5 September Nicoya, Costa Rica Mw 7.6 Earthquake Rupture Process from Joint Inversion of High-Rate GPS, Strong-Motion, and Teleseismic $P$ Wave Data and Its Relationship to Adjacent Plate Boundary Interface Properties. Journal of Geophysical Research, 118, 5453-5466. https://doi.org/10.1002/jgrb.50379

[55] Kyriakopoulos, C. and Neuman, A.V. (2016) Structural Asperity Focusing Locking and Earthquake Slip along the Nicoya Megathrust, Costa Rica. Journal of Geophysical Research, 121, 5461-5476. https://doi.org/10.1002/2016JB012886

[56] Protti, M., González, V., Newman, A.V., Dixon, T.H., Schwartz, S.Y., Marshall, J.S., Feng, L., Walter, J.I., Malservisi, R. and Owen, S.E. (2014) Nicoya Earthquake Rupture Anticipated by Geodetic Measurement of the Locked Plate Interface. Nature Geoscience, 7, 10017-10121. https://doi.org/10.1038/ngeo2038

[57] Yoshimoto, M., Kumagai, H., Acero, W., Ponce, G., Vásconez, F., Arrais, S., Ruiz, M., Alvarado, A., Garcia, P.P., Dionicio, V., Chamorro, O., Maeda, Y. and Nakano, M. (2017) Depth-Dependent Rupture Mode along the Ecuador-Colombia Subduction Zone. Geophysical Research Letters, 109, B07307.

[58] Mothes, P.A., Rolandone, F., Nocquet, J.-M., Jarrin, P.A., Alvarado, A.P., Ruiz, M.C., Cisneros, D., Páez, H.M. and Segovia, M. (2018) Monitoring the Earthquake Cycle in the Northern Andes from the Ecuadorian cGPS Network. Seismological Research Letters, 89, 534-541. https://doi.org/10.1785/0220170243

[59] Collot, J.Y., Sanclemente, E., Nocquet, J.-M., Leprêtre, A., Ribodetti, A., Jarrin, P., Chlieh, M., Graindorge, D. and Charvis, P. (1917) Subducted Oceanic Relief Locks the Shallow Megathrust in Central Eduacdor. Geophysical Research Letters, 122, 3286-3305. https://doi.org/10.1002/2016JB013849

[60] Chlieh, M., Perfettini, H., Tavera, H., Avouac, J.-P., Remy, D., Nocquet, J.-M., Rolandone, F., Bondoux, F., Gabalda, G. and Bonvalot, S. (2011) Interseismic Coupling and Seismic Potential along the Central Andes Subduction Zone. Journal of Geophysical Research, 116, B12405. https://doi.org/10.1029/2010JB008166

[61] Chlieh, M., DeChaballier, J.B., Ruegg, J.C., Armijo, R., Dmowska, R., Campos, J. 
and Feigi, K.L. (2014) Crustal Deformation and Fault Slip during the Seismic Cycle in the North Chile Subduction Zone, from GPS and InSAR. Geophysical Journal International, 158, 695-711. https://doi.org/10.1111/j.1365-246X.2004.02326.x

[62] Pritchard, M.E. and Simons, M. (2006) An Aseismic Slip Pulse in Northern Chile and Along-Strike Variations in Seismogenic Behavior. Journal of Geophysical Research, 111, B08405. https://doi.org/10.1029/2006JB004258

[63] Ji, C. (2007) Preliminary Result of the Nov 14, 2007 Mw 7.81 ANTOFAGASTA, CHILE Earthquake. http://www.geol.ucsb.edu/faculty/ji/big_earthquakes/2007/11/anto/anto.html

[64] Li, L., Lay, T., Cheung, K.F. and Ye, L. (2016) Joint Modeling of Teleseismic and Tsunami Wave Observations to Constrain the 16 September 2015 Illapel, Chile Mw 8.3 Earthquake Rupture Process. Geophysical Research Letters, 43, 4302-4312. https://doi.org/10.1002/2016GL068674

[65] Barrientos, S.E. and Ward, S. (1990) The 1960 Chile Earthquake: Inversion for Slip Distribution from Surface Deformation. Geophysical Journal International, 103, 589-598. https://doi.org/10.1111/j.1365-246X.1990.tb05673.x

[66] Cifuentes, I. and Silver, P. (1989) Low-Frequency Source Characteristics of the Great Chilean Earthquake. Journal of Geophysical Research, 94, 643-663. https://doi.org/10.1029/JB094iB01p00643

[67] Chlieh, M., Avouac, J.-P., Hjorleifsdottir, V., Song, T.-R., Ji, C., Sieh, K., Sladen, A., Hebert, H., Prawirodirdjo, L., Bock, Y. and Galetzka, J. (2007) Coseismic Slip and Afterslip of the Great Mw 9.15 Sumatra-Andaman Earthquake of 2004. Bulletin of the Seismological Society of America, 97, S152-S173.

https://doi.org/10.1785/0120050631

[68] Shao, G. and Ji, C. (2005) Preliminary Result of the Mar 28, 2005 Mw 8.68 Nias Earthquake.

https://ji.faculty.geol.ucsb.edu/big_earthquakes/2005/03/smooth/nias.html

[69] Morgan, P.M., Feng, L., Qiu, Q., Melzner, A.J., Tsang, L.L. and Hill, E. (2015) The Diverse Slip Behavior of the Banyak Islands Section of the Sunda Megathrust Offshore Sumatra. American Geophysical Union, Fall Meeting 2015, San Francisco, December 2015, Abstract ID T21D-2858.

[70] Hayes, G.P. (2010) Mw 7.8 Sumatra Earthquake of 6 April 2010. U.S. Geological Survey, Unpublished Document, $1 \mathrm{p}$.

[71] Feng, L., Hill, E.M., Banerjee, R., Hermawan, I., Tsang, L.H., Natawidjaja, D.H., Suwargadi, B.W. and Sieh, K. (2015) A Unified GPS-Based Earthquake Catalog for the Sumatran Plate Boundary between 2002 and 2013. Journal of Geophysical Research, 120, 3566-3598. https://doi.org/10.1002/2014JB011661

[72] Konca, A.O., Avouac, J.-P., Sladen, A., Meltzner, A.J., Sieh, K., Fang, P., Li, Z., Galetzka, J., Genrich, J., Chlieh, M., Natawidjaja, D.H., Bock, Y., Fielding, E.J., Ji, C. and Helmberger, D.V. (2008) Partial Rupture of a Locked Patch of the Sumatra Megathrust during the 2007 Earthquake Sequence, Nature, 456, 632-635.

https://doi.org/10.1038/nature07572

[73] Lentas, K., Ferreira, A.M.G. and Vallée, M. (2013) Assessment of SCARDEC Source Parameters of Global Large ( $\mathrm{Mw}>7.5)$ Subduction Earthquakes. Geophysical Journal International, 195, 1989-2004. https://doi.org/10.1093/gji/ggt364

[74] Lay, T., Ammon, C.J., Kanamori, H., Yamazaki, Y., Cheung, K.F. and Hutko, A.R. (2011) The 25 October2010 Mentawai Tsunami Earthquake (Mw7.8) and the Tsunami Hazard Presented by Shallow Megathrust Ruptures. Geophysical Research Letters, 38, L06302. https://doi.org/10.1029/2010GL046552 
[75] Das, S. and Henry, C. (2003) Spatial Relation between Main Earthquake Slip and Its Aftershock Distribution. Reviews of Geophysics, 41, 1013-1036. https://doi.org/10.1029/2002RG000119

[76] Furlong, K.P., Lay, T. and Ammon, C.J. (2009) A Great Earthquake Rupture across a Rapidly Evolving Three-Plate Boundary. Science, 324, 226-229.

https://doi.org/10.1126/science.1167476

[77] Lay, T., Ye, L., Kanamori, H., Yamazaki, Y., Cheung, K.F. and Ammon, C.J. (2013) The February 6, $2013 \mathrm{Mw}$ 8.0 Santa Cruz Islands Earthquake and Tsunami. Tectonophysics, 608, 1109-1121. https://doi.org/10.1016/j.tecto.2013.07.001

[78] Zhang, Y., Chen, Y.-T. and Xu, L. (2012) Fast and Robust Inversion of Earthquake Source Rupture Process and Its Application to Earthquake Emergency Response. Earthquake Science, 121, 121-128. https://doi.org/10.1007/s11589-012-0838-2

[79] Kikuchi, M. and Kanamori, H. (1995) The Shikotan Earthquake of October 4, 1994: Lithospheric Earthquake. Geophysical Research Letters, 22, 1025-1028. https://doi.org/10.1029/95GL00883

[80] Tanioka, Y., Ruff, L. and Satake, K. (1995) The Great Kurile Earthquake of October 4, 1994 Tore the Slab. Geophysical Research Letters, 22, 1661-1664. https://doi.org/10.1029/95GL01656

[81] Harada, T. and Ishibashi, K. (2007) Two Parallel Trench-Normal Planes within the Pacific Slab Associated with the 1994 and 2000 Kurile Earthquakes as Revealed by Simultaneous Relocation of Their Main Shocks and Aftershocks. Earth Planets Space, 59, e25-228. https://doi.org/10.1186/BF03352025

[82] Schwartz, S. (1999) Noncharacteristic Behavior and Complex Recurrence of Large Subduction Zone Earthquakes. Journal of Geophysical Research, 104, 23111-23125. https://doi.org/10.1029/1999JB900226

[83] Wetzler, N., Lay, T., Brodsky, E.E. and Kanamori, H. (2018) Supplementary Material for Systematic Deficiency of Aftershocks in Areas of High Coseismic Slip for Large Subduction Zone Earthquakes. Science Advances, 4. https://doi.org/10.1126/sciadv.aao3225

[84] Tanioka, Y. and Gonzalez, F.I. (1998) The Aleutian Earthquake of June 10, 1996 (Mw 7.9) Ruptured Parts of Both the Andrdeanof and Delarof Segments. Geophysical Research Letters, 25, 2245-2248. https://doi.org/10.1029/98GL01578

[85] Cross, R.S. and Freymueller, J.T. (2006) Plate Coupling Variation and Block Translation in the Andreanof Segment of the Aleutian Arc Determined by Subduction Zone Modeling Using GPS Data. Geophysical Research Letters, 34, L06304. https://doi.org/10.1029/2006GL028970

[86] Boyd, T.M. and Nábêlek, J.L. (1988) Rupture Process of the Andreanof Islands Earthquake of May 7, 1986, Bulletin of the Seismological Society of America, 78, 1653-1673.

[87] Johnson, J.M., Tanioka, Y., Ruff, L.J., Satake, K., Kanamori, H. and Sykes, L.R. (1994) The 1957 Great Aleutian Earthquake. PAGEOPH, 142, 3-28. https://doi.org/10.1007/BF00875966

[88] Bürgmann, R., Kogan, M.G., Levin, V.E., Scholz, C.H., King, R.W. and Steblov, G.M. (2001) Rapid Aseismic Moment Release Following the 5 December 1997 Kronotsky, Kamchatka, Earthquake. Geophysical Research Letters, 28, 1331-1334. https://doi.org/10.1029/2000GL012350

[89] Bürgmann, R.M., Kogan, M.G., Steblov, G.M., Hilley, G., Levin, V.E. and Apel, T. (2005) Interseismic Coupling and Asperity Distribution along the Kamchatka Subduction Zone. Journal of Geophysical Research, 110, B07405. 
https://doi.org/10.1029/2005JB003648

[90] Johnson, J.M. and Satake, K. (1999) Asperity Distribution of the 1952 Great Kamchatka Earthquake and Its Relation to Future Earthquake Potential in Kamchatka. Pure and Applied Geophysics, 154, 541-553. https://doi.org/10.1007/978-3-0348-8679-6_8

[91] Zobin, V.M. and Levina, V.I. (2001) The Rupture Process of the Mw 7.8 Cape Kronotsky, Kamchatka, Earthquake of 5 December 1997 and Its Relationship to Foreshocks and Aftershocks. Bulletin of the Seismological Society of America, 91, 1619-1628. https://doi.org/10.1785/0119990116

[92] Sulelimani, E. and Freymueller, J.T. (2020) Near-Field Modeling of the 1964 Alaska Tsunami: The Role of Splay Faults and Horizontal Displacements. Journal of Geophysical Research, 125, e2020JB019620. https://doi.org/10.1029/2020JB019620

[93] Ho, T.-C., Sataki, K., Watada, S. and Fujii, Y. (2019) Source Estimate for the 1960 Chile Earthquake from Joint Inversion of Geodetic and Transoceanic Tsunami Data. Journal of Geophysical Research, 124, 2812-2828. https://doi.org/10.1029/2018JB016996

[94] Christensen, D.H. and Beck, S.L. (1994) The Rupture Process and Tectonic Implications of the Great 1964 Prince William Sound Earthquake. Pageoph, 142, 29-53. https://doi.org/10.1007/BF00875967

[95] Bletery, Q., Sladen, A., Jiang, J. and Simons, M. (2016) A Bayesian Source Model for the 2004 Great Sumatra-Andaman Earthquake. Journal of Geophysical Research, 121, 5116-5135. https://doi.org/10.1002/2016JB012911

[96] Froment, B., McGuire, J.J., van der Hilst, R.D., Gouédard, P., Roland, E.C., Zhang, H. and Collins, J.A. (2014) Imaging Along-Strike Variations in Mechanical Properties of the Gofar Transform Fault, East Pacific Rise. Journal of Geophysical Research, 119, 7175-7194. https://doi.org/10.1002/2014JB011270

[97] Sykes, L.R. and Ekström, G. (2012) Earthquakes along Eltanin Transform System, SE Pacific Ocean: Fault Segments Characterized by Strong and Poor Seismic Coupling and Implications for Long-Term Earthquake Prediction. Geophysical Journal International, 188, 421-434. https://doi.org/10.1111/j.1365-246X.2011.05284.x

[98] Sieh, K. (1978) Central California Foreshocks of the Great 1857 Earthquake. Bulletin of the Seismological Society of America, 68, 1731-1749.

[99] Sykes, L.R. and Jaumé, S. (1990) Seismic Activity on Neighboring Faults as a Long-Term Precursor to Large Earthquakes in the San Francisco Bay Area. Nature, 348, 595-599. https://doi.org/10.1038/348595a0

[100] Roeloffs, E.A. (2006) Evidence for Aseismic Deformation Rate Changes Prior to Earthquakes. Annual Review of Earth and Planetary Sciences, 34, 591-627. https://doi.org/10.1146/annurev.earth.34.031405.124947

[101] Bürgmann, R. (2018) The Geophysics, Geology and Mechanics of Slow Fault Slip. Earth and Planetary Science Letters, 495, 112-134. https://doi.org/10.1016/j.epsl.2018.04.062

[102] Sacks, I.S., Suyehiro, S. and Linde, A.T. (1978) Slow Earthquakes and Stress Distribution. Nature, 275, 599-602. https://doi.org/10.1038/275599a0

[103] Pritchard, M.E., et al. (2020) New Opportunities to Study Earthquake Precursors. Seismological Research Letters, 91, 2444-2447. https://doi.org/10.1785/0220200089 


\section{Supplement}

\section{Introduction}

This section contains information on some of the smaller great earthquakes studied, those with no or poor information on the zones of high displacements and those for which no or little forerunning activity occurred.

\section{Poorly Coupled Subduction Zones}

\subsection{Lesser Sunda Islands, Indonesia}

Few thrust events of $\mathrm{Mw} \geq 5.5$ and no known shocks of $\mathrm{Mw} \geq 7.7$ occurred in Figure S1 along this subduction zone. One exception is where the continental margin of Australia is impinging on the subduction zone between $119^{\circ}$ and $120^{\circ} \mathrm{E}$ where thrust shocks as large as Mw 6.5 occurred. Most earthquakes in the figure involved either strike-slip mechanisms along the inner wall of the subduction zone, thrust faulting along planes dipping to the south near the islands or normal faulting near the trench. This contrasts with the greater numbers of thrust events shown earlier along well-coupled subduction interfaces. Normal-faulting shocks were relatively common near the trench including one in 1977 of Mw 8.3 (large open blue circle in Figure S1). It generated a large tsunami and was located far to the east of the two large Javanese earthquakes of 1994 and 2006 in the main paper.

In summary, most of the Lesser Sunda islands were devoid of forerunning thrust activity just to the north of the trench. That part of the plate boundary appears to be poorly coupled as is that south of Java to the west. Many thrust events of moderate size occurred to the north of the island chain along faults that dip southerly. As Australia has converged with the Indonesian subduction zone, plate motion has jumped to the north side of the Sunda islands.

\subsection{Mariana Islands, Thrust Earthquake of 1993 Near Guam, Mw 7.7}

This was one of the smaller earthquakes examined. The Mariana subduction zone and its extension farther north along the Volcano, Izu and Bonin island arc are considered by most geoscientists to be poorly coupled. Seafloor (back arc) spreading occurs behind the subduction zone. Only two shocks in the Marianas of Mw > 7.0 are known between 1976 and 2018 and one between 1916 and 1976. The subduction zone farther north has a similar paucity of events of those magnitudes except at its northernmost end near the Izu Peninsula of Japan. The Marianas have experienced a number of shocks of $\mathrm{Mw}<6.0$ (not shown).

The largest known shallow earthquake ( $\mathrm{Mw} 7.7)$ in the southern Marianas occurred in 1993. It likely was an intraplate thrust event at a depth of $74 \mathrm{~km}$ in the downgoing Pacific plate, not an earthquake along the plate interface [1]. Forerunning shocks of $\mathrm{Mw} \geq 5.5$ between 1976 and its occurrence in 1993 were very few and most had strike-slip mechanisms (Figure S2). Only two possible 


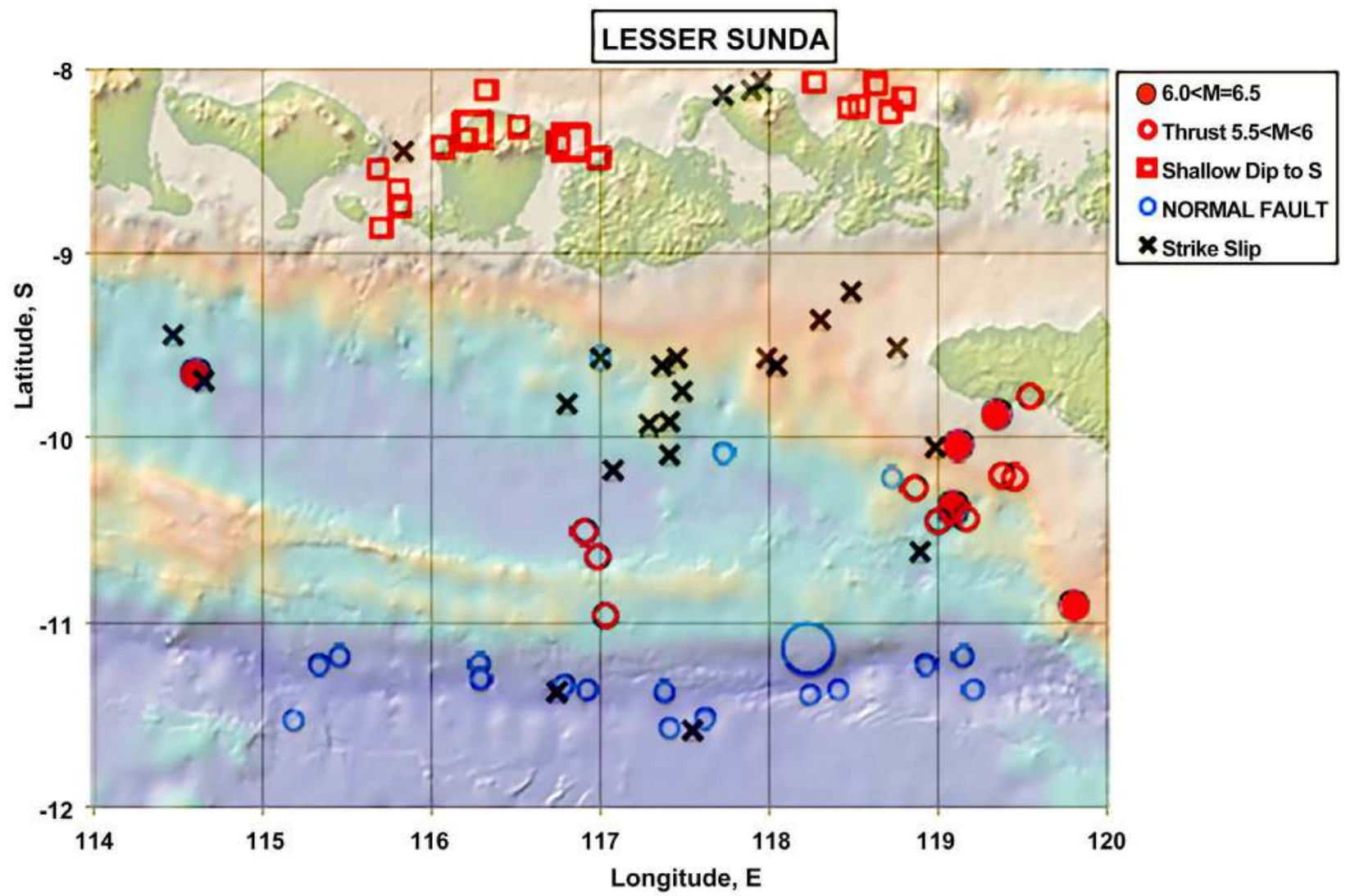

Figure S1. Locations of earthquakes near the Lesser Sunda Islands of Indonesia of Mw $\geq 5.5$ from 1977 through February 2019. Colors depict sizes and mechanisms of earthquakes.

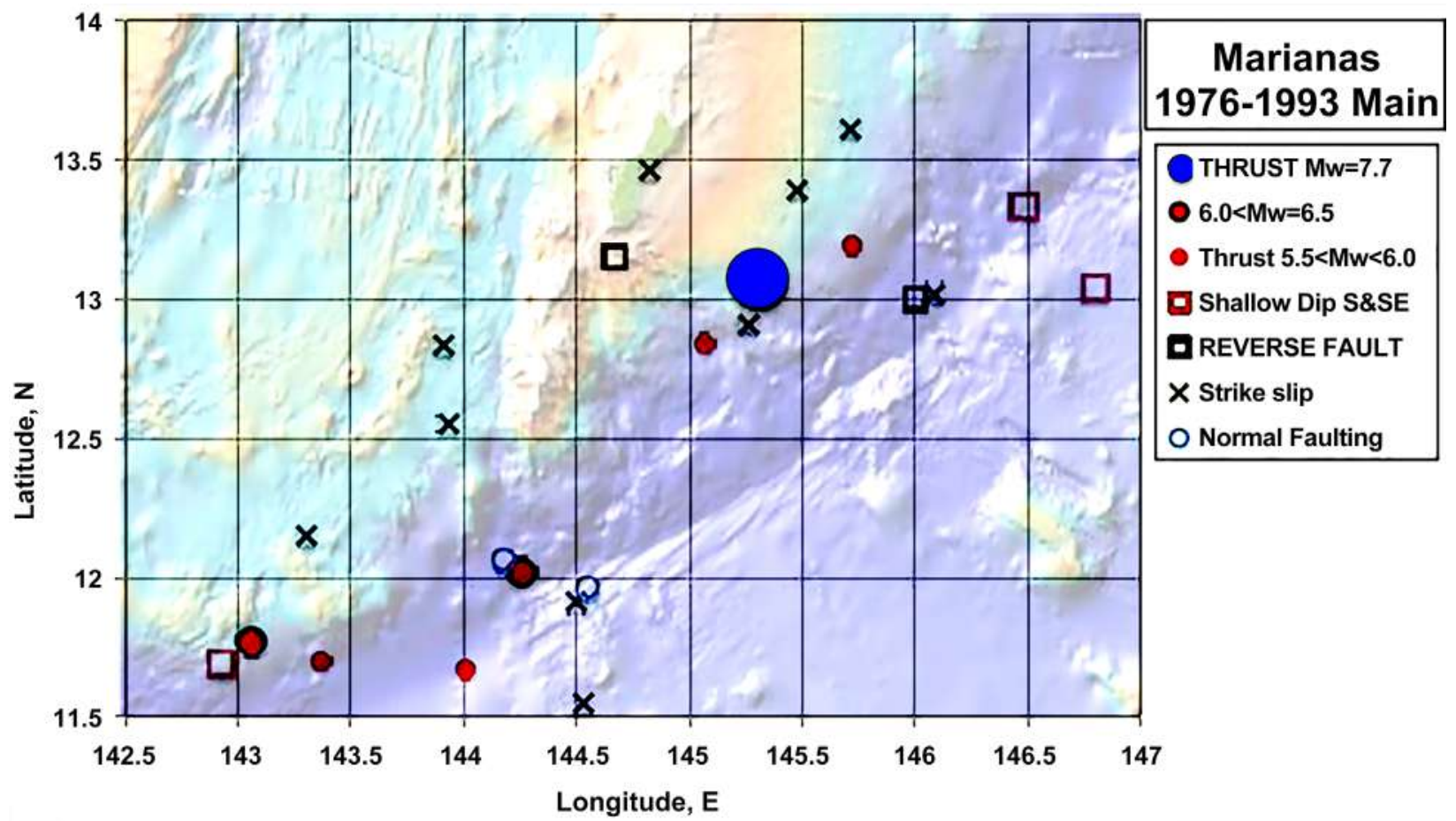

Figure S2. Earthquakes in the southern Mariana Islands of $\mathrm{Mw} \geq 5.5$ from 1976 until the mainshock of 1993 (large blue circle). Colors denote sizes and mechanisms of earthquakes. 
forerunning thrust events, each of Mw 5.5, took place within $150 \mathrm{~km}$ of the 1993 mainshock. A pattern of forerunning activity cannot be identified unless strike-slip mechanisms are included. The data reinforce the idea that the Mariana subduction zone is either mostly or entirely decoupled. To my knowledge a finite-fault computation has not been published.

In summary, the great thrust earthquake of 1993 appears to have occurred within the downgoing plate, not along the plate interface. Most, if not all, of the subduction zone along the southern Marianas is poorly coupled

\subsection{An Unusual Thrust-Faulting Earthquake Beneath Tonga in 2006, Mw 8.0}

The Tonga-Kermadec plate boundary also is taken by most geoscientists to be poorly coupled. While thrust earthquakes as large as Mw 6.5 have occurred historically, few great thrust events are known. The number of earthquakes along the entire Tonga arc falls off rapidly as Mw increases (Figure S3). That activity also drops off dramatically with depth (not shown). This supports the hypothesis of poor coupling for most of the shallow plate boundary. Several asperities likely exist that are large enough to break in events of $\mathrm{Mw}<6.5$.

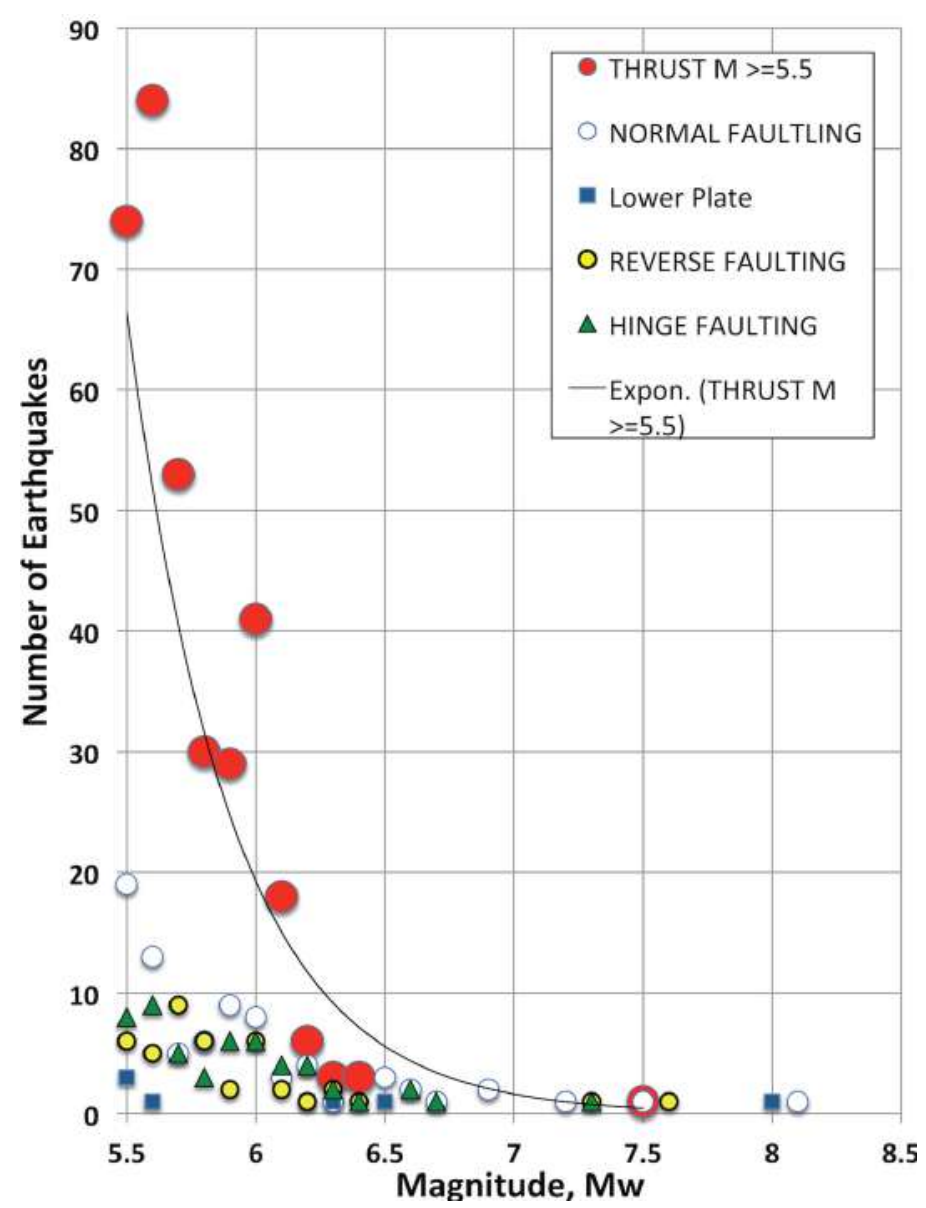

Figure S3. Number of Tongan earthquakes per 0.1 unit of magnitude Mw from 1977 through 2018. 
Most thrust events in the centroid catalog are confined to the upper $20 \mathrm{~km}$, which makes the thrust-faulting mainshock of 2006 unusual since its reported long-period (centroid) depth was $69 \mathrm{~km}$. Meng et al. reanalyzed long-period $\mathrm{P}$ and surface waves and concluded the mainshock occurred at a similar depth [2]. They analyzed data from regional seismic stations in Tonga and several GPSobservation points along the island chain. They deployed additional local stations after the mainshock. They concluded that the 2006 mainshock occurred within the downgoing Pacific plate 30 to $40 \mathrm{~km}$ below the plate boundary. The locations of many of their aftershocks, however, were located above it close to the plate boundary. Their analysis of an Mw 7.6 earthquake farther south in Tonga near $23^{\circ} \mathrm{S}$ in 2009 indicates it too occurred within the downgoing plate. Its mechanism, unlike that for the 2006 event, involved reverse faulting with a steeper dip.

Meng et al. [2] performed a joint inversion of the slip distribution for the 2006 event. Since their computed zone of high slip extended outward only about 25 $\mathrm{km}$, it was too small to compare it with locations of possible forerunning activity. Many long-period GCMT locations for thrust events appear to be biased at least $25 \mathrm{~km}$ to the east since they fall beyond the deepest part of the trench. The centroid location of the 2006 mainshock was located beneath the plate boundary but only $25 \mathrm{~km}$ from the deepest part of the trench. Those GCMT locations were likely biased too far east since they did not take into account sufficiently the spreading center of very of low velocity to the west of the Tongan arc in the Lau basin.

In summary, the 2006 earthquake ruptured within the downgoing Pacific plate at a depth of about $65 \mathrm{~km}$ and not along the plate boundary. It may have been like the great Kuril shock of 1994 described in the main body of the paper.

The Kermadec subduction zone extends from the southern end of the Tongan arc at $26^{\circ} \mathrm{S}$ to northern New Zealand near $36^{\circ} \mathrm{S}$. Its largest thrust earthquake from 1976 through 2018 was of Mw 7.9. The three largest events from 1916 to 1976 were of Mw 7.8 to 8.1. Shallow shocks of Mw > 7.0 since 1976 all occurred along just a part of the plate boundary between $28.7^{\circ}$ and $30.6^{\circ} \mathrm{S}$. Since most of them took place soon after the start of the GCMT catalog in 1976, forerunning activity could not be calculated for them using that catalog.

\section{Well-Coupled Subduction Zones with Complicated or Poorer Data}

\subsection{Jalisco, Mexico 1995, Mw 8.0}

The 1995 mainshock of Mw 8.0 occurred along the Mexican subduction zone near a plate triple junction. The Cocos plate and the small Rivera plate underthrust the North American plate along the rupture zone of the 1995 earthquake. Only two forerunning events and a number of aftershocks with thrust mechanisms can be seen in Figure S4. Strike-slip activity, most of it after the mainshock, occurred just to the southwest along the Revilla Gigedo transform fault system. 


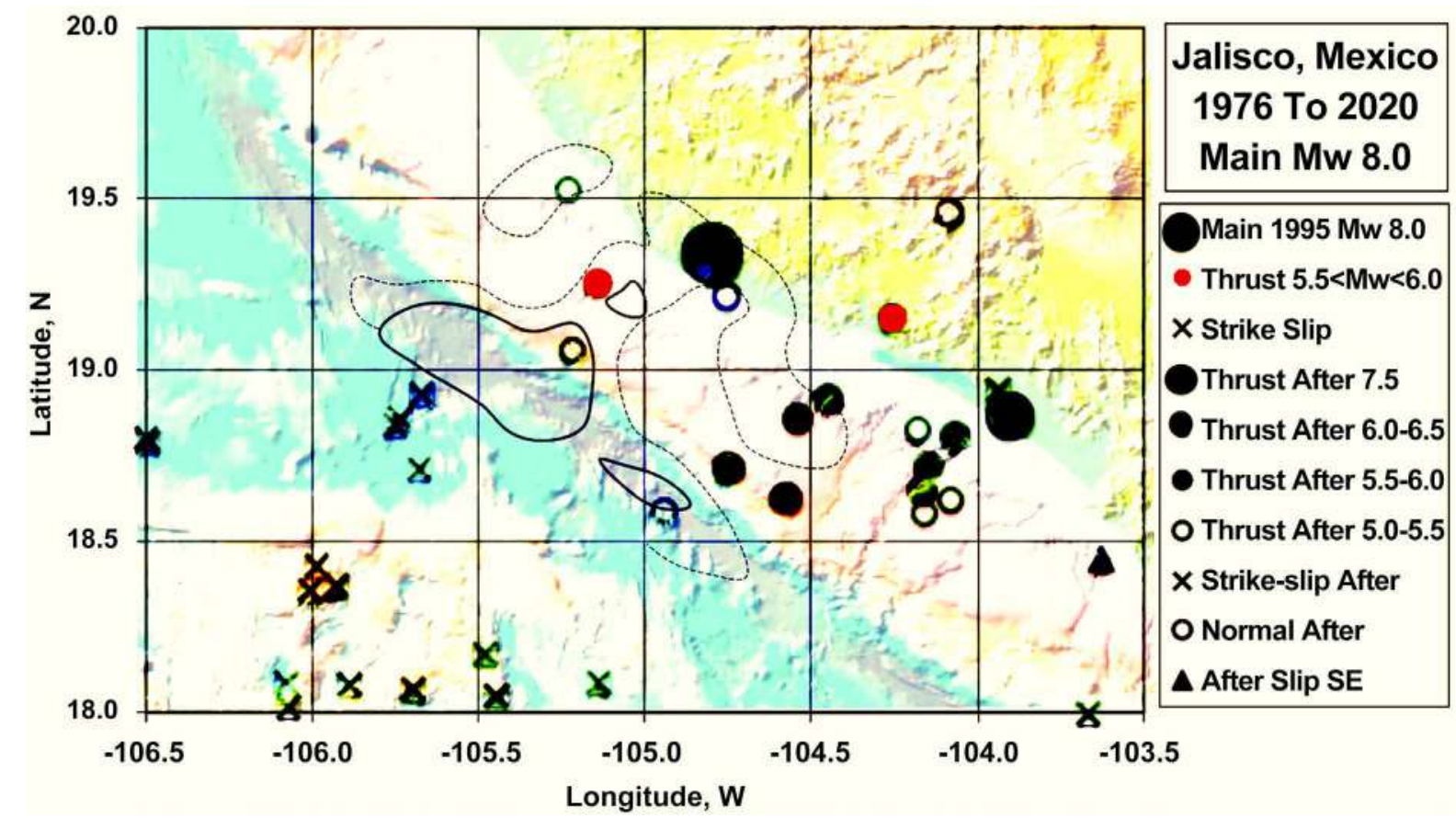

Figure S4. Locations of earthquakes off Jalisco, Mexico of Mw $\geq 5.0$ from 1976 through the mainshock of 1995 of Mw 8.0 (large blue-black circle). Heavy and dashed lines indicate computed displacements of 2 and $1 \mathrm{~m} \mathrm{[3].}$

In summary, the near lack of forerunning thrust activity is difficult to compare with the zones of high computed slip for this region of tectonic complexity.

\subsection{Minahassa Peninsula of Sulawesi Island Earthquake of 1996, Mw 7.9}

The 1996 mainshock of Mw 7.9 occurred along the northern peninsula of the Indonesian island of Sulawesi. The rocks of the peninsula consist of a major ophiolite complex. The thrust-fault mechanism of the mainshock and those of its aftershocks were situated at the western end of a subduction zone to the north and northwest of the peninsula. Its westernmost end abuts a major transform fault that strikes southerly. The mainshock (Figure S5) consisted of a simple pulse [4].

In summary, the centroid of the mainshock is situated inside the estimated high-slip area. That area is identified as a major asperity that broke in the mainshock. It was located at the intersection of thrust and transform plate boundaries. Most forerunning activity was located more than $50 \mathrm{~km}$ from the small high-slip area.

\subsection{Irian Jaya, Indnesian Earthquake of 2009, Mw 7.7}

The 2009 Irian Jaya shock of Mw 7.66 was one of the smallest earthquakes examined. It occurred near the northwest coast of New Guinea along the Manokwari trench. The computed slip contour in Figure S6 of $3 \mathrm{~m}$, about half of the maximum, is quite small. A single shock of $\mathrm{Mw} 5$ can be seen within that contour. The $1 \mathrm{~m}$ contour (not shown) extended about as far west as the aftershocks 


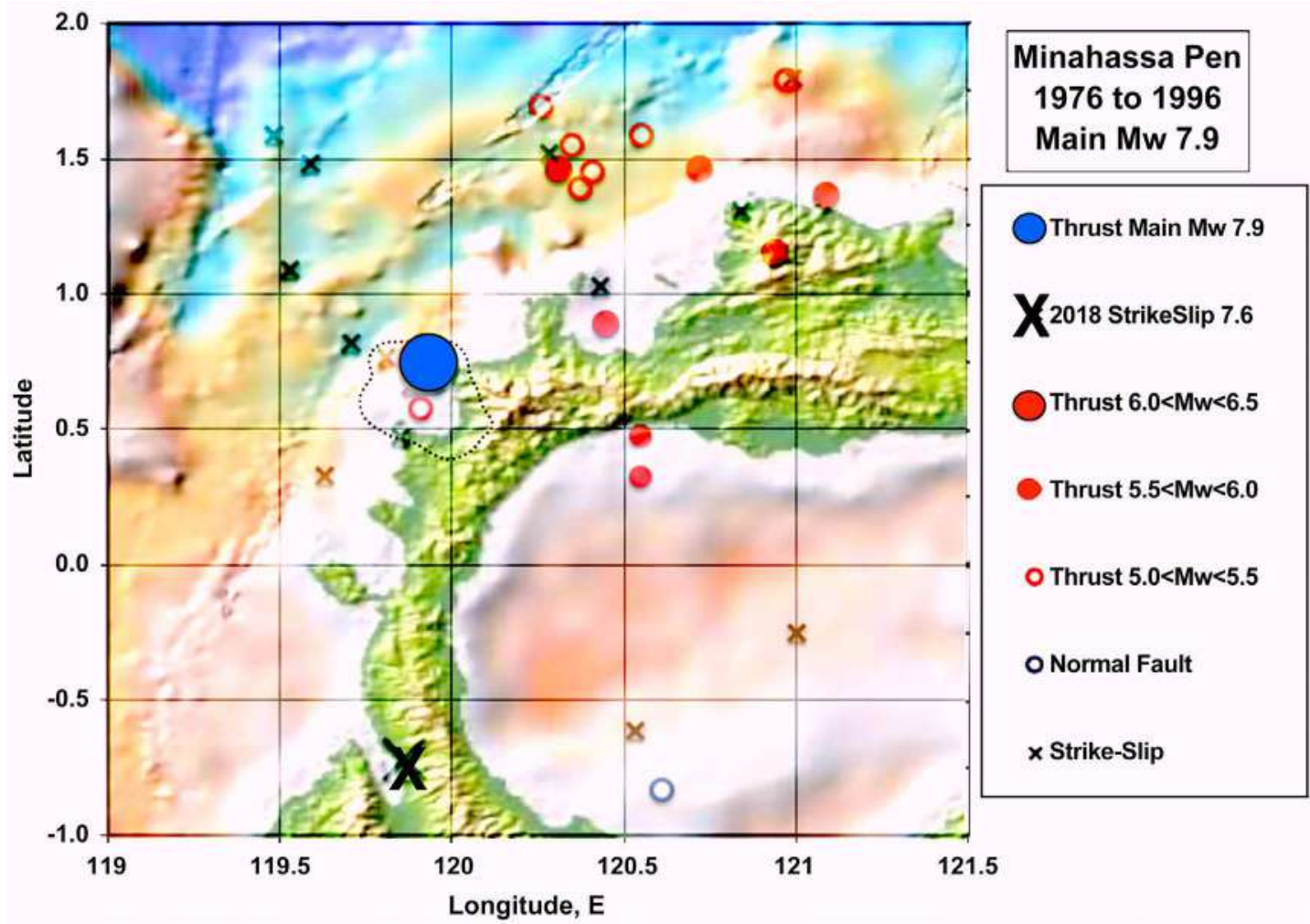

Figure S5. Locations of earthquakes of Mw > 5.0 from 1976 until mainshock of 1996 of Mw 7.9 near the Minahassa Peninsula of Sulawesi, Indonesia. Large blue circle denotes centroid of mainshock. Dotted line encloses $85 \%$ of the area of computed slip [5].

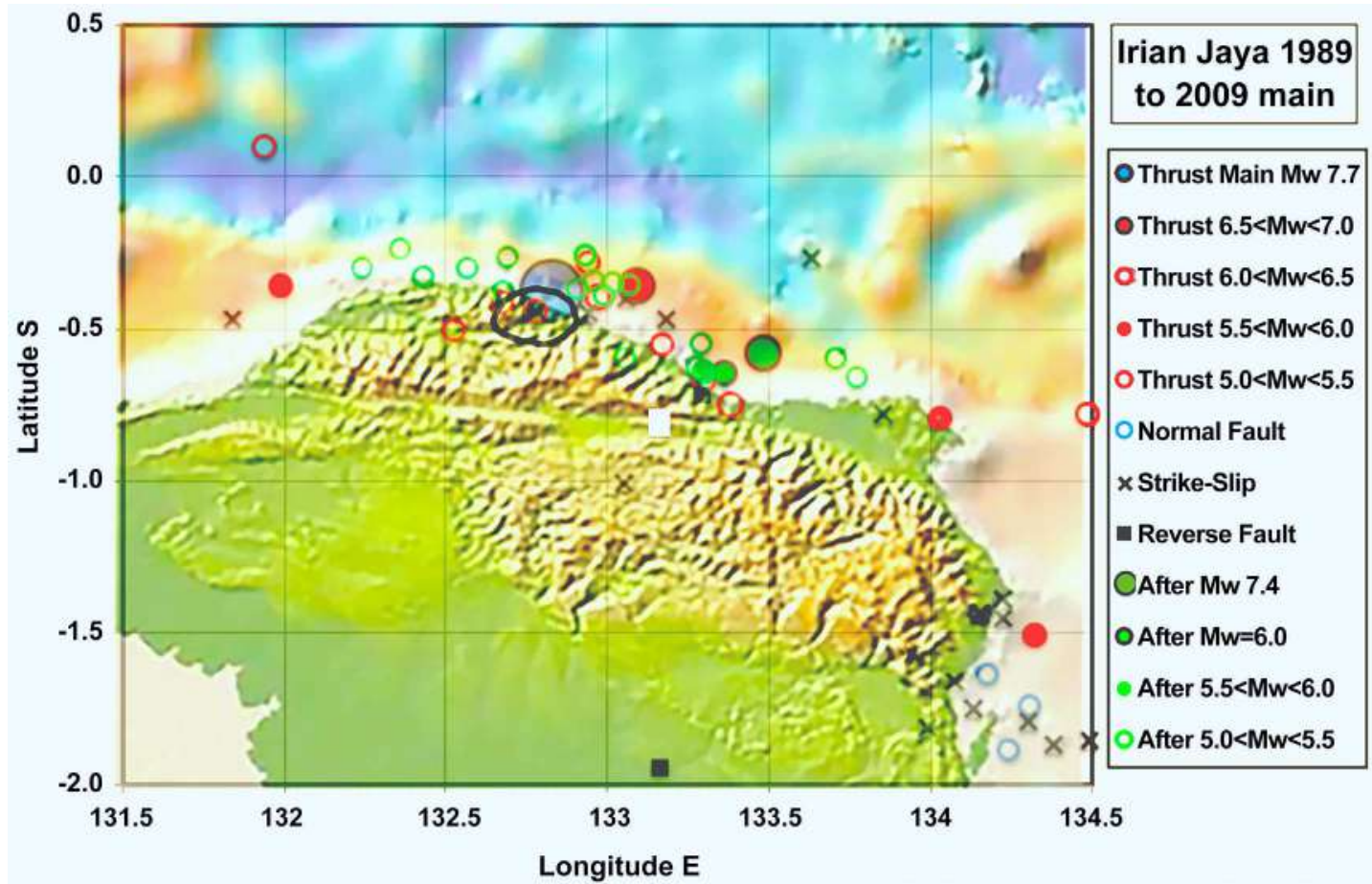

Figure S6. Locations of earthquakes near Irian Jaya, Indonesia of Mw > 5.0 from 1989 until mainshock of Mw 7.7 of 2009. Large blue circle denotes centroid of mainshock. Black oval encloses computed displacement of 3 $\mathrm{m}$ and larger from [6]. 
shown in the figure and about as far east as the large aftershock of Mw 7.4. The mainshock consisted of a relatively simple source pulse [6].

In summary, the 3-meter slip contour, which extended about $40 \mathrm{~km}$ along strike, may define a relatively small asperity that ruptured in the mainshock. The number of forerunning shocks was small; uncertainties in their locations may well be sizable with respect to the dimensions of the $3 \mathrm{~m}$ slip contour.

\subsection{Triple Junction Near New Ireland, New Britain and Bouganville-Papua New Guinea-Three Great Earthquakes of 2000, Mw 7.8 and 8.0}

An unusual sequence of three great earthquakes occurred in and near New Ireland within 40 hours in 2000. The first of Mw 8.0, a strike-slip event (blue X in Figure S7), ruptured the Weitin-Kamdaru fault, which crosses New Ireland with a strike of NNW [7]. The two shocks of Mw 7.8 (large blue circles) were thrust events along the shallow-dipping, ENE-striking New Britain subduction zone. A major plate triple junction is present just to the south of the more eastern $\mathrm{Mw}$ 7.8 shock. The strike-slip event broke the surface of the Weitin-Kamdaru fault about $15 \mathrm{~km}$ west its computed centroid. The fault then broke farther to the northwest in 2019.

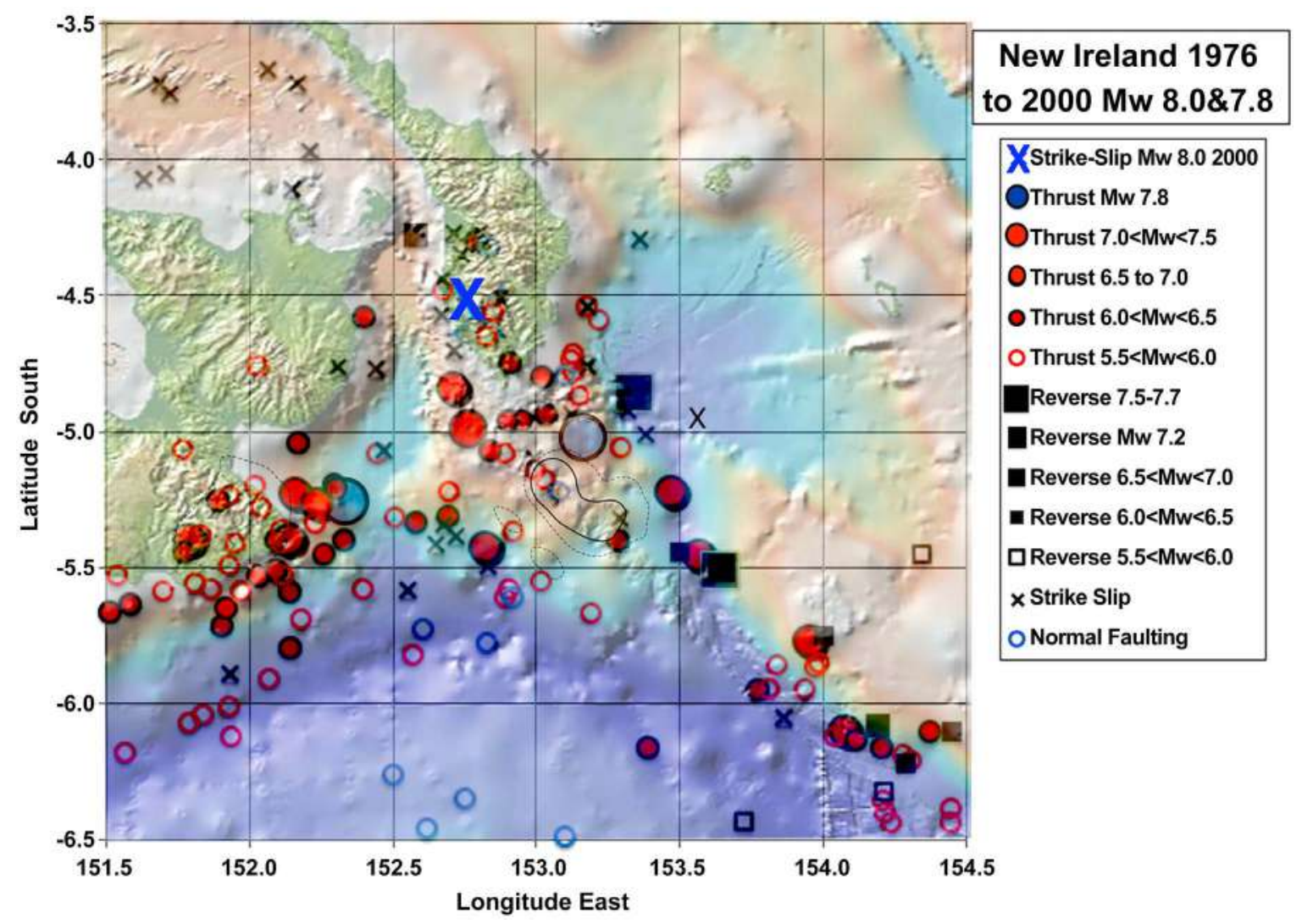

Figure S7. Locations of earthquakes near the plate triple junction south of New Ireland and east of New Britain. The first of three mainshocks on November 16 and 17 of Mw 8.0 involved strike slip faulting (large blue $\mathbf{X}$ ). The next two mechanisms were thrust faulting of $\mathrm{Mw} 7.8$ (two large blue circles). Computed displacements during the two thrust events of Mw 7.8 of 3 and $1 \mathrm{~m}$ are shown in solid and small dashed black lines [8]. 
Park and Mori [8] modelled displacements during the Mw 8.0 event. They concluded that left-lateral, strike-slip motion first occurred within the island of New Ireland transitioning to a thrust component farther southeast. This helps to understand why the overall centroid mechanism indicated slip on a fault dipping $43^{\circ}$ NE. Park and Mori obtained a steeper dip and a larger Mw of 8.2. They find it ruptured as far southeast as the first Mw 7.8 shock [8].

I show estimated displacements for the two largest thrust events, which are relatively small. Park and Mori [8] obtained Mw 7.5 and 7.4, smaller than the two GCMT values of 7.8. The centroids of the latter are located outside the maximum slip zones of Park and Mori. Forerunning thrust activity surrounds the centroid of the eastern thrust event of $\mathrm{Mw}$ 7.8. Only one thrust foreshock occurred within the $3 \mathrm{~m}$ slip zone, suggesting that mainshock may have occurred within a major asperity. Many forerunning thrust shocks occurred, however, within the $1 \mathrm{~m}$ slip zone of the second $\mathrm{Mw} 7.8$ event. Its centroid lies outside that calculated high slip zone.

In summary, the two largest thrust events of 2000 occurred in a complex three-plate tectonic setting. It is difficult to reconcile the locations of forerunning activity with the small size of their calculated zones of maximum slip. The latter do not agree with the two centroids, suggesting one of them is incorrect. Uncertainties in the locations of the centroids of thrust events of Mw 5.5 to 7.5 may be comparable to the sizes of the slip zones of the two largest thrust earthquakes.

\subsection{New Ireland-Bouganville Earthquake of 2016, Mw 7.9}

The 2016 shock along the Solomon subduction zone occurred about halfway between New Ireland and Bougainville and to the southeast of the three great earthquakes of 2000 (Figure S7). It was a reverse-faulting mechanism with a centroid depth of $53 \mathrm{~km}$. Initial slip, however, began about $100 \mathrm{~km}$ to the north-north west at a depth of about $105 \mathrm{~km}$ (Bulletin of International Seismological Centre). Lay et al. [9] modelled the initial $30 \mathrm{~s}$ of rupture as occurring over depths of 90 to $120 \mathrm{~km}$ on a fault dipping to the southwest. They conclude It was then followed by $50 \mathrm{~s}$ of rupture along the plate interface from depths of 32 to $47 \mathrm{~km}$. Their calculated slip contours for the shallower half of their solution, solid and black lines in Figure S8, are situated well to the east of the centroid. They place deeper slip (not shown in Figure S8) as extending farther north than that shallower.

In summary, the contours of maximum slip on the plate boundary by [9] are located well to the east of the centroid of the mainshock. What asperities ruptured in the mainshock are uncertain.

\subsection{Santa Cruz Earthquakes 2009, Mw 7.6 and 7.8}

In summary, the calculated slip contours are about $35 \mathrm{~km}$ from the centroid of the 7.6 mainshock, making it difficult to determine the location of an asperity 
that ruptured during it. Thrust forerunning activities surrounding both the $\mathrm{Mw}$ 7.6 and 7.8 centroids better define the two asperities broke in the mainshocks (Figure S9).

\subsection{Vanuatu Earthquake of 1997, Mw 7.69}

The 1997 mainshock in the northernmost Vanuatu islands of Mw 7.69 was among the smallest earthquakes examined. Its centroid is situated along the inner wall of the Vanuatu (New Hebrides) trench (Figure S10). It caused a moderate-sized tsunami [11]. No forerunning activity occurred within the 50\% slip contour. Most forerunning thrust and reverse activity was situated more than $25 \mathrm{~km}$ from the centroid. The centroid of the mainshock is located trenchward than most of the calculated high slip.

In summary, forerunning seismic activity was situated on three sides of the centroid of the mainshock and what is taken as a large asperity about $50 \mathrm{~km}$ along strike that ruptured in the mainshock. The centroid, however, is located seaward (trenchward) of the estimated large slip contours.

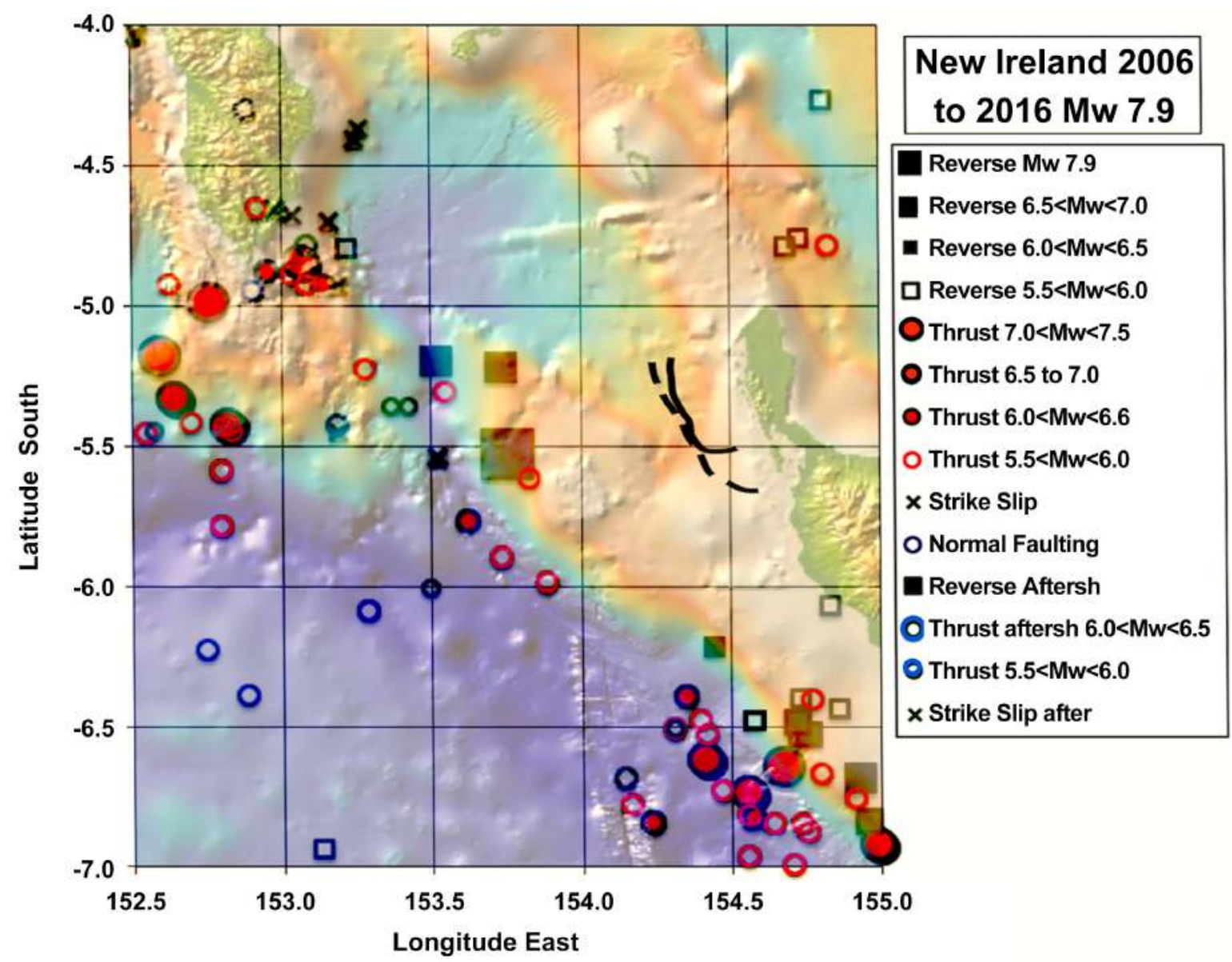

Figure S8. Locations of earthquakes of Mw $\geq 5.5$ south of New Ireland and west of Bougainville from 2006 until 2016 mainshock of Mw 7.9; aftershocks are also shown. Large black square indicates centroid of mainshock with its reverse-faulting mechanism. Black solid and dashed lines denote estimated maximum displacements of 2 and $1 \mathrm{~m}$ from [9]. 


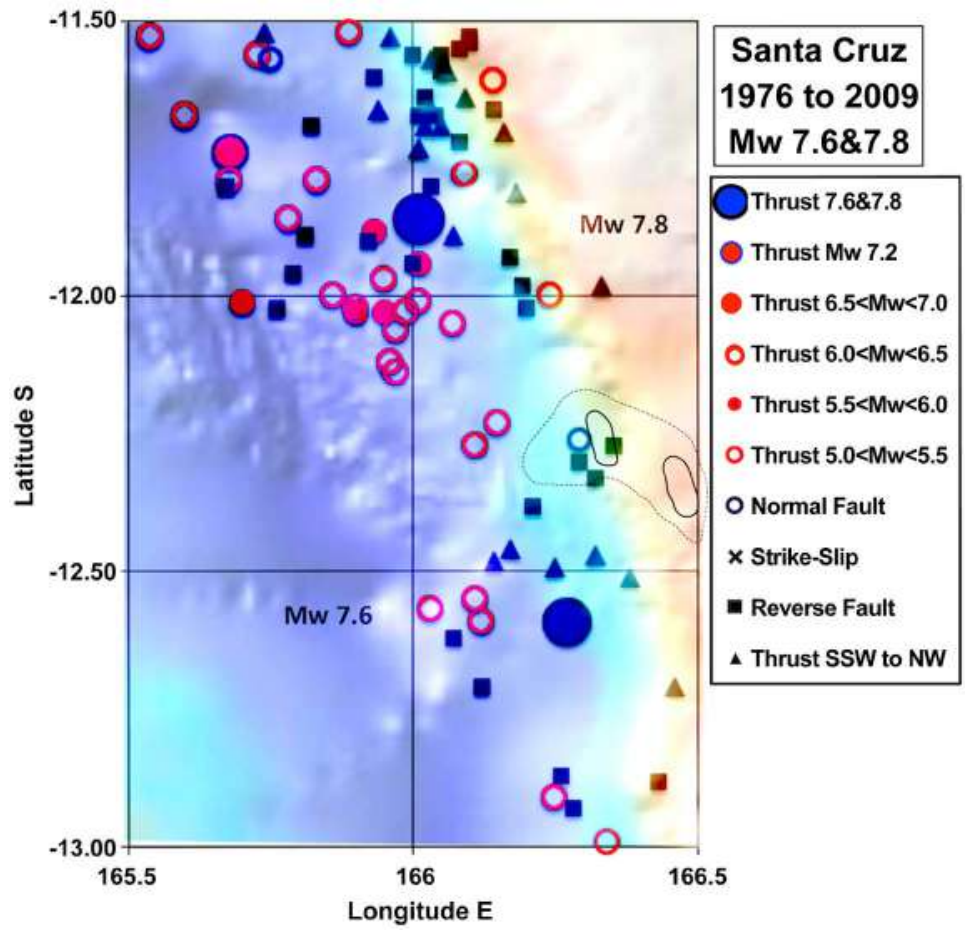

Figure S9. Locations of earthquakes in the Santa Cruz Islands of the southwest Pacific of Mw $\geq$ 5.0 from 1976 through two 2009 mainshocks of Mw 7.6 and 7.8 (large blue circles). The Mw 7.8 shock occurred 15 minutes after the Mw 7.6. Hence, detailed slip in the Mw 7.8 was not be modelled. Solid and dashed lines denote estimated slip contours of 4 and $1.5 \mathrm{~m}$ after [10] for the Mw 7.6 shock, one of the smallest mainshocks examined.

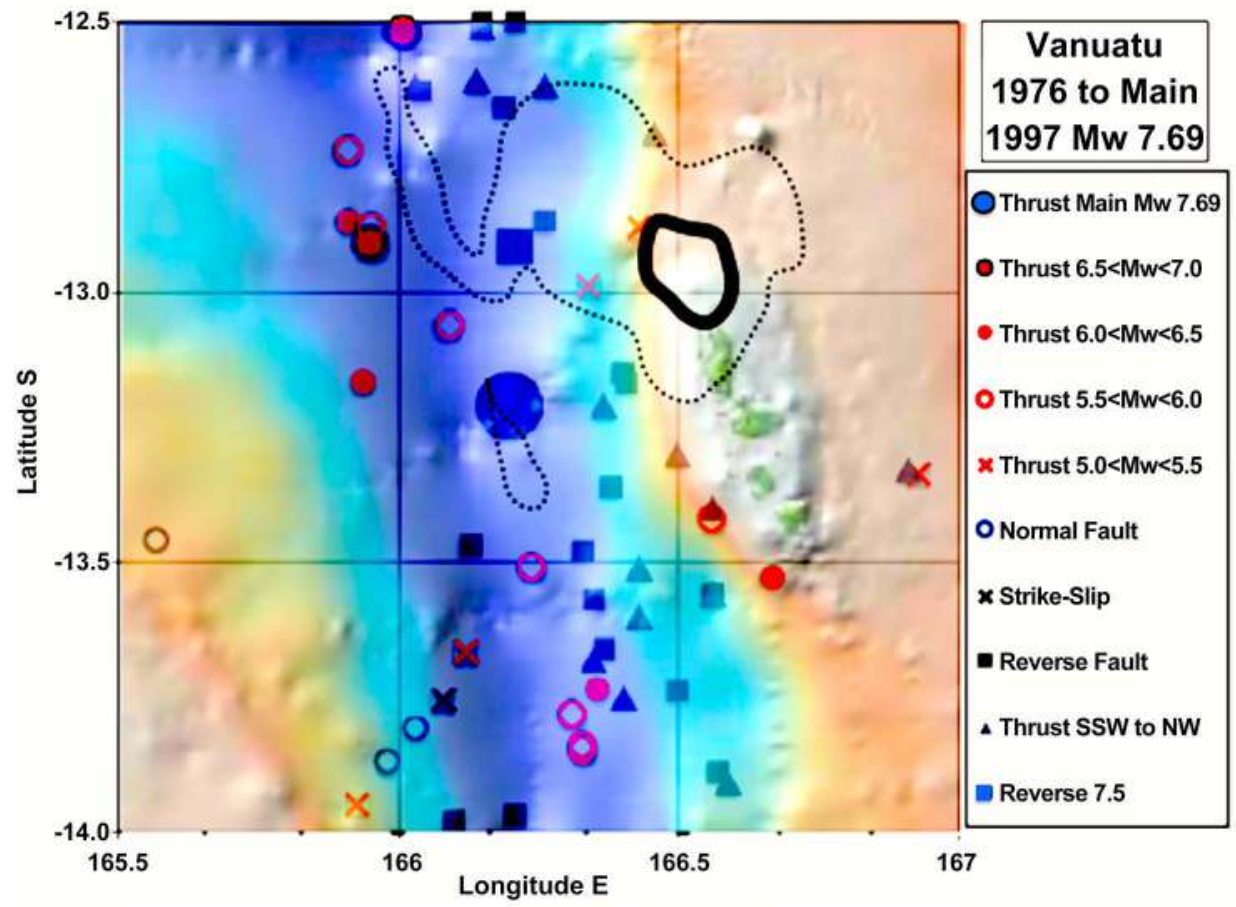

Figure S10. Locations of earthquakes in the Vanuatu islands of the southwest Pacific of Mw $\geq$ 5.0 from 1976 through the 1997 mainshock of Mw 7.69 (large blue circle). Solid and dashed lines are contours enclosing 50 and $85 \%$ of the estimated slip areas in the mainshock from [5]. 


\subsection{North Honshu Offshore Earthquake of 1994, Mw 7.73}

The 1994 earthquake of Mw 7.73 occurred off the east coast of Honshu, Japan between the rupture zones of the great 1968 shock to the north and the giant 2011 Tohoku event to the south. The 1994 event was one of the smaller earthquakes studied; its maximum slip zone of (only $0.5 \mathrm{~m}$ in Figure S11) extended about $75 \mathrm{~km}$ along strike and $35 \mathrm{~km}$ down dip. Possible uncertainties in the locations of nearby forerunning events may be a non-negligible fraction of those dimensions. Most forerunning activity occurred farther along strike of the plate boundary and the centroid. Aftershocks through 1998 (not shown) took place largely outside the $0.5 \mathrm{~m}$ slip contour.

In summary, the $0.5 \mathrm{~m}$ slip contour contains the centroid of the mainshock. The large asperity that broke in the mainshock was surrounded by decadal forerunning activity. It includes the centroid and may extend somewhat farther northwest than the calculated slip contour.

\subsection{Earthquake off the West Coast of Hokkaido Japan in 1993, Mw 7.7}

The 1993 Japanese earthquake was one of the smaller events examined. It occurred off the west coast of the northern island of Hokkaido along a plate boundary with a very slow rate of long-term slip, especially when compared to that

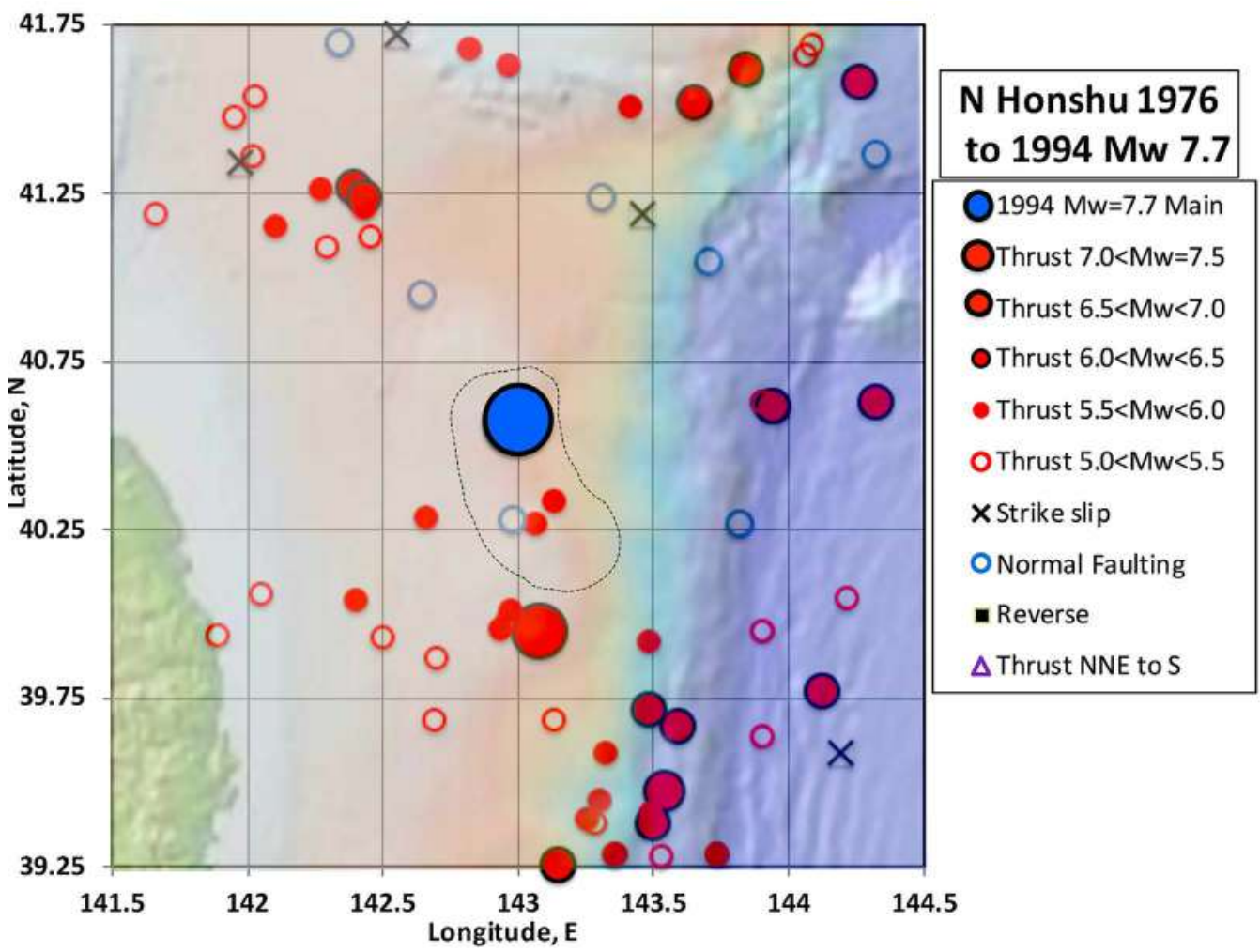

Figure S11. Earthquakes of M > 5.0 from 1976 until the mainshock of 1994 (large blue circle) off the coast of northern Honshu, Japan of Mw 7.7. Dotted line encloses area of calculated displacement greater than $0.5 \mathrm{~m}$ from [12]. 
for the east coast of Honshu. This slow rate likely accounts for the lack of forerunning thrust activity and only three forerunning reverse-thrusting events in the 18 years before the mainshock (Figure S12). Several aftershocks surrounded the centroid of the mainshock at distances of 30 to $75 \mathrm{~km}$. Kato and Tsuji [13] computed two areas of large displacements (not shown) from tsunami arrival times and some geodetic data that extended from $42.95^{\circ} \mathrm{N}$ to the north of the centroid to $41.8^{\circ} \mathrm{N}$ to its south.

In summary, the centroid of the mainshock was centered inside the region of maximum computed slip. Aftershocks and the few forerunning events occurred outside that region. The mainshock likely took place within a large, poorly defined asperity along a plate boundary characterized by slow long-term motion.

\subsection{Earthquake off the Eastern Shumagin Islands, Alaska in 2020, Mw 7.8}

Forerunning activity to the Shumagin Islands mainshock (Figure S13) was mainly distributed either southwest or about $80 \mathrm{~km}$ to the northeast of both the centroid of the mainshock and the estimated zone of slip larger than $1.2 \mathrm{~m}$. The computed slip zone (Figure S13 and Figure S14) was relatively small. Rupture in the mainshock (small blue circle in Figure S14) initiated about $50 \mathrm{~km}$ ENE of the centroid.

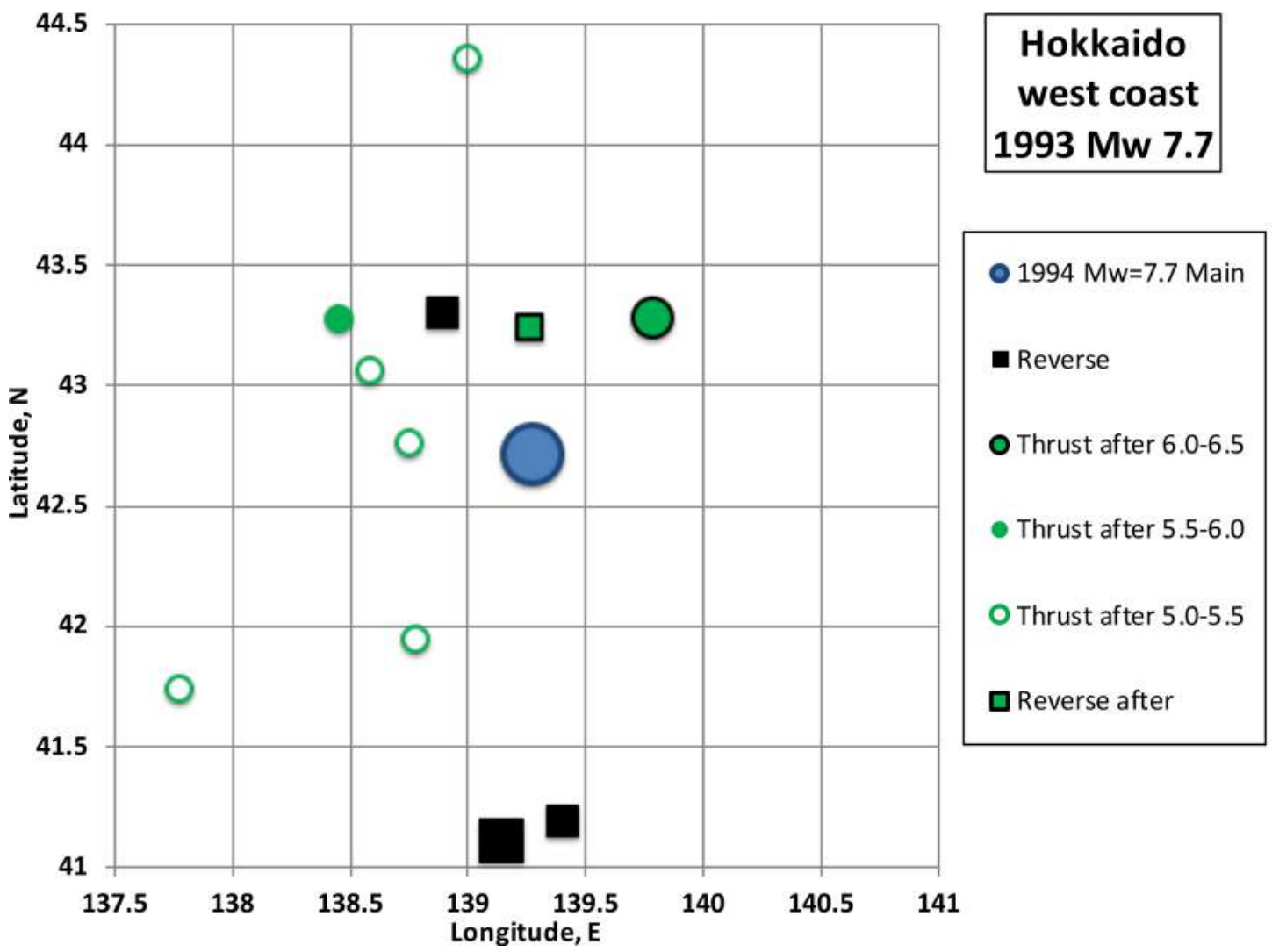

Figure S12. Forerunning activity from 1976 until mainshock off west coast of Hokkaido, Japan of 1993 (large blue circle). 


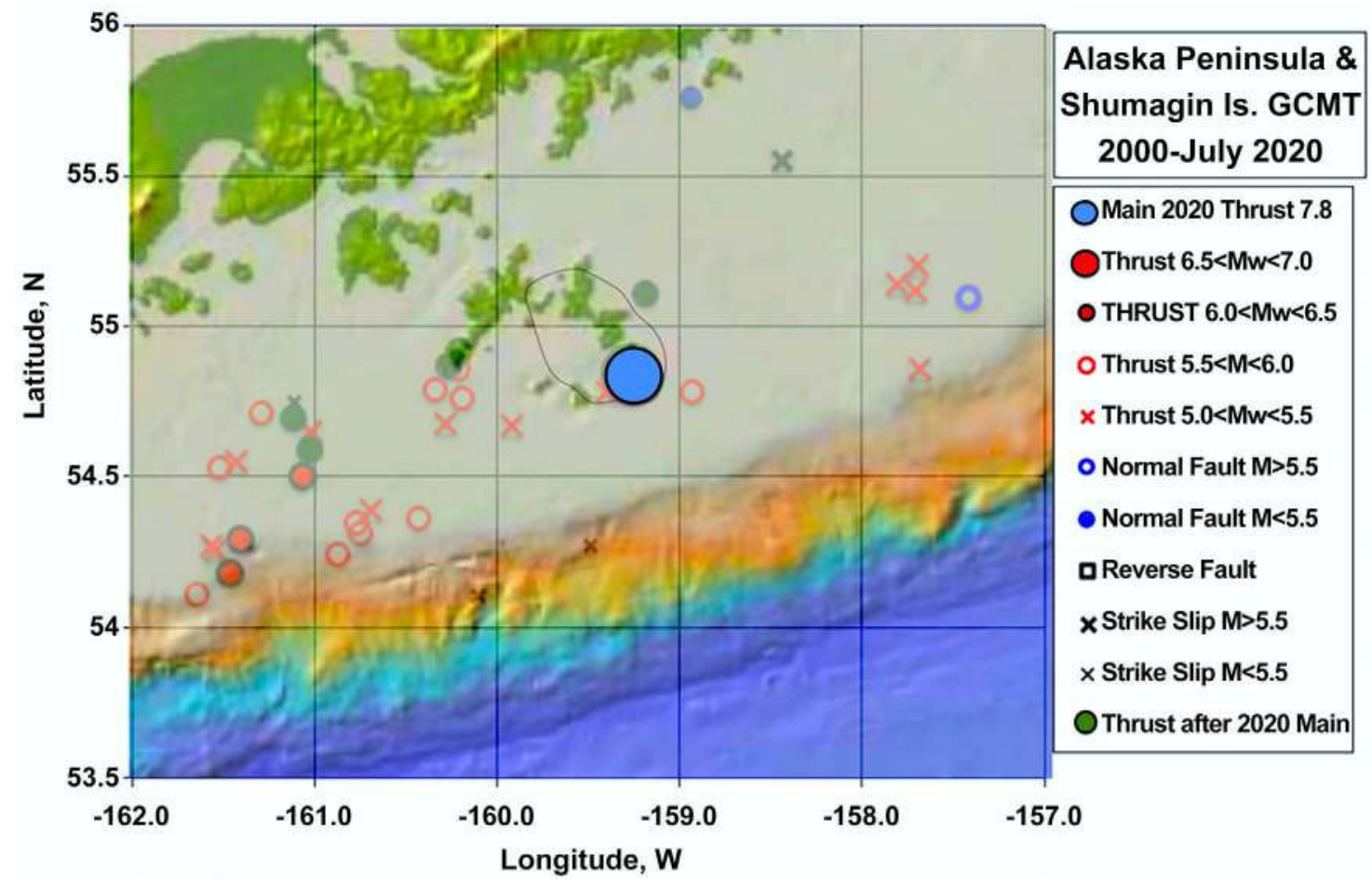

Figure S13. Forerunning events of Mw > 5.0 from 2000 until Shumagin Islands earthquake of July 22, 2020. Large blue circle denotes mainshock. Aftershocks shown through 20 October 2020. Black oval denotes estimated zone of slip greater than $1.2 \mathrm{~m}$ during July mainshock from [17].

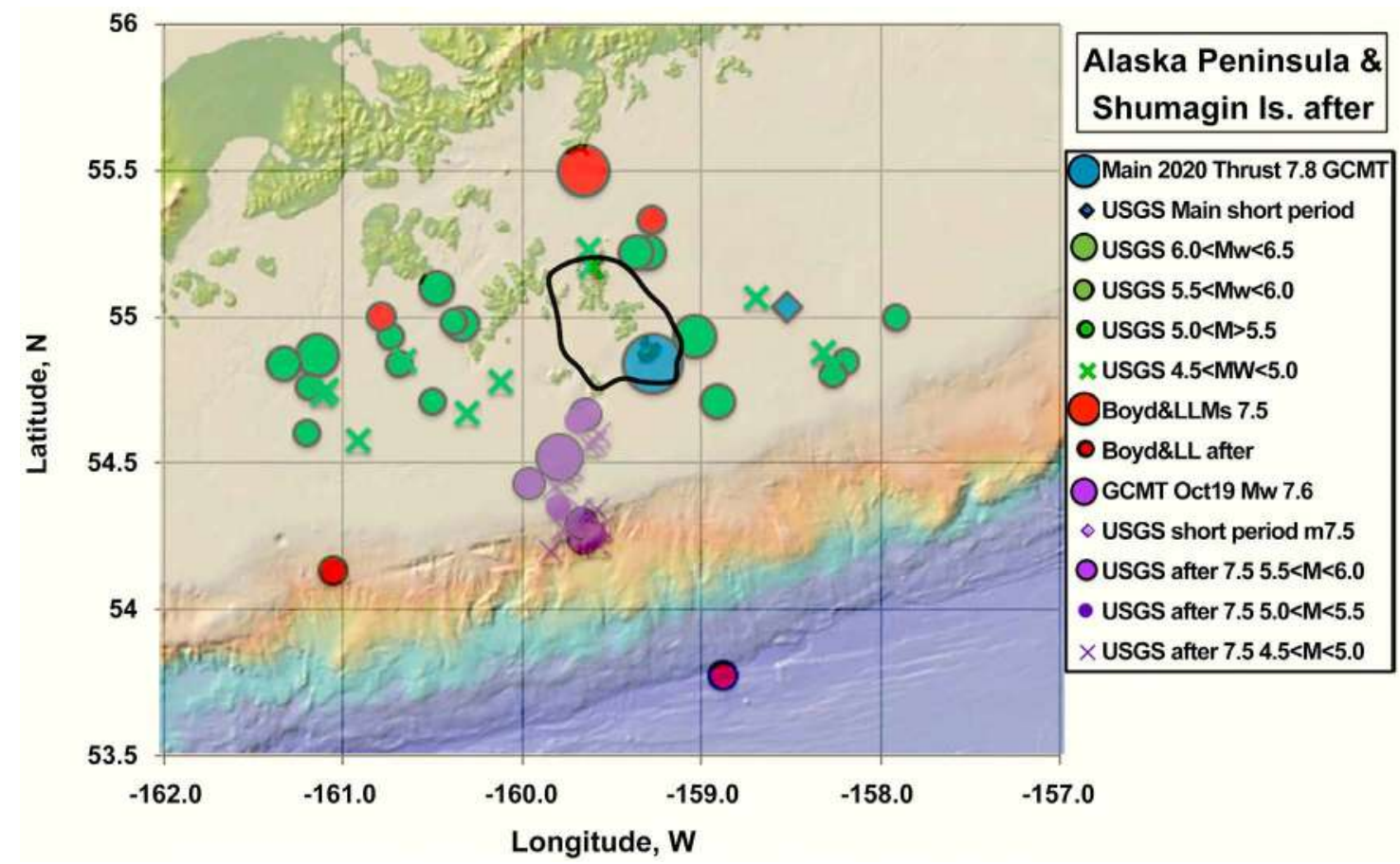

Figure S14. Aftershocks through 19 Oct 2020 for the Shumagin Islands earthquake of July 22, 2020 of short-period magnitudes greater than 4.5 as determined by the U.S. Geological Survey. Large blue circle denotes centroid of mainshock. Red circles denote short-period locations of mainshock of 1917 (largest circle) and its aftershocks from [14]. Purple indicates mainshock of Mw 7.5 of October 19, 2020 and three days of aftershock activity. Slip contour same as in previous figure. 
Aftershocks of Mw $\geq 5.0$ as of October 2020 were few. Figure S14 shows epicenters of aftershocks for short-period magnitudes greater than 4.5. Most occurred on three sides of the centroid and none to the south closer to the deepest part of the Aleutian trench. The main event did not generate a significant tsunami.

The 2020 shock may be a repeat of the Mw 7.5 earthquake of 1917. The short-period location of the 1917 mainshock and four aftershocks as relocated by [14] form a band encircling the 2020 centroid (Figure S14). A mainly strike-slip event of Mw 7.6 broke to the south of the computed rupture zone and centroid of the July mainshock on 19 October 2020.

In summary, the centroid of the 2020 Shumagin earthquake occurred in a relatively quiet zone surrounded by some forerunning activity and aftershocks. The zone of estimated slip larger than $1.2 \mathrm{~m}$ coincides with the quiet zone. It defines an asperity with dimensions of about 40 by $50 \mathrm{~km}$. Approximately the same zone broke in 1917 but in a smaller mainshock. The section of the plate boundary to the northeast last broke in 1938 in a great thrust earthquake of Mw 8.1 [15]. The adjacent plate boundary to the southwest appears to be poorly coupled [16] and did not rupture in July 2020.

\subsection{Flores Indonesia Earthquake of 1992, Mw 7.7}

The earthquake of 1992 occurred along the Lesser Sunda region of Indonesia near the north side of Flores island (Figure S15). It is one of the smallest mainshocks studied. Its mechanism involved thrust faulting with a southerly dip, like events just to its west in Figure S1. In those two areas Australia has converged with Indonesia with much plate motion now occurring on the north side of the former north-dipping subduction zone. More than 3000 lives were lost in the destructive earthquake and its large tsunami [18]. The tectonics are described in greater detail in [18].

The zones of high computed slip were devoid of forerunning activity in Figure S15 as well as aftershocks (not shown). The two largest are interpreted as major asperities.

In summary, the zones of high computed slip were devoid of forerunning activity. They are interpreted as major asperities. Forerunning thrust and strike-slip activity occurred on four sides of those asperities.

\subsection{Nepal Earthquake of 2015, Mw 7.9}

The Nepal shock of 2015 occurred along a continental convergence plate boundary, not a subduction zone. It is included here because of the similarity of its thrust mechanism to those at subduction zones. Not enough forerunning activity took place (Figure S16), however, for it to be compared with details of the computed slip in the mainshock.

\subsection{Haida Gwaii (Queen Charlotte), Canada Thrust Earthquake of 2012, Mw 7.8}

The 2012 mainshock was unusual in that it was a great thrust event just to the 


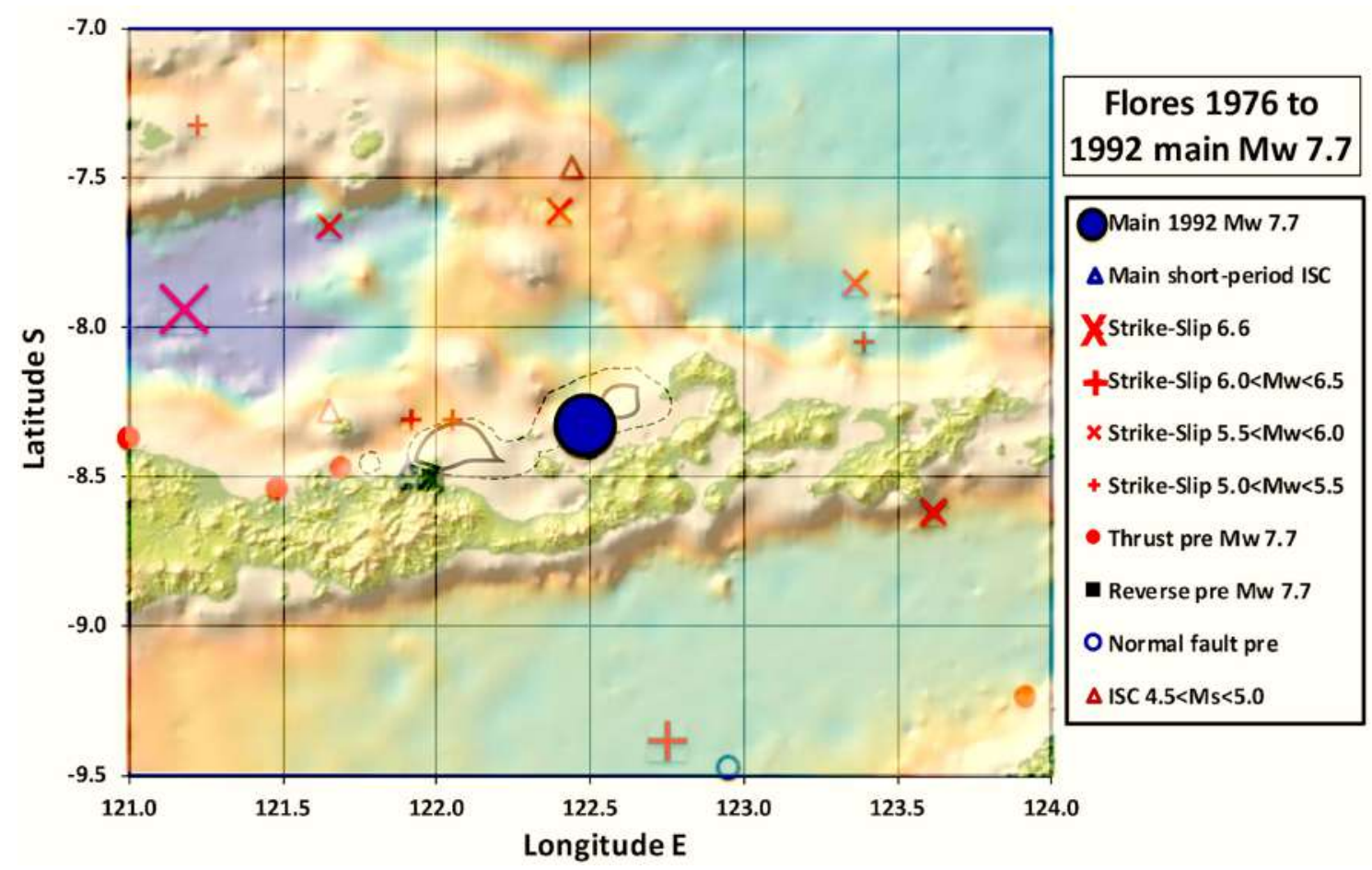

Figure S15. Flores Indonesian mainshock of 1992, Mw 7.7 (large blue circle). Solid and dashed contours denote computed slip greater than 10 and $4 \mathrm{~m}$ from [18].

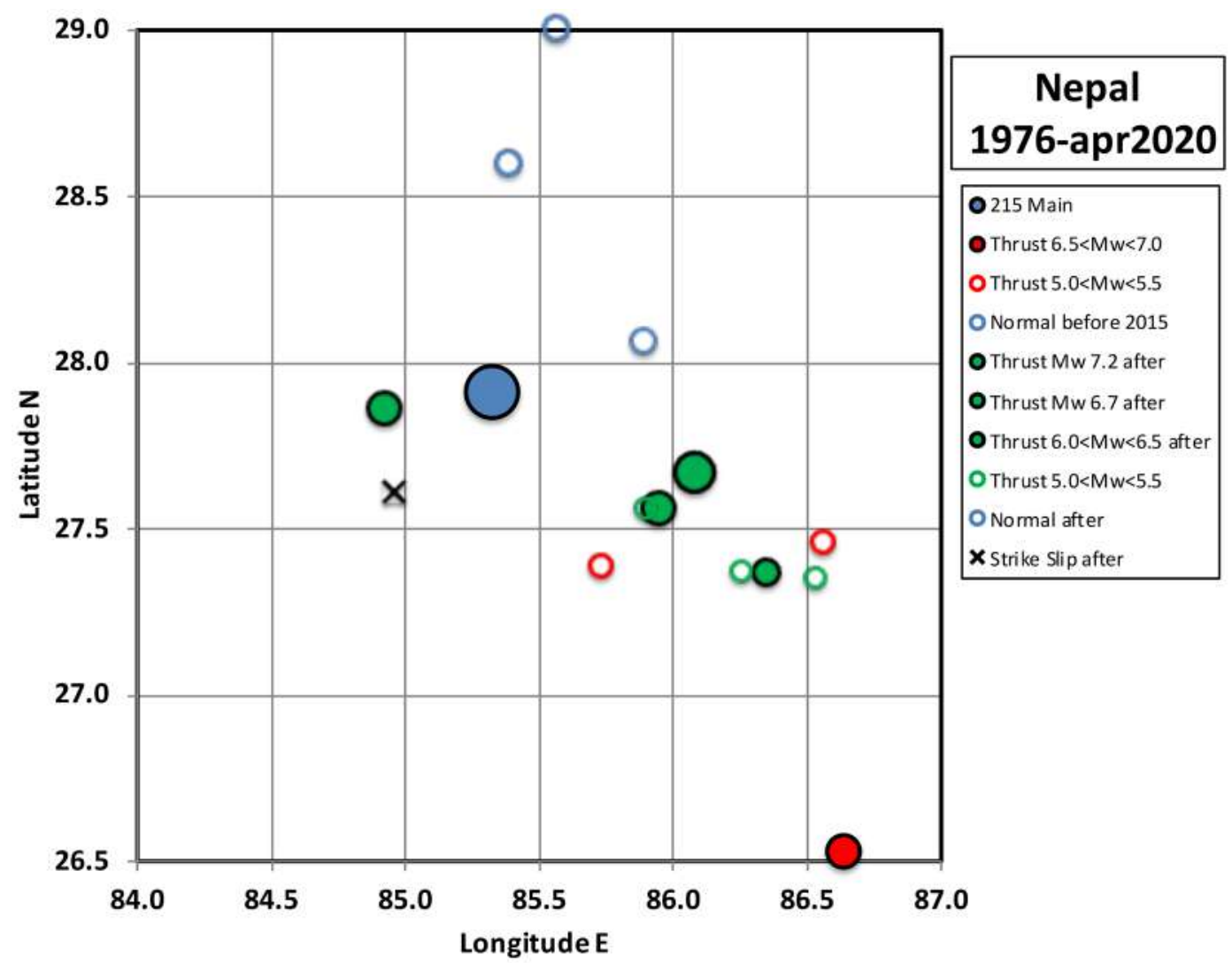

Figure S16. Forerunning and aftershock activity for Nepal earthquake of 2015. Large blue circle denotes centroid of mainshock. 
west of the Queen Charlotte strike-slip fault. That plate boundary is largely a transform fault but one with a smaller thrust component. Only one thrust foreshock (Figure S17) occurred between 1976 and the mainshock. All but one of the aftershocks shown involved normal faulting. Lay et al. [19] found that slip in the mainshock (not shown) was concentrated largely between the coastline and the normal-fault aftershocks within the hard-rock of the upper plate beneath a young sedimentary basin.

In summary, the mainshock is not explored further since the number of forerunning earthquakes was so small. It was an unusual thrust earthquake that occurred adjacent to the main strike-slip fault of the plate boundary that last ruptured in a great strike-slip mainshock in 1949.

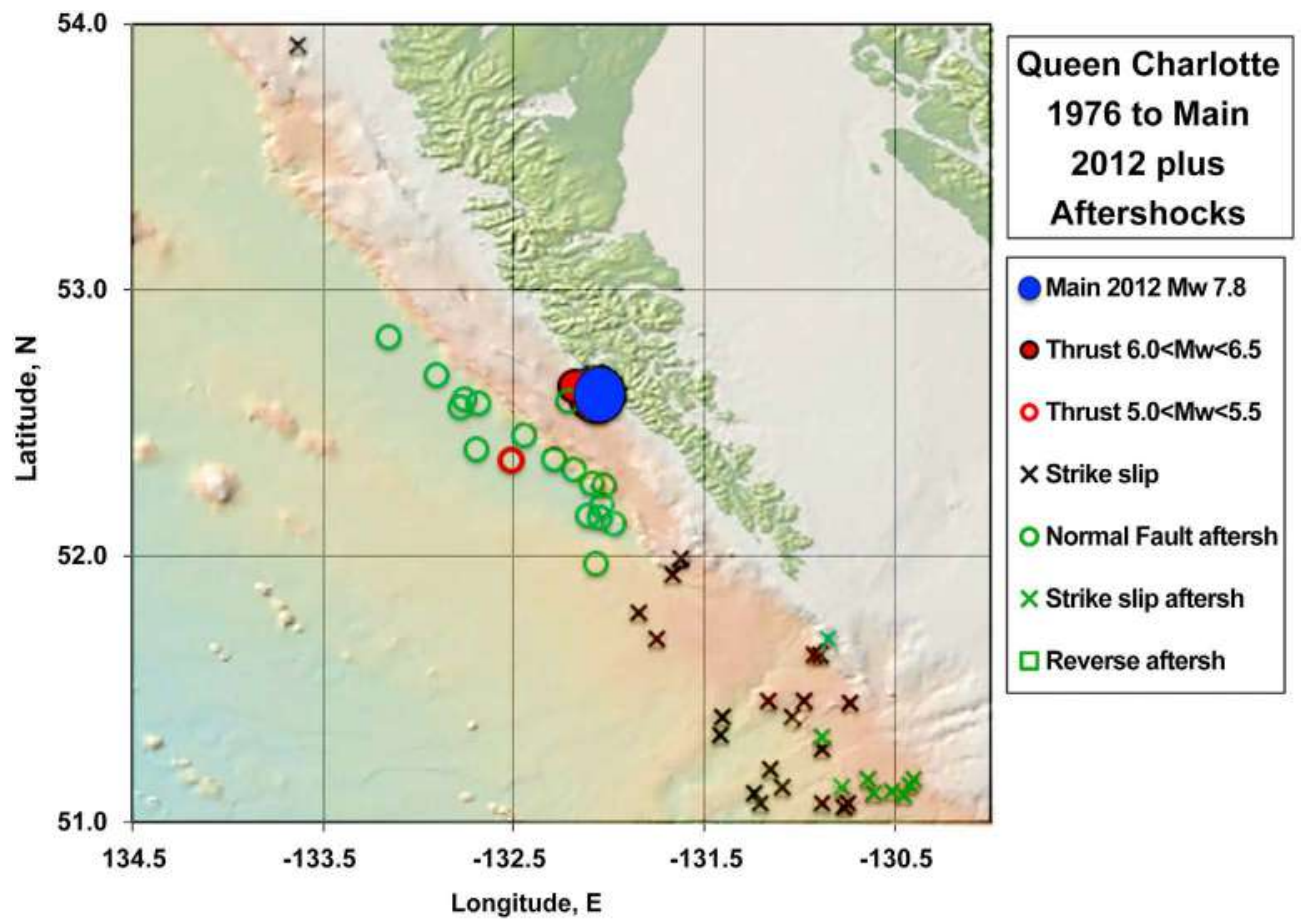

Figure S17. Forerunning and aftershock activity to the Haida Gwaii (Queen Charlotte) earthquake of 2012. Large blue circle denotes centroid of mainshock.

\section{Conflicts of Interest}

The author declares no conflicts of interest regarding the publication of this paper.

\section{References for Supplementary Section}

[1] Harada, T. and Ishibashi, K. (2008) Interpretation of the 1993, 2001, and 2002 Guam Earthquakes as Intraslab Events by a Simultaneous Relocation of the Main Shocks, Aftershocks, and Background Earthquakes. Bulletin of the Seismological Society of America, 98, 1581-1587. https://doi.org/10.1785/0120060227

[2] Meng, Q., Heeszel, D.S., Ye, L., Lay, T., Wiens, D.A., Jia, M. and Cummins, P.R. (2015) The 3 May 2006 (Mw 8.0) and 19 March 2009 (Mw 7.6) Tonga Earthquakes: Intraslab Compressional Faulting below the Megathrust. Journal of Geophysical Re- 
search, 120, 6297-6316. https://doi.org/10.1002/2015JB012242

[3] Mendoza, C. and Hartzell, S. (1999) Fault-Slip Distribution of the Colima-Jalisco, Mexico, Earthquake. Bulletin of the Seismological Society of America, 109, 1338-1344. https://doi.org/10.1785/BSSA0890051338

[4] Gomez, J.M., Madariaga, R., Walpersdorf, A. and Chalard, E. (2000) The 1996 Earthquake in Sulawesi, Indonesia. Bulletin of the Seismological Society of America, 90, 739-751. https://doi.org/10.1785/0119990055

[5] Wetzler, N., Lay, T., Brodsky, E.E. and Kanamori, H. (2018) Supplementary Material for Systematic Deficiency of Aftershocks in Areas of High Coseismic Slip for Large Subduction Zone Earthquakes. Science Advances, 4.

https://doi.org/10.1126/sciadv.aao3225

[6] Poliata, N., Koketsu, K. and Miyake, H. (2010) Source Processes of the Irian Jaya, Indonesia, Earthquake Doublet. Earth Planets and Space, 62, 475-481.

https://doi.org/10.5047/eps.2010.02.008

[7] Tregoning, P., Sambridge, M., McQueen, H., Toulmin, S. and Nicholson, T. (2005) Tectonic Interpretation of Aftershock Relocations in Eastern Papua New Guinea Using Teleseismic Data and the Arrival Pattern Method. Geophysical Journal International, 160, 1103-1111. https://doi.org/10.1111/j.1365-246X.2005.02567.x

[8] Park, S.-C. and Mori, J. (2007) Triggering of Earthquakes during the 2000 Papua New Guinea Earthquake Sequence. Journal of Geophysical Research: Solid Earth, 112, B03302. https://doi.org/10.1029/2006JB004480

[9] Lay, T., Ye, L., Ammon, C.J. and Kanamori, H. (2016) Intraslab Rupture Triggering Megathrust Rupture Coseismically in the 17 December 2016 Solomon Islands Mw 7.9 Earthquake. Geophysical Research Letters, 44, 1286-1292. https://doi.org/10.1002/2017GL072539

[10] Hayes, G.P. (2009) M7.6, 7.8 and 7.3 Vanuatu Region Earthquakes of 7 October 2009. U.S. Geological Survey, 1 p.

[11] Kaverina, A., Dreger, D. and Antolik, M. (1998) Source Process of the 21 April 1997 Santa Cruz Island Earthquake (Mw 7.8). Geophysical Research Letters, 25, 4027-4030. https://doi.org/10.1029/1998GL900017

[12] Yagi, Y., Kikuchi, M. and Nishimura, T. (2003) Co-Seismic Slip, Post-Seismic Slip, and Largest Aftershock Associated with the 1994 Sanriku-haruka-oki, Japan Earthquake. Geophysical Research Letters, 30, 2177. https://doi.org/10.1029/2003GL018189

[13] Kato, K. and Tsuji, Y. (1994) Estimation of Fault Parameters of the 1993 Hokkaido-Nansei-Oki Earthquake and Tsunami Characteristics. Bulletin of the Earthquake Research Institute, 69, 39-66.

[14] Boyd, T.M. and Lerner Lam, A.L. (1988) Spatial Distribution of Turn-of-the-Century Seismicity along the Alaska-Aleutian Arc. Bulletin of the Seismological Society of America, 78, 636-650.

[15] Pacheco, J.F. and Sykes, L.R. (1992) Seismic Moment Catalog of Large, Shallow Earthquakes, 1900-1989. Bulletin of the Seismological Society of America, 82, 1306-1349. https://doi.org/10.1785/BSSA0820031306

[16] Li, S. and Freymueller, J.T. (2018) Spatial Variation of Slip Behavior beneath the Alaska Peninsula along Alaska-Aleutian Subduction Zone. Geophysical Research Letters, 45, 3453-3460. https://doi.org/10.1002/2017GL076761

[17] Crowell, B.W. and Melgar, D. (2020) Slipping the Shumagin Gap: A Kinematic and Early Afterslip Model of the Mw 7.8 Simeon of Island, Alaska, Earthquake. Geophysical Research Letters, 47, e2020GL090308. 
https://doi.org/10.1029/2020GL090308

[18] Pranantyo, I.R. and Cummins, P.R. (2019) Multi-Data-Type Source Estimation for the 1992 Flores Earthquake and Tsunami. Pure and Applied Geophysics, 176, 2969-2983. https://doi.org/10.1007/s00024-018-2078-4

[19] Lay, T., Ye, L., Kanamori, H., Yamazaki, Y., Cheung, K.F., Kwong, K. and Koper, K.D. (2013) The October 28, 2012 Mw 7.8 Haida Gwaii Underthrusting Earthquake and Tsunami: Slip Partitioning along the Queen Charlotte Fault Transpressional Plate Boundary. Earth Planetary Science Letters, 375, 57-70.

https://doi.org/10.1016/j.epsl.2013.05.005 